\title{
Comparative morphology and evolution of the lungless caecilian Atretochoana eiselti (Taylor) (Amphibia: Gymnophiona: Typhlonectidae)
}

\author{
MARK WILKINSON
}

School of Biological Sciences, University of Bristol, Bristol, BS8 1UG, and

Department of Zoology, The Natural History Museum, London, SW7 5BD

\author{
RONALD A. NUSSBAUM \\ Museum of Zoology, University of Michigan Ann Arbor, MI 48109, U.S.A.
}

Received 3 May 1996; accepted for publication 13 February 1997

\begin{abstract}
Atretochoana eiselit is a radically divergent aquatic caecilian until recently known from only a single specimen from South America. In addition to its status as the largest lungless tetrapod known, and the only known lungless caecilian, this species has a suite of highly unusual morphological features that sets it apart from all other tetrapods, including sealed choanae (internal nostrils), complete loss of pulmonary arteries and veins, novel cranial architecture, and a novel stapedial muscle. The external, buccal, skeletal, muscular and cardiovascular anatomies of Atretochoana eiseli are described and compared to these features in other caecilians, particularly representatives of all typhlonectid genera which are its closest relatives. The comparative morphological data are used as a basis for interpretations of the ecology and evolution of Atretochoana eiselti. It is argued that lunglessness and the transition to cutaneous gas exchange is correlated with life in cold, montane, fast-flowing streams. Here, high oxygen concentrations and reduced metabolic rate serve to relax the physiological limitations on body size imposed by a reliance upon cutaneous gas-exchange, and lungs can produce disadvantageous buoyancy. Cranial evolution has increased the gape of Atretochoana eiselti relative to other caecilians, and seems likely to be associated with a shift in prey size and possibly type. Several modifications of the cranium appear to be associated with enhanced cranial kinesis in which a distinct cheek unit is highly mobile. The novel stapedial musculature is interpreted as contributing to this cranial kinesis. Respiratory and cranial evolution are argued to be correlated, with the ventilatory function of the buccopharyngeal pump constraining the evolution of the skull. The evolution of lunglessness removed this constraint facilitating repatterning of the skull.
\end{abstract}

(C) 1997 The Linnean Sociery of Iondon

ADDITIONAL KEY WORDS:- South America-Evolution-Morphology-LunglessnessCranial kinesis. 


\section{CONTENTS}

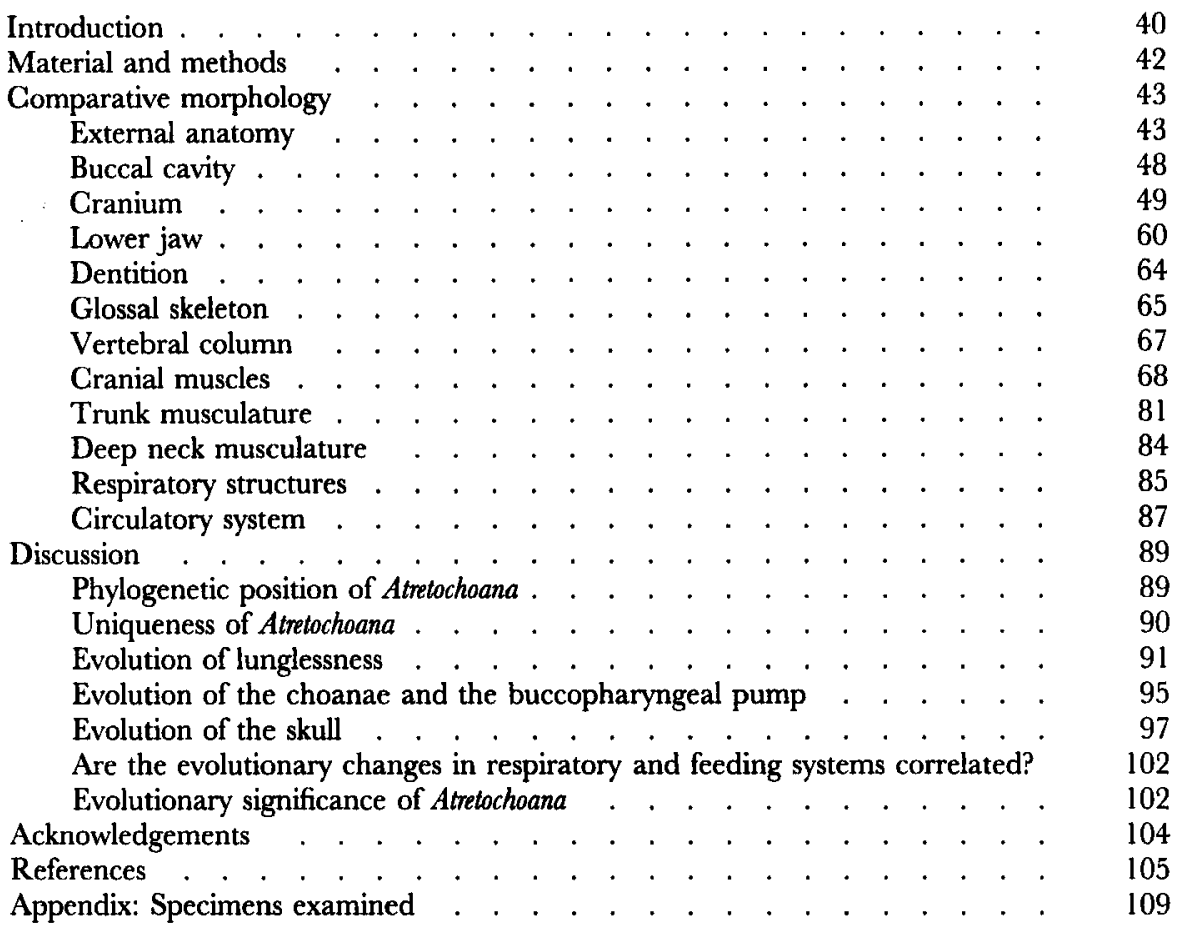

\section{INTRODUCTION}

Caecilian amphibians are amongst the most poorly known vertebrates, and this is unfortunately true for almost all aspects of their biology. Studies of the behaviour and ecology of caecilians have lagged well behind those of other amphibians primarily because their mostly secretive burrowing habits, and their tropical distribution make such studies difficult. However, the fact that the diversity of morphological form within the order has never been adequately surveyed reflects the lack of attention that vertebrate biologists have afforded this group. As a result, new taxa are regularly described both from material that has been newly collected (e.g. Nussbaum, 1986; Lahanas \& Savage, 1992; Nussbaum \& Hinkel, 1994) and from specimens that have been part of museum collections for many years but have not been the subject of detailed examination (e.g. Nussbaum \& Wilkinson, 1987; Wilkinson \& Nussbaum, 1992). A recent and most striking example is provided by the genus Atretochoana described by Nussbaum \& Wilkinson (1995) for a radically divergent caecilian species then known only from the holotype and previously included in the Neotropical aquatic genus Typhlonectes Peters.

Typhlonectes eiselti was described (Taylor, 1968) from a single specimen, in the collections of the Naturhistorisches Museum, Vienna (NMW 9144, a mature female), which previously had been assigned to $T$. compressicauda (Duméril \& Bibron). The original description of this species was unusually brief. It is the shortest of the 39 descriptions of new species established in Taylor's (1968) monograph and one of 
only three lacking any illustration. Taylor's diagnosis focused on the large body size and unusually high number of splenial teeth of the holotype. The specimen was the largest typhlonectid seen by Taylor, but its size is approached by T. natans (Fischer) and exceeded by T. compressicauda (Moodie, 1978). The high number of splenial teeth, however, distinguishes NMW 9144 from all other typhlonectids.

The senior author first examined NMW 9144 in Vienna. It was on display as a public exhibit and, at that time, could only be viewed through glass. Taylor had not informed the Museum's curators of his designation of the specimen as a holotype, and thus it is not listed in the Museum's Type Catalogue (Häupl \& Tiedemann, 1978). The specimen was later received on loan, and examination not only confirmed the distinctive high number of splenial teeth reported by Taylor (1968), but also led to the discovery of a more distinctive and intriguing feature of the buccal cavity. In caecilians, as in other tetrapods, the nasal passages extend from the external nares to the primary palate. The passages communicate with the buccal cavity through internal nares or choanae, except in mammals and crocodilians where the development of the secondary palate has led to their communicating with the pharynx more directly. The choanae of caecilians are guarded by fleshy 'valves' which, in the Typhlonectidae, are large (as are the choanae) and conspicuously superficial. However, in NMW 9144 each choanal aperture is completely closed by a fleshy sheet of tissue continuous with the buccal mucosa. Each sheet is presumed to represent the fused flaps of a choanal valve. Closure of the choana means that no connection exists between the external nares and the buccal cavity, and this is a unique condition among tetrapods (for an alternative view of the nomenclature of tetrapod nasal apertures see Bjerring, 1989).

These observations raised questions regarding the respiration of this species. Caecilians use a form of buccopharyngeal pumping to fill the lungs in which the floor of the buccal cavity is rhythmically lowered and raised with the mouth closed (Marcus, 1923; Wilkinson, 1980, Carrier \& Wake, 1995). During the downstroke air is drawn into the posterior of the buccal cavity through the external nares and choanae, and during the upstroke this air is forced into the lungs. With the choanal aperture sealed in NMW 9144, how could the lungs be filled? Subsequent dissection revealed the total absence of left, right and tracheal lungs. The species thus represents the only known lungless caecilian, and NMW 9144 is by far the largest known lungless tetrapod (Nussbaum \& Wilkinson, 1995).

Parallel to these investigations, radiographs of the holotype revealed a fundamental departure in the cranial morphology of this species from that of all other caecilians. In other caecilians, as well as salamanders and frogs, the lower jaw articulates with the quadrate adjacent to the otic region, with the short stapes (when present) extending anterolaterally from the foramen ovalis to the posterodorsal edge of the quadrate, often articulating with a distinct processus oticus of the quadrate. In striking contrast, the quadrate and stapes of NMW 9144 project far posterior and the quadrate supports a postoccipital jaw articulation that is superficially more snakelike than caecilian. These findings, along with others described below, suggest major functional shifts in morphology, physiology and ecology, and led Nussbaum \& Wilkinson (1995) to describe a new genus, Atretochoana, to receive this disparate form. Here we present the results of a more detailed comparison of the morphology of Atretochoana to that of other typhlonectids and elaborate our interpretation of its evolution and significance. 
TABLE 1. Taxonomy of the Typhlonectidae used in this study

\begin{tabular}{|c|c|c|}
\hline Genus & Species & Authors \\
\hline \multirow[t]{4}{*}{ Typhlonectes } & & Peters $(1879)$ \\
\hline & compressicauda ${ }^{\prime}$ & Duméril \& Bibron (1841) \\
\hline & natans & Fischer, in Peters (1879) \\
\hline & cunhat ${ }^{2}$ & Cascon, Lima-Verde \& Marque (199l) \\
\hline \multirow[t]{2}{*}{ Atretachoana } & & Nussbaum \& Wilkinson (1995) \\
\hline & eiselti & Taylor (1968) \\
\hline \multirow[t]{2}{*}{ Potomotyphlus } & & Taylor (1968) \\
\hline & kaupii & Berthold (1859) \\
\hline \multirow[t]{2}{*}{ Nectocaecilia } & & Taylor (1968) \\
\hline & petersii & Boulenger (1882) \\
\hline \multirow[t]{7}{*}{ Chthonerpeton } & & Peters (1879) \\
\hline & indistinclum & Reinhardt \& Lütken (1861) \\
\hline & viviparum & Parker \& Wettstein (1929) \\
\hline & braestrupi & Taylor (1968) \\
\hline & onorei & Nứssbaúm (1986) \\
\hline & exile & Nussbaum \& Wilkinson (1987) \\
\hline & perrisodus & Nussbaum \& Wilkinson (1987) \\
\hline
\end{tabular}

\footnotetext{
' Originally described as Caecilia compressicauda, Peters (1879) emended the specific name to compressicaudus. Usage has been mixed since then. There exists no genuine Latin compound adjectives in-cauda, hence the species name must be regarded as a noun in apposition, and remains unchanged.

${ }^{2}$ species of doubtful validity (Wilkinson, 1996b).
}

\section{MATERIAL AND METHODS}

We compared the morphology of Atretochoana to that of representatives of all currently recognised genera of the Typhlonectidae. Except where noted, reference to the anatomy of Chthonerpeton Peters is based on examination of the type of the genus, C. indistinctum (Reinhardt \& Lutken). Nectocaecilia Taylor and Potomotyphlus Taylor are considered by us to be monotypic (Nussbaum \& Wilkinson, 1989; Wilkinson, 1996a), so that reference to these genera is to the type species $\mathcal{N}$. petersii (Boulenger) and P. kaupii (Berthold) respectively. Similarly, reference to Atretochoana is to $A$. eiselti, or more specifically to NMW 9144, the holotype of this species. A second specimen of $A$. eiselti was discovered after the preparation of this paper and will be reported on elsewhere. Our taxonomy of the Typhlonectidae is based on that of Nussbaum \& Wilkinson (1989), and is summarized in Table 1.

With the exceptions of Atretochoana, and the trunk vertebrae of Potomotyphlus, observations of skeletal morphology were made from cleared and stained specimens supplemented by observations of dry skeletal preparations. The cranial morphology of Atretochoana was examined by dissection of the left side of the holotype. We were unable to examine most of the vertebral colurtin of Atretochoana directly and have used radiographs for our observations. Similarly, for Potomotyphlus, only the anteriormost six vertebrae were examined directly with other observations based on radiographs. Examination of the musculature of the adductor chamber was facilitated, in species other than Atretochoana, by detachment of the squamosal and ascending process of the quadrate on one side. Numbers of nuchal and postcloacal vertebrae were determined from radiographs following the methods of Wilkinson (1989). Skin samples were embedded in glycol methacrylate, cut at two or three micrometers, and stained with haematoxylin and eosin, or Masson's trichrome with either aniline blue or light green. Observations on the circulatory system were made by dissection, 


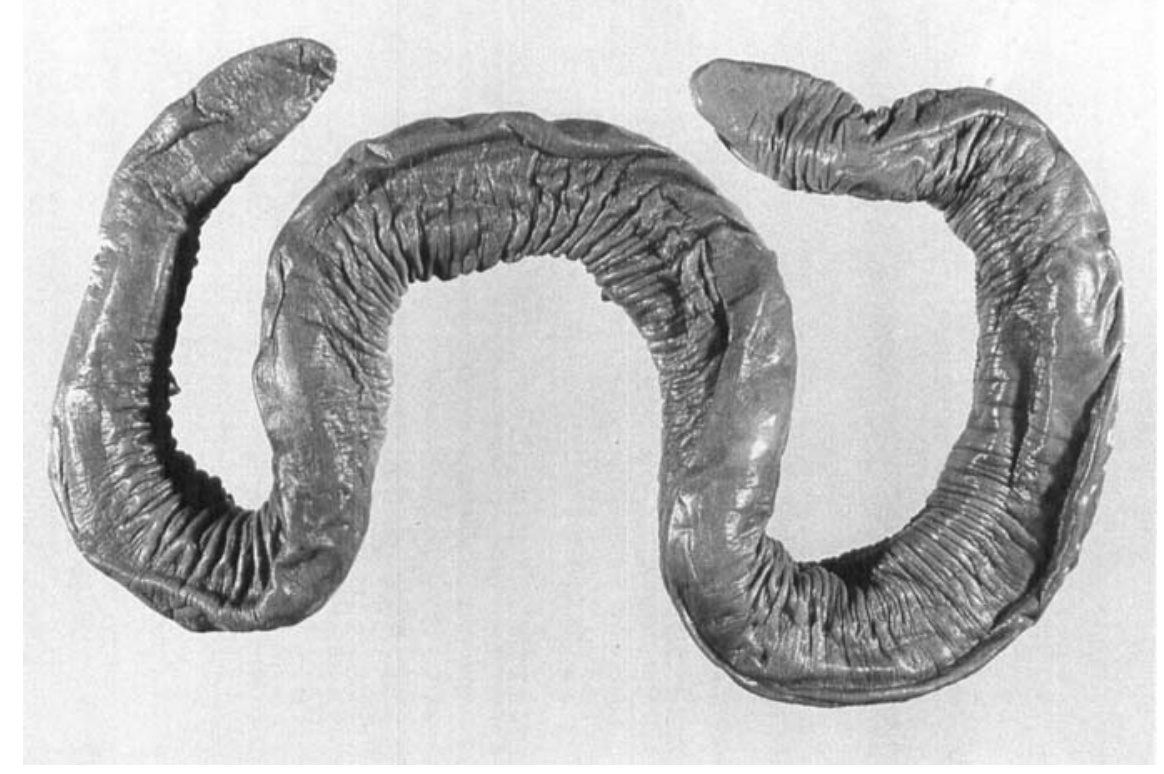

Figure 1. Dorsal view of NMW 9144, the holotype of Atretochoana eiselti.

supplemented, in the case of Typhlonectes natans, by latex injection of the arterial system followed by clearing and staining of a single specimen. Line drawings were prepared using a camera lucida attachment to a Wild M10 binocular dissecting microscope. Single anterior dentary teeth of selected specimens were excised and gold sputter coated for scanning electron microscopy. Specimens examined are listed in the Appendix.

\section{COMPARATIVE MORPHOLOGY}

Background knowledge of caecilian anatomy is limited and does not facilitate detailed comparison of the anatomy of Atretochoana to that of most other caecilians. In the following sections we describe the external anatomy, cranial and vertebral osteology and myology, and aspects of the respiratory and circulatory system of Atretochoana and compare these features to representatives of all other recognized typhlonectid genera. This broad comparison across the typhlonectid clade allows us to document distinctive features of the morphology of Atretochoana and to consider its evolution. Where practical, we also make more general comparisons with nontyphlonectid caecilians.

\section{External anatomy}

Some morphometric and meristic characters for the holotype of Atretochoana eiselti and for other typhlonectids are given in Table 2. Atretochoana has a body shape similar to that of female Typhlonectes, with strong lateral compression beginning immediately after the nuchal collars and extending to the body terminus (Fig 1). 


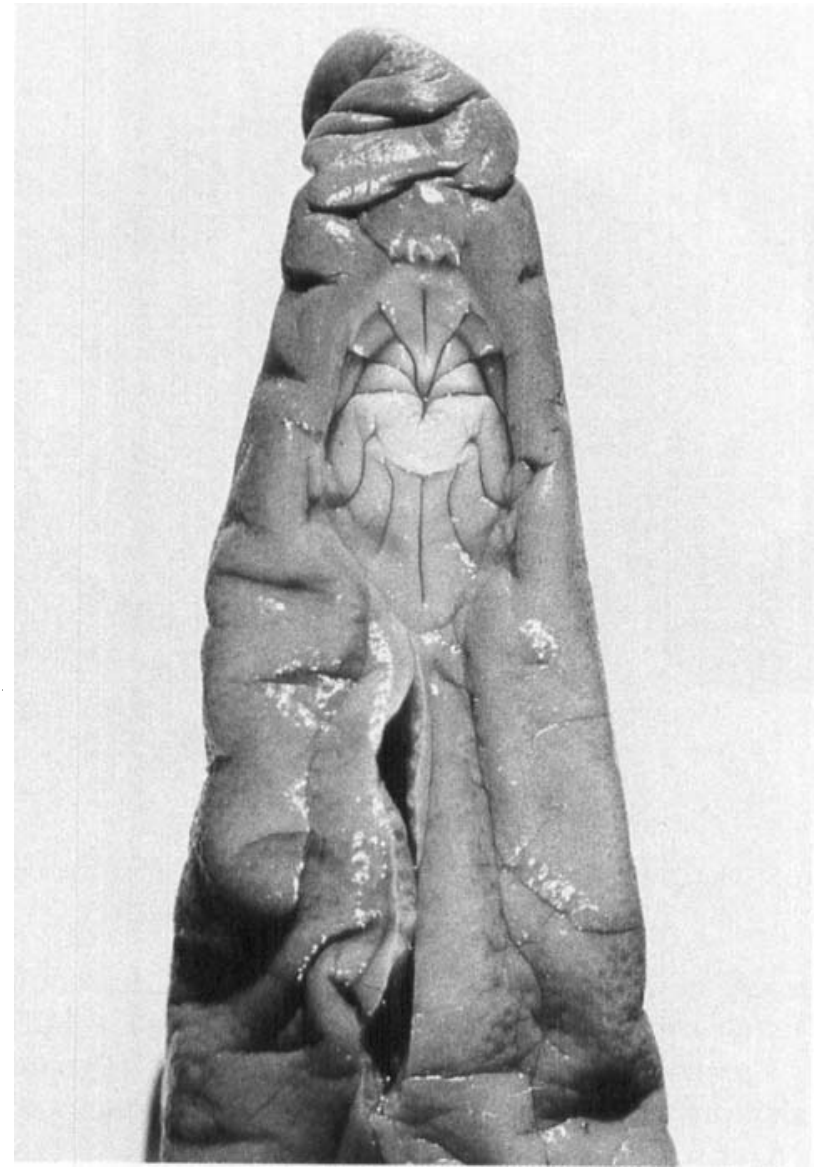

Figure 2. Ventral view of the body terminus of NMW 9144, the holotype of Atretochoana eiselti, showing the vent and cloacal disk.

The dorsal 'fin', which is well-developed as a thick, fleshy, free fold (Wilkinson, 1988) along the entire length of the body and onto the collars, is especially expansive posteriorly, where it accounts for over half the height of the body. The presence of a free fold and lateral body compression indicate that Atretochoana is aquatic. The body narrows distinctly over the posterior $130 \mathrm{~mm}$, and the terminus is narrow and somewhat pointed (Fig. 2) as in female aquatic caecilians. Males are unknown, but presumably they have laterally expanded body termini and have a more weakly developed fin, especially in younger specimens, as in other aquatic caecilians (Gonçalves, 1977; Wilkinson, 1988, 1989).

The cloacal disk of Atretochoana has a distinctive regular geometric pattern of denticulations, six anterior and six posterior (Fig. 2). Different regular patterns are found in the species of Typhlonectes and in Potomotyphlus (Fig 3), whereas the patterns in Chthonerpeton and Nectocaecilia show greater variation in which an underlying geometric pattern of nine or ten denticulations is frequently distorted either by subdivisions of, or fusions between adjacent, denticulations. The disk of Atretochoana is roughly circular, a little depressed, and surrounded laterally and posteriorly by distinct skin folds. Females of Typhlonectes have a similar condition, as do Potomotyphlus, 

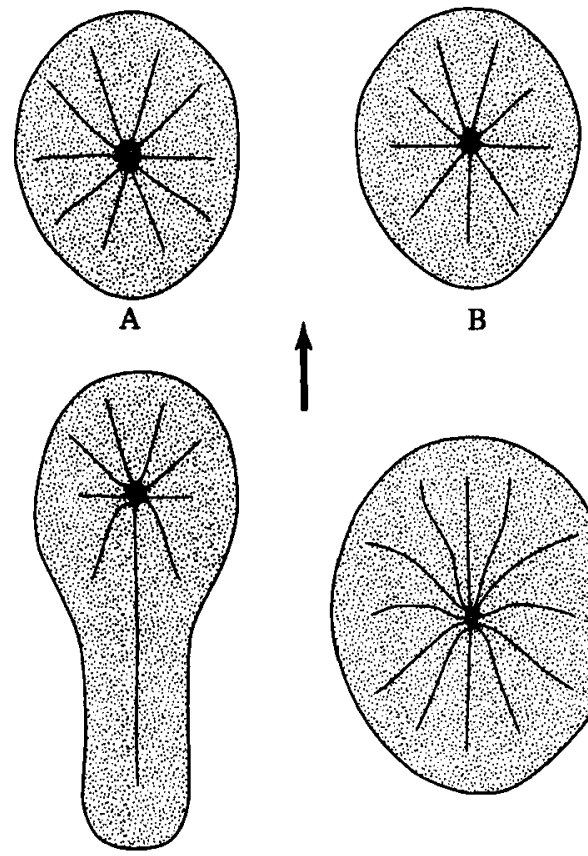

C
$\mathbf{B}$

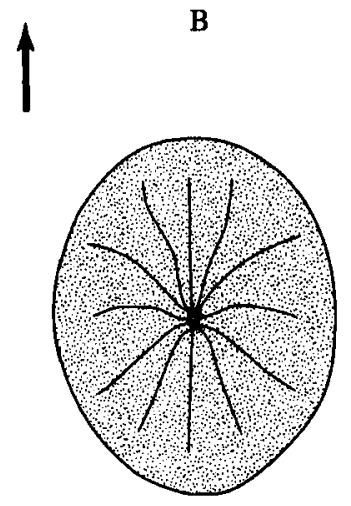

D

Figure 3. Semi-diagrammatic representations of the cloacal disks of (A) Typhlonectes compressicauda, (B) T. natans, (C) Potomotyphlus and (D) Atretochoana.

except that the disk and the anteromedial pair of denticulations of the latter are greatly extended anteriorly. There are no obvious cloacal papillae in the holotype of Atretochoana. Taylor (1968, and other works) considered the presence of cloacal (or anal) papillae to be characteristic of males and used this as a basis for determining the sex of museum specimens. At least within the Typhlonectidae, this is not always true. Males tend to have more pronounced cloacal papillae, but they are frequently, though not universally, present in females also. Taylor also sometimes referred to these structures as glands but a glandular structure is not evident in sections of the male papillae of T. natans and the caeciliid Boulengerula taitanus Loveridge (Wilkinson, pers. obs.). The holotype of Atretochoana has a weak mid-ventral ridge extending for about $30 \mathrm{~mm}$ anterior to the disk that may constitute a ventral fin. In other typhlonectids such a structure is seen only in some specimens of Potomotyphlus, though some irregular, and clearly artifactual, longitudinal ventral folds are sometimes present in Typhlonectes.

In the centre of the disk of Atretochoana, the denticulations are partially everted forming an elevated rim around the vent, especially anteriorly (Fig. 2). Taylor (1968) remarked upon cloacal protrusion in $T$. obesus $(=T$. compressicauda, see Wilkinson, 1991) and suggested that this might be important in copulation. Taylor's interpretation is supported by the fact that the diameter of fully everted caecilian intromittant organs greatly exceeds that of female vents. In addition, we have observed partial eversion of the cloacal denticulations in female Typhlonectes natans and $T$. compressicauda that are gravid with nearly term foetuses. The holotype of Atretochoana has slightly expanded oviducts possibly indicating parturition shortly 


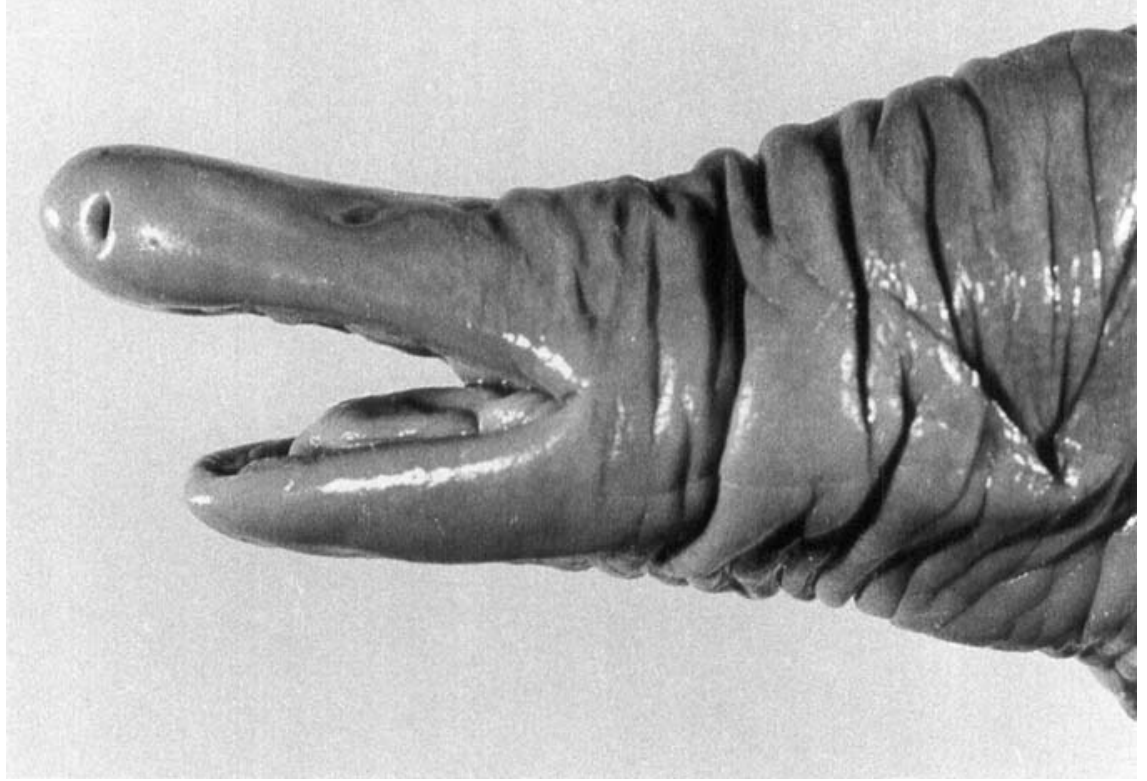

Figure 4. Lateral view of the head of NMW 9144, the holotype of Atretochoana eiselti.

before fixation. We suspect that female typhlonectids undergo some morphological changes in the aperture of the vent prior to giving birth which lead to protrusion of the cloacal lips, and that these changes facilitate expansion of the disk during parturition.

Compared with other caecilians, the head of Atretochoana (Fig. 4) is distinctive in several respects. It is relatively broader and significantly more dorsoventrally compressed, the tip of the snout is distinctly bulbous in lateral view, the sides of the head in dorsal view are relatively straight from the jaw angle to the level of the nares, and there are very distinctive indentations at the nares so that the narial apertures are deeply recessed (Figs $1,4 \& 5$ ). In addition, the sides of the cheek region form a strong curve in the transverse plane such that the border of the mouth is strongly countersunk below the cheek. None of these features is seen in any other caecilian. The size of the head relative to the body of Atretochoana is similar to (slightly larger than) other typhlonectids with the exception of Potomotyphlus in which the head, collars, and anterior body region are disproportionately small.

The eyes of Atretochoana are dorsal (dorsolateral in other caecilians) and far more distant from the sides of the head than in other caecilians, lying at the bottoms of uniquely strong ocular depressions. The eyes are relatively far forward of the jaw angle such that the angle between the margin of the mouth and an imaginary line connecting the eye to the jaw angle is much smaller $\left(c .15^{\circ}\right)$ than in other caecilians $\left(c .30^{\circ}\right)$. The nares of Atretochoana are large and roughly subtriangular as in Nectocaecilia, Potomotyphlus and Typhlonectes. The tentacular apertures are small, and the tentacle is presumed to be non-protrusible as in other aquatic caecilians. If the tentacle is chemosensory, as is generally presumed, then passive diffusion may obviate the need for active protrusion in an aquatic environment. The tentacular apertures are relatively close to the eyes in all species of Chthonerpeton, further anterior and closer 


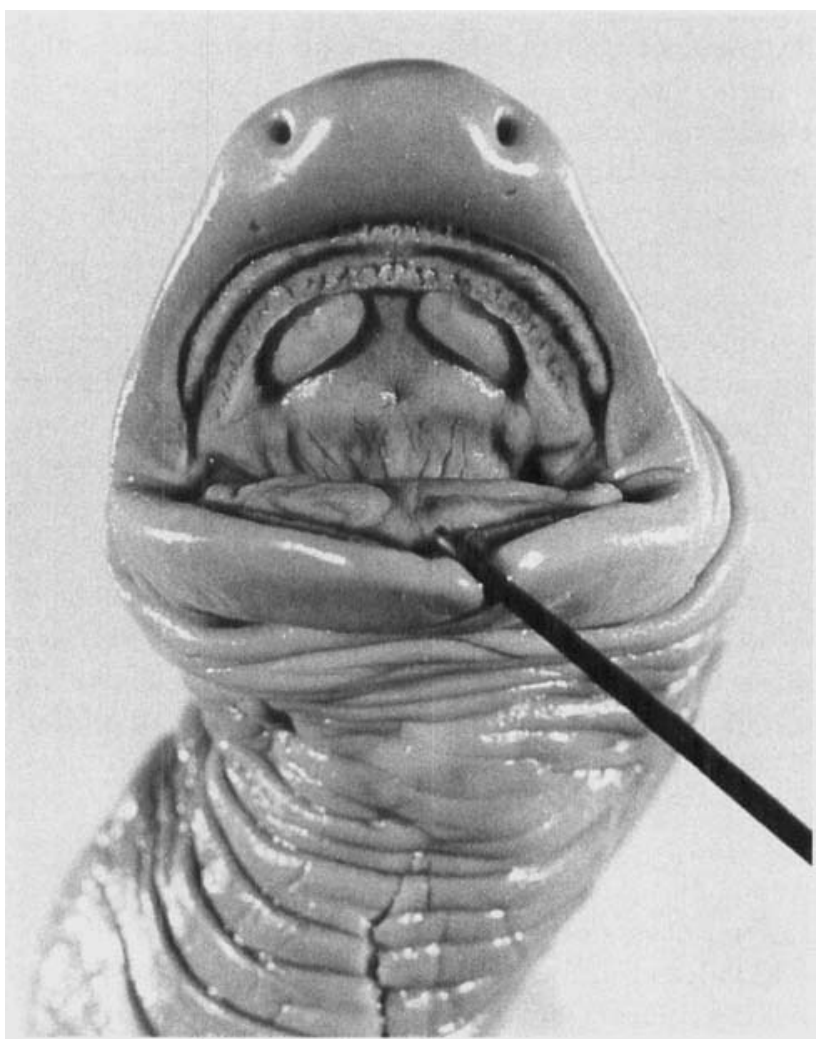

Figure 5. Open mouth of NMW 9144, the holotype of Atretochoana eiselti, showing narial plugs and sealed choanae.

to the nares in Atretochoana and Potomotyphlus, and closer still to the nares in Nectocaecilia and Typhlonectes.

In Atretochoana, the three nuchal grooves delimiting the two collars are indistinct, and the collars bear many irregular folds and grooves. Similarly, annuli are mostly indistinct and difficult to count. There are approximately 102 primary annuli, and, as in other typhlonectids, secondary or tertiary annuli are absent. Some pseudosecondaries (Nussbaum \& Wilkinson, 1989) are well-developed but irregularly distributed, and the skin has numerous irregular folds and wrinkles throughout. Most mid-body annuli are complete (encircle the body) ventrally, and almost complete dorsally, though they become strikingly irregular as they extend onto the dorsal fin. The indistinctiveness of the annular and nuchal grooves is not unusual for aquatic caecilians, forms in which the body walls tend to be rather plastic. Annuli of the semiaquatic typhlonectids (Chthonerpeton and Nectocaecilia) are usually more distinctive.

The colour of the holotype of Atretochoana eiselti is light slate grey on the dorsum, becoming paler on the venter. The differentiation of lighter and darker parts is not very noticeable except on the throat and collars where the ventral colour is creamy yellowish white. There is a small white patch on the left flank, presumably a result of discoloration through exposure to light. The dorsal colour in life was probably darker. The cloacal disk is creamy white centrally and on the anteromedial pair of 
denticulations, but greyer peripherally on the other denticulations. Colour in typhlonectids is quite variable. Some variation is attributable to fading and/or browning of preserved specimens, but this probably does not account for all the variation encountered within some species. Most specimens of Typhlonectes compressicauda are dark grey-brown both in life and in alcohol, but occasional specimens are a lighter blue-grey. The reverse is true of $T$. natans. Most specimens are blue grey but a few have the darker colour typical of $T$. compressicauda. The same range of colours is encountered in preserved Potomotyphlus. Preserved Nectocaecilia have a distinctive combination of a light lilac-grey ground coloration interrupted by purplish annular grooves, and similar purplish annular grooves occur in many specimens of Potomotyphlus. Gudynas, Williams \& Azpelicueta (1988) reported that Chthonerpeton indistinctum is uniformly black dorsally and slightly lighter on the venter. Preserved specimens of this species examined by us are rarely black and are mostly blue-grey or have become brown or faded in preservative. C. braestrupi Taylor is unique among typhlonectids in being distinctly bicolour with a yellowish venter. In other typhlonectids, the change from dorsal to ventral colour is due to a gradual reduction in the density of melanophores on the flanks (Nussbaum \& Wilkinson, 1987).

\section{Buccal cavity}

The choanae of typhlonectids show a phyletic increase in size and a transition from deeply placed valves to more superficial ones (Wilkinson, 1989). In Atretochoana, the choanae are extremely large and the valves superficial (Fig 5). Taylor (1968) described the choanal apertures of Atretochoana as very small. In fact, there are no apertures. The choanae are sealed, probably through fusion of the choanal valves, which bulge ventrally from the choanae into the buccal cavity (Fig. 5). All other typhlonectids, except Potomotyphlus, have choanal valves with a long medial aperture that do not project ventrally from the choana into the buccal cavity. The choanal valves of Potomotyphlus are partially fused, and the aperture is restricted to just below the tip of a small, posterior, funnel-shaped, fleshy projection of the valves, which is adpressed against the body of the valves resulting in a concealed aperture (Fig 6). There is no indication of the originally separate choanal valve flaps in Atretochoana, whereas, in Potomotyphlus, the line of fusion is marked by a thickened ridge. Although the choanal valves of Potomotyphlus do not project into the buccal cavity from the choanal apertures, they are more superficial than in other typhlonectids. The tongue of typhlonectids, like that of all adult caecilians, is a fleshy pad of limited mobility in the floor of the mouth. Narial plugs on the tongue are present in all typhlonectids and in many caeciliid taxa, and their size covaries positively with that of the choanae.

Wake (1978) reported that the presence of muscular valves in the nares is characteristic of the Typhlonectidae. We have been unable to find muscular narial valves in gross dissection of any typhlonectid, and they are perhaps only apparent in sections. Similarly, Bruner (1914) reported smooth narial muscles in the caeciliid Siphonops annulatus (Mikan), but we were unable to confirm these observations in our dissections of this species. Serial sections of the caeciliids Grandisonia alternans (Stejneger), Hypogeophis rostratus (Cuvier), and Geotrypetes seraphini (Duméril) that we have examined show no trace of smooth muscle associated with the nasal cartilages. In these species, a discrete cluster of fibres of the $m$. genioglossus extends into each narial plug, and similar fibres are evident in gross dissection of typhlonectids (see below). 


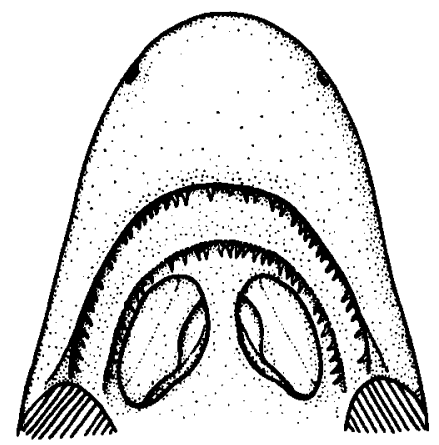

A

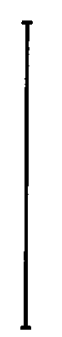

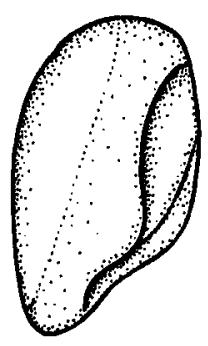

B

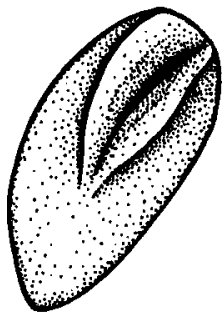

$\mathrm{C}$

Figure 6. Palates and choanal valves of aquatic caecilians. (A) and (B) Potomotyphlus kaupii (FMNH 206189), (C) Typhlonectes natans (LACM 67452). Scale bar $=2 \mathrm{~mm}$.

We suspect that narial plugs (when present), in combination with the choanal valves (and any muscular narial valves), serve to occlude the nasobuccal passage during the upstroke of the buccopharyngeal pump when air is forced into the lungs and the narial plugs are pressed into the choanae. Opening of the nasobuccal passage would follow from the depression of the floor of the mouth and/or the independent contraction of the narial plugs. The presence of well-developed narial plugs in Atretochoana, despite the absence of an open nasobuccal passage, suggests some other function (see below). Atretochoana is unique among caecilians in lacking a glottis.

\section{Cranium}

The skulls of a number of typhlonectids have been illustrated and briefly described. The skull of Chthonerpeton indistinctum was illustrated several times, based on both whole preparations (Peters, 1879; Weidersheim, 1879; Ihering, 1911; Gaggero, 1934; Azpelicuelta, Williams \& Gudynas, 1987) and serial sections (Gronowski, 1980). Skuk (1985) provided a terse description of the tentacular region of the skull of this species. Taylor (1969) published photographs of the skulls of three typhlonectid species (Typhlonectes compressicauda, T. natans, Potomotyphlus kaupii), but these are of poor quality, have suture lines inaccurately drawn in by hand, and are accompanied by only superficial descriptions. Wake, Exbrayat \& Delsol (1985) described some aspects 


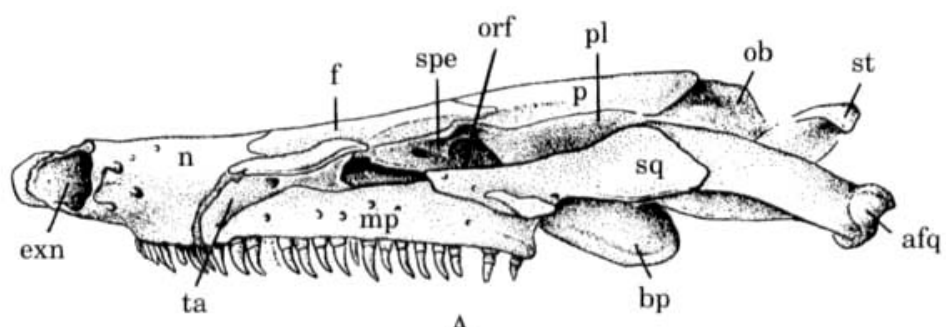

A
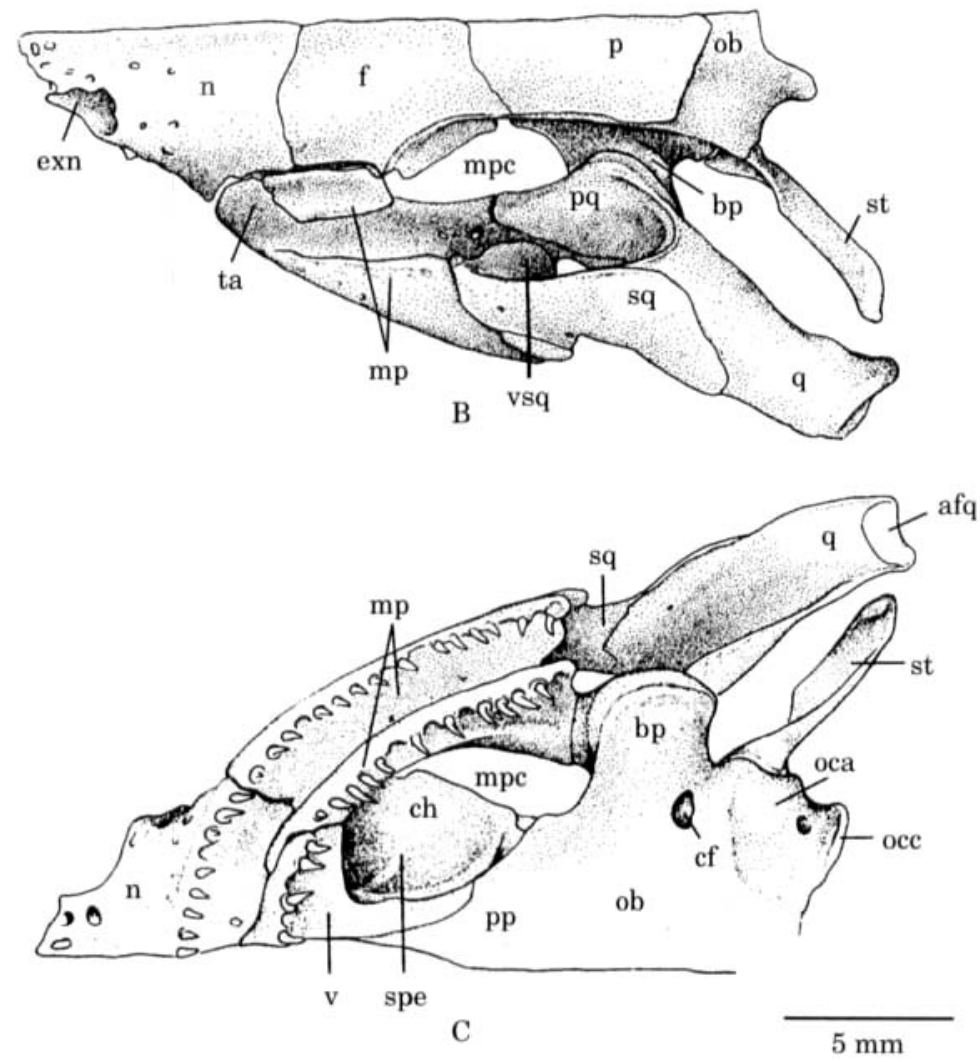

Figure 7. Lateral (A), dorsal (B) and ventral (C) views of the left side of the skull of NMW 9144, the holotype of Atretochoana eiselti. afq=articular facet of quadrate; bp =basipterygoid process of the os basale; $\mathrm{cf}=$ carotid foramen; $\mathrm{ch}=$ choana; $\operatorname{exn}=$ external naris; $\mathrm{f}=$ frontal; $\mathrm{mp}=$ maxillopalatine; $\mathrm{mpc}=$ mediopalatinal canal; $\mathrm{n}=\mathrm{nasal} ; \mathrm{ob}=$ os basale; $\mathrm{oca}=$ otic capsule; occ $=$ occipital condyle; orf $=$ orbital foramen; $\mathrm{p}=$ parietal; $\mathrm{pl}=$ pleurosphenoid portion of the os basale; $\mathrm{pp}=$ parasphenoid process of the os basale; $\mathrm{pq}=$ pterygoid process of quadrate; $\mathrm{q}=$ quadrate; $\mathrm{spe}=$ sphenethmoid; $\mathrm{sq}=$ squamosal; $\mathrm{st}=$ stapes; $\mathrm{ta}=$ tentacular aperture; $\mathrm{v}=$ vomer. Scale $\mathrm{bar}=5 \mathrm{~mm}$.

of the development of the chondrocranium of Typhlonectes compressicauda. Nussbaum \& Wilkinson (1995) illustrated and briefly described the skulls of Atretochoana and $\mathcal{T}$. natans. Dorsal, ventral and lateral views of the crania of Atretochoana, Potomotyphlus and T. natans are illustrated in Figures 7, 8, and 9. 

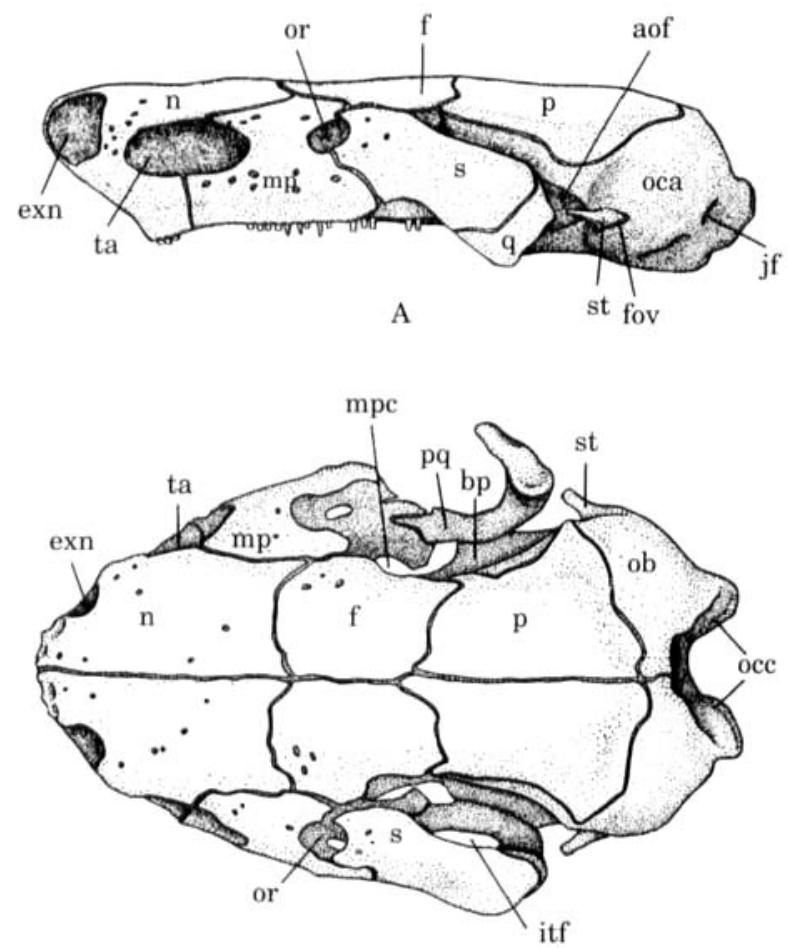

B

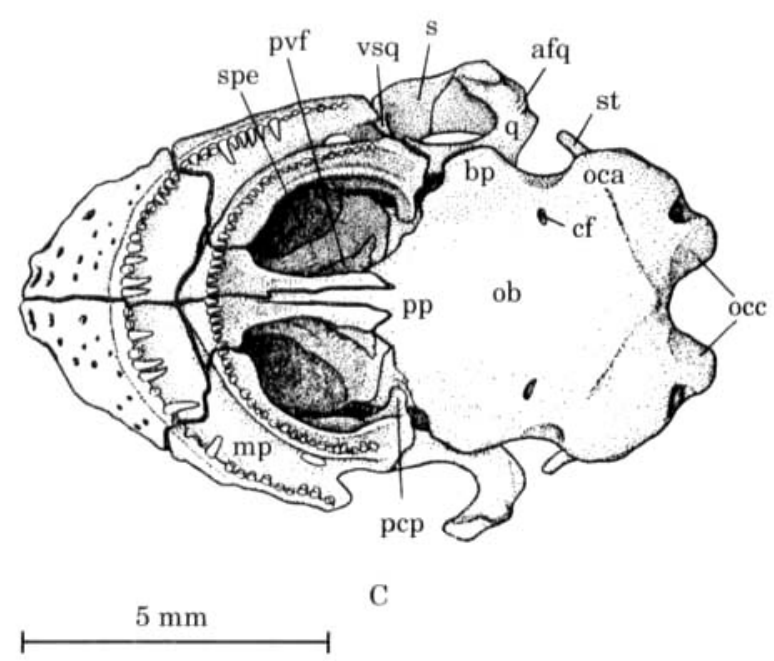

Figure 8. Lateral (A), dorsal (B), and ventral (C) views of the skull of UMMZ 211206, Potomotyphlus kaupii, with the squamosal and part of the quadrate removed from the right side. aq $=$ ascending process of the quadrate; itf=lower temporal fossa; $j f=j u g u l a r$ foramen; or =orbit; $p c p=$ post-choanal process of the maxillopalatine; $s=$ squamosal; utf = upper temporal fossa; $v s q=$ ventral process of the squamosal; other abbreviations as in Fig. 7. Scale bar $=5 \mathrm{~mm}$.

The skulls of typhlonectids are zygokrotaphic, presumably secondarily (Nussbaum, $1977,1979,1983)$. Boulenger (1882) mistakenly reported the absence of an upper temporal fossa in Typhlonectes, and this has confused some subsequent workers (e.g. 

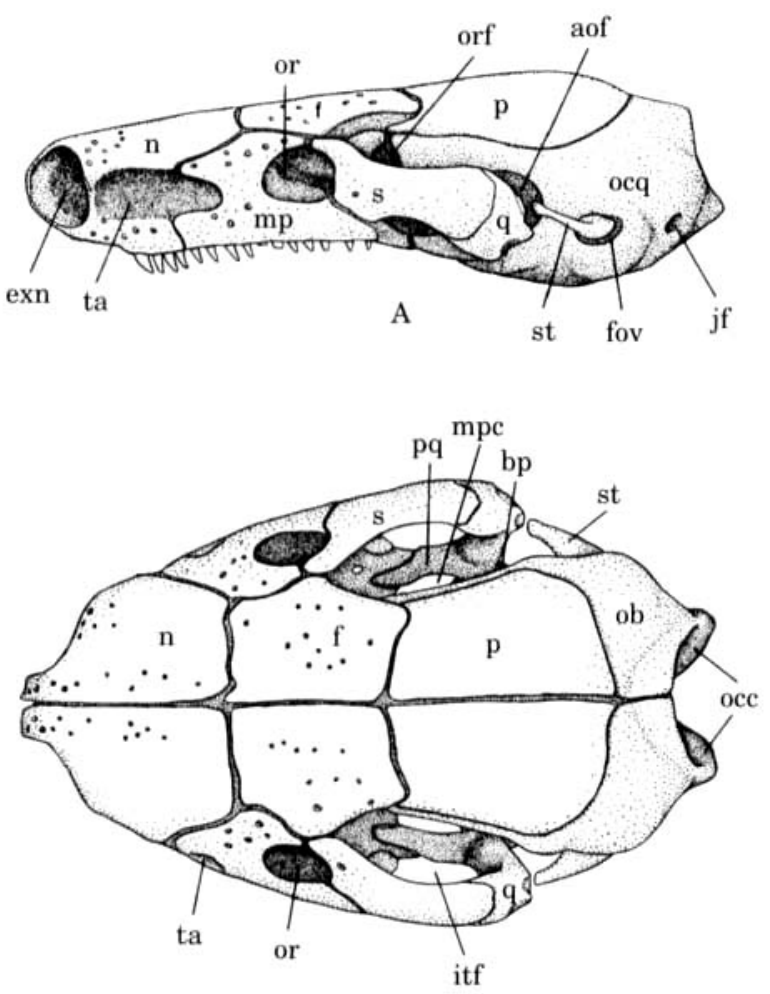

B

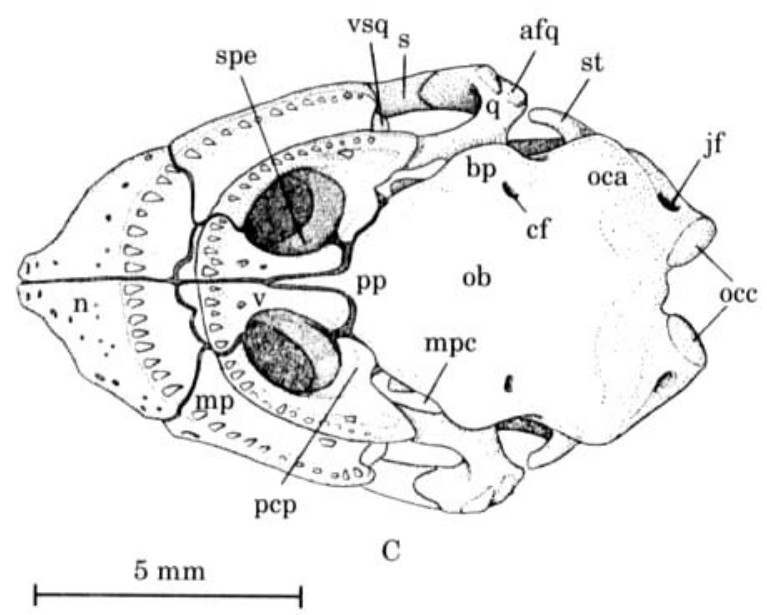

Figure 9. Lateral (A), dorsal (B), and ventral (C) views of the skull of LACM 67454, Typhlonectes natans. Abbreviations as in Figs 7 and 8 . Scale bar $=5 \mathrm{~mm}$.

Ihering, 1911; Roze \& Solano, 1963), but in all typhlonectids the squamosal makes no contact with the parietal nor with the pleurosphenoid portion of the os basale dorsally. The skull of Atretochoana is composed of the same elements as those of other typhlonectids, with major modification of the suspensorial region (Fig 7). Separate 
TABLE 3. Relative lengths of the bones of the median skull roof and the degree of rostral projection of the nasopremaxillae beyond the mouth in cleared and stained adult typhlonectids. All values are expressed as percentages of the total mid-dorsal skull length. $s s=$ sample size, Rostrum $=$ rostral projection of the nasopremaxillae, Occiput $=$ supraoccipital portion of the os basale.

\begin{tabular}{lcccccc}
\hline & Ss & Rostrum & Nasopremaxillae & Frontals & Parietals & Occiput \\
\hline Chthonerpetan & 2 & $10-11$ & $29-30$ & $22-23$ & $41-42$ & $6-7$ \\
Nectocaecilia & 1 & 9 & 26 & 31 & 37 & 6 \\
Potomotyphlus & 1 & 16 & 38 & 19 & 37 & 6 \\
Atretochoana & 1 & 19 & 38 & 22 & 32 & 8 \\
Typhlonectes natans & 10 & $13-14$ & $31-34$ & $23-27$ & $32-37$ & 10 \\
Typhlonectes compressicauda & 2 & 14 & $33-34$ & 23 & $32-33$ & 10 \\
\hline
\end{tabular}

septomaxillae, premaxillae, prefrontals, postfrontals, pterygoids and pseudoectopterygoids, characteristics of some non-typhlonectids, are not present. Compared to other caecilians, typhlonectid skulls are most similar to those of caeciliids which, except for the presence of a pseudoectopterygoid in some species, are composed of the same elements.

The paired nasopremaxillae, frontals, parietals, and the supraoccipital region of the os basale form the dorsal medial roof of the cranium, and vary considerably in their proportions between taxa (Table 3, Figs 7-9). There is also interspecific variation in the degree to which the nasopremaxillae form a rostral projection beyond the mouth that correlates with the relative size of the nasopremaxillae. For all elements, the range of variation in size is greatest in the species represented by the largest sample, Typhlonectes natans, and additional variation in the other taxa is to be expected. The skull of Atretochoana is extremely dorsoventrally compressed, more than in any other caecilian. Compression is also apparent, but to a lesser degree, in Potomotyphlus, and is weaker still in Typhlonectes. In Chthonerpeton and Nectocaecilia, compression is slight and is comparable to that found in non-typhlonectid caecilians.

Atretochoana, Potomotyphlus, and Typhlonectes are similar in having the nasopremaxillae narrow at their anterior tips due to emargination of bone around the narial aperture and its replacement by well-developed cupular cartilages. The edges of the nasopremaxillae bordering the cupular cartilages are irregular, but distinctly concave. In Chthonerpeton, the nasopremaxillae are broader terminally, and their edges are straighter and slightly convex, with the cupular cartilages less extensive. Nectocaecilia has narrow nasopremaxillary tips but, like Chthonerpeton, it lacks concave nasopremaxillary margins.

The tentacular groove is unroofed by bone, and thus the orbit is open anteriorly, in Atretochoana and Chthonerpeton. In the other typhlonectids, medial and lateral portions of the maxillopalatine grow over the tentacular groove adjacent to the eye and fuse to form a bridge of bone that closes the orbit. In Typhlonectes compressicauda, there is developmental plasticity in the extent of this growth and fusion such that in occasional individuals, especially young ones, there is only a partial bony covering of the tentacular groove with incomplete fusion. A single specimen of 'Chthonerpeton' of indeterminate species (BMNH 1922.11.13.10) has a completely roofed tentacular groove. This specimen was removed from the belly of a snake and is partially digested. All other Chthonerpeton examined have the tentacular groove unroofed.

Within the tentacular groove, the medial portion of the maxillopalatine of all 
typhlonectids is perforated close to the orbit by a foramen for the passage of the paired tentacular ducts. These ducts connect the lumen of the tentacle sac to the vomeronasal organ. This connection has been widely reported in non-typhlonectid caecilians (e.g. Weidersheim, 1879; Ramaswami, 1941), and has been hypothesized to be important in the chemosensory function of the tentacle (Laubmann, 1927; Badenhorst, 1978; Billo \& Wake, 1987), and even to play a role in respiration (Laubmann, 1927; Marcus, 1930) as an accessory narial opening. That the tentacle is an accessory organ of olfaction has become a common assertion in the literature on caecilians but has only recently received some support from experimental behavioural studies (Himstedt \& Simon, 1995).

In Atretochoana, the tentacular grooves are confined entirely within the maxillopalatines, whereas in other typhlonectids the anterior part of the groove is an emargination of the nasopremaxillae. Azpelicueta et al. (1987) reported the tentacular aperture to be entirely within the maxillopalatine in Chthonerpeton indistinctum, but this is not true of the material we have examined. In Chthonerpeton, an anterior nasopremaxillary portion of the groove is present, but is short and weakly defined, and this clearly reflects the position of the tentacular aperture closer to the eye. The lack of a nasopremaxillary portion of the groove in Atretochoana occurs in spite of the anterior position of the tentacular apertures.

Atretochoana is unique among caecilians in having the orbit open posteriorly. In other typhlonectids, the squamosal braces against the frontals anteromedially and separates the orbit from the upper temporal fossa. The squamosal is usually distinctly narrowed and curved forming a postorbital process in Typhlonectes natans, although Taylor (1969) illustrated a $22 \mathrm{~mm}$ skull, larger than the skulls that we have seen, in which the postorbital region of the squamosal is thick and less distinctly curved, more like the condition seen in other typhlonectids. In Chthonerpeton, an orbital process of the frontal projects laterally so as to separate the maxillopalatine and squamosal and form a small portion of the medial wall of the orbit. In other typhlonectids, the frontal does not interpose, and the squamosal abuts against the maxillopalatine. Atretochoana is atypical in that the squamosal completely lacks any postorbital portion, makes no contact with the frontals, and braces solely against the maxillopalatine rostrally. The most medial part of the squamosal at this contact is extended as an extremely small medial process that may be all that remains of the posterior border of the orbit. Laterally, the squamosal bears a thickened and elevated tuberosity not seen in other forms.

All typhlonectids have an upper temporal fossa between the parietal and the squamosal. In Chthonerpeton and Nectocaecilia, the parietal slopes ventrally at the medial border of the upper temporal fossa to form the dorsal portion of the medial wall of the adductor chamber. Nectocaecilia has a strong posterolateral projection of the frontals forming a ledge that partially overlies the adductor chamber anteriorly. This ledge may be developed in other typhlonectids but always very weakly. In Potomotyphlus and Typhlonectes compressicauda, the parietal slope into the adductor chamber is much weaker. The parietal of Atretochoana is a simple flat horizontal plate lacking any slope into the adductor chamber. Foetal and small T. natans have only a very weak parietal slope, but the slope is as great as it is in Potomotyphlus and $T$. compressicauda in larger and presumably older skulls indicating a late ontogenetic transformation in the shape of the parietal.

In Atretochoana, the parietals have somewhat pointed posterolateral corners. The shape in both Typhlonectes natans and $T$. compressicauda is very variable, ranging from 
a gentle curvature to an extreme anterolaterally directed point, and similar variation might be expected in Atretochoana. The posterior margins of the parietals of Nectocaecilia and Chthonerpeton curve strongly ventrally onto the supraoccipital region and contribute a relatively large area for muscle attachment that is delimited from the more horizontal anterior parts of the parietals by a strong ridge. In contrast, the parietals of other typhlonectids have a less steep slope posteriorly and a relatively smaller area for muscle attachment, or, in the case of Atretochoana, completely lack any posterior sloping of the parietals. These characteristics of the parietals in Atretochoana contribute to the strong degree of dorsoventral compression of the skull.

The upper temporal fossa of Atretochoana is considerably enlarged by the lack of a post-orbital portion of the squamosal anteriorly and by the relatively more lateral placement of the maxillopalatine, squamosal, and quadrate. In addition to lateral displacement, the squamosal and quadrate are elongate, the latter exceptionally so. The squamosal extends posteriorly, closely approaching the level of the foramen ovalis and the posterior ends of the parietals. In other typhlonectids the squamosal extends posteriorly only as far as the level of the middle of the parietal. The squamosal normally is a simple flat element, very slightly concave medially, and oriented dorsolaterally. In typhlonectids, it has an anterior ventral process that descends, where the squamosal contacts the maxillopalatine, so as to brace against the posterior and dorsal edges of the toothbearing maxillary arcade. This ventral process is relatively poorly developed in Chthonerpeton, but it is more elongate and partially fills the recess between the maxillary and palatine dentigerous shelves of the maxillopalatine in other typhlonectids. It is particularly pronounced in Nectocaecilia.

The ventral process of the typhlonectid squamosal, where it occupies the notch between the palatine and maxilla, resembles topologically the pseudoectopterygoid of those caeciliids that have this separate element (e.g. Hypogeophis Peters and Geotrypetes Peters). This bone, when present, also braces against the maxillopalatine, but usually extends posteromedially so as to contact the pterygoid process of the quadrate also. In late foetuses of Typhlonectes natans, the ventral squamosal process is present as a poorly developed outgrowth of the squamosal, with no indication of any fusion of initially separate elements. In contrast, in the caeciliids Sylvacaecilia Wake and Hypogeophis, the pseudoectopterygoid forms from an anteromedial part of the pterygoid process of the quadrate that becomes isolated through the posterior development of the palatine shelf of the maxillopalatine (Nussbaum \& Willinson, unpubl.). Thus, despite their similar positions, the ventral process of the squamosal and the pseudoectopterygoid are unlikely to be homologous.

The squamosal of Atretochoana is nearly horizontal. Its ventral process projects more medially and does not occupy the recess between the maxillary and palatine shelves, but lies dorsal to them and forms an expanded flat plate. The ventral process can be seen through the upper temporal fossa in dorsal view whereas in other typhlonectids it is hidden from view by the rest of the squamosal. Laterally, the articulation of the squamosal with the maxillopalatine is relatively short in Atretochoana, Potomotyphlus, and Typhlonectes, and more extensive in other typhlonectids.

Posteriorly the typhlonectid squamosal broadly overlies the plate-like ascending process of the quadrate, and the quadrate thickens into what is usually a roughly vertical block with a $>$-shaped posterior margin. The processus pterygoideus of the quadrate projects anteriorly from its ventral margin and braces against the palatine shelf of the maxillopalatine. The squamosal, maxillopalatine, and quadrate thus form a closed loop which ventrally delimits the lower temporal fossa and through 
which the classical jaw adductors pass before inserting on the lower jaw. Gronowski (1980) illustrated a separate pterygoid in Chthonerpeton indistinctum, and Taylor (1969) reported that the pterygoid is at least partially fused to the quadrate in the typhlonectids he illustrated. Azpelicueta et al. (1987) claimed that the skull of Chthonerpeton differs from those of other typhlonectids in the complete fusion of the pterygoid and quadrate. No typhlonectids or caeciliids we have examined have any indication of separate pterygoids as adults, although a separate pterygoid ossification in the early ontogeny of the caeciliid Dermophis mexicanus (Duméril \& Bibron) that fuses with the quadrate to form the adult pterygoid process of the quadrate has been reported (Wake \& Hanken, 1982).

The quadrate of Atretochoana is extremely elongate caudally, forming a long tubular sheath with the lower temporal fossa correspondingly enlarged. Over half of the length of the fossa is posterior to the articulation of the quadrate with the basipterygoid process of the os basale instead of being almost entirely anterior to this articulation as it is in all other caecilians. The lower temporal fossa of Atretochoana is oriented more laterally than in other caecilians, reflecting the more dorsal and horizontal position of the squamosal and ascending process of the quadrate.

The form of the articulation between the squamosal and the ascending process of the quadrate varies. In Atretochoana and Chthonerpeton, there is a broad overlap at their ventrolateral margins and little or no free margin of the quadrate dorsally that is not covered by the squamosal. In Nectocaecilia, Potomotyphlus, and Typhlonectes, the ventral overlap is more restricted and in the latter two genera (with the exception of a single specimen of $T$. natans) there is an exposed portion of the quadrate dorsally. The articular facet of the quadrate occupies the entire posterior edge of this bone in Atretochoana, whereas in all other caecilians it forms only the posteroventral margin of the more vertically oriented quadrate. In Chthonerpeton, the facet is somewhat straight, rather than curving as it does in other typhlonectids, corresponding to the articular surface of the pseudangular (see below).

The upper temporal fossa of typhlonectids is usually bordered posteriorly by the stapes. In all caecilians that have one, the stapes has a broad footplate which fills the fenestra ovalis and a dorsoventrally flattened, narrower, rod-like style which extends anteriorly, laterally and slightly dorsally forming a sliding articulation with the quadrate. The stapedial style is generally more slender and elongate in typhlonectids than in other caecilians, though it is fairly broad in Nectocaecilia and more distinctly narrow and delicate in the small headed Potomotyphlus. A distinct processus oticus may not be developed. It is present in Chthonerpeton, either present or absent in Typhlonectes, and absent in the single specimens of Potomotyphlus and Atretochoana we have examined. In both T. compressicauda and Nectocaecilia, there may be a distinct ossification in the connective tissue between the style and the quadrate, a condition also seen in some salamanders. In the single skull of Nectocaecilia available, this heterotopic ossification is free on one side, but partially fused to the stapedial style on the other. Similar variation is seen in $T$. compressicauda.

A short broad ligament typically extends from the quadrate to the parietal above the stapes, which presumably limits the lateral displacement of the cheek and suspensorium. Atretochoana lacks this quadratoparietal ligament, and the stapes is greatly modified. It projects posteriorly, laterally, and dorsally and is extremely elongate, stretching slightly further than the quadrate, approximately parallel to it. It has a very short proximal region that is slightly thinner than the footplate, and more distally has the form of an expanded blade-like sheet, somewhat concave on 


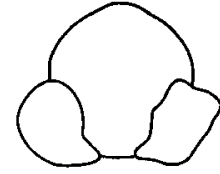

A

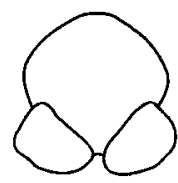

D

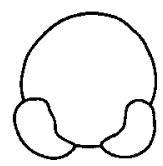

B

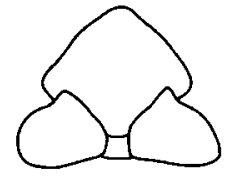

$\mathbf{E}$

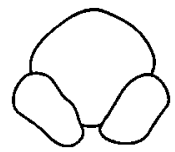

C

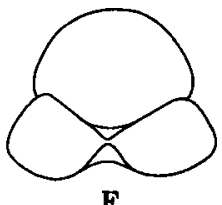

F

Figure 10. Semi-diagrammatic occipital views of the skulls of (A) Potomotyphlus; (B) Typhlonectes (C) Chthonerpeton; (D) Grandisonia; (E) Ichthyophis; (F) Epicrionops.

its ventrolateral surface and with a slight lateral projection of its distal tip ending in a point. The stapes makes no contact with the quadrate but is instead free and capable of considerable lateral movement about the foramen ovalis. Strict dorsoventral displacement may be restricted by thickenings of the margins of the foramen. Some dorsoventral movement appears possible in combination with lateral displacement, in a dorsolateral-ventromedial plane. In all typhlonectids, the foramen ovalis perforates the lateral dorsal wall of the otic capsule, and is recessed below a lateral expansion of the os basale dorsal to the otic capsule which we designate the supraotic shelf. The recession is particularly weak in Chthonerpeton.

The posterior end of the skull is formed by the os basale, which in all caecilians has a concave margin dorsal to the foramen magnum. In Typhlonectes, the dorsal margin is only weakly concave such that the ventral margin of the foramen magnum is not visible in dorsal view. We have been unable to examine this directly in Atretochoana, but it is clear from measurements that the ventral border of the foramen magnum projects posteriorly beyond the dorsal border as in Chthonerpeton, Potomotyphlus, and Nectocaecilia.

The occipital condyles vary in their degree of medial separation at the ventral margin of the foramen magnum, being only weakly separated from each other in Chthonerpeton and Nectocaecilia and more widely separated in Atretochoana and the other typhlonectids. In typhlonectids, the occipital condyles are oriented more dorsolaterally than in other caecilians, though the less dorsal and more lateral orientation of nontyphlonectids is approached in Chthonerpeton (Fig. 10).

The otic capsules are bulbous structures, which in ventral view lie just anterior to the occipital condyles. In Chthonerpeton and Nectocaecilia, their posterior margins are transversely oriented, and thus have a rather squarish shape in which the posterolateral corner extends laterally beyond the more dorsal walls of the os basale in the otic region. The posterior border of the otic capsules is oriented more obliquely in an anterolateral direction in Typhlonectes, and the capsules are recessed ventrally under the dorsolateral portions of the os basale rather than projecting beyond them. The difference affects the form of the jugular foramen also. This foramen lies between the otic capsule and the occipital condyle close to its base. It lies at the end of an oblique groove formed by the recession of the otic capsule in Typhlonectes. In Chthonerpeton and Nectocaecilia, the groove is weak, except very close to the foramen, and its orientation is transverse. Atretochoana and Potomotyphlus have an intermediate 
condition in which the otic capsules are distinctly recessed and oriented anterolaterally except close to the jugular foramen where they are more transverse. In larger and presumably older specimens of Typhlonectes, such as that illustrated by Taylor (1969), the otic capsules appear to extend laterally so as to not be completely recessed under the dorsal portions of the os basale. This is due, however, to the exceptional development of thickened ridges, which serve for the attachment of ventral neck muscles and delimit the anterior extent of these muscles. This condition is very different from the transverse orientation and lateral projection of the otic capsules in Chthonerpeton and Nectocaecilia.

The only direct articulation of the quadrate with the os basale is at the basipterygoid process of the os basale anterior to the otic capsuitès. All typhlonectids have welldeveloped basipterygoid processes, but, as they contribute to the lateral displacement of the check and suspension, they are massively enlarged in Atretochoana and project much more strongly from the body of the os basale.

There is considerable variation in the size of the parasphenoid region of the palate within the Typhlonectidae. Basically, the region is most elongate in Chthonerpeton and Nectocaecilia, shortest in Atretochoana and Potomotyphlus, and intermediate in Typhlonectes. In Chthonerpeton and Nectocaecilia, the pterygoid process of the quadrate is relatively elongate and narrow, and the mediopalatinal cavity (= pterygoideal vacuity or fenestra) is an elongate longitudinal diastema between the pterygoid process and the os basale anterior to the basipterygoid process and posterior to the postchoanal process of the maxillopalatine. These forms, especially Chthonerpeton, also have a relatively elongate portion of the palatine shelf of the maxillopalatine posterior to the dentigerous region and a long area of overlap between this and the pterygoid process of the quadrate. In Typhlonectes, the pterygoid process of the quadrate is much shorter and broader, the posterior adentigerous portion of the palatine is far less extensive and the two elements have a shorter region of overlap. The mediopalatinal cavity is correspondingly shorter, but remains posterior to the postchoanal process. In Atretochoana, and to a slightly lesser extent in Potomotyphlus, the pterygoid process of the quadrate is shorter still, and the posterior portion of the palatine is considerably reduced, with the overlap between them very small. The palatine shelf extends so close to the basipterygoid process in these forms that the mediopalatinal cavity posterior to the palatine is extremely small, and the cavity extends anteriorly (beyond the postchoanal process in Potomotyphlus) into the dorsolateral wall of the choana.

Typhlonectid taxa can be ranked according to the size of their choana from small to large in the following order: Chthonerpeton, Nectocaecilia, Typhlonectes, Potomotyphlus, Atretochoana. Generally, choanal size is inversely correlated with the size of the parasphenoid region. That the choanae of Atretochoana are proportionately the largest is due in part to the complete absence of a postchoanal process of the maxillopalatine, a feature that is unique among caecilians. In all other typhlonectids, except $P_{0}$ tomotyphlus, the postchoanal process is thick (especially so in Nectocaecilia) and extends medially, bracing against the os basale and closely approaching the posterior margins of the vomers. In Potomotyphlus, the process is distinctly short, not reaching close to the vomers.

The vomers form the superficial medial rims of the choanae. They are most elongate in Chthonerpeton where they extend posteriorly slightly beyond the postchoanal processes. Only in Atretochoana and Potomotyphlus do the vomers not expand as they approach the posterior margins of the choanae, and in the latter form they are 
exceptionally narrow, contributing to an extremely wide choanal aperture. The degree of posterior expansion in Typhlonectes natans is variable. The sphenethmoid forms the deeper medial walls of the choanae dorsal to the vomers. These walls are vertical and not visible from below in Chthonerpeton, and slant dorsolaterally (weakly so in T. compressicauda) such that they are visible below along their posterior halves in other typhlonectids. Potomotyphlus is unique in having this dorsolateral slanting visible on the anterior half also, resulting, at least partially, from the extreme narrowness of the vomers, and in having the most superficial posterior parts of the medial choanal walls developed into raised 'pseudovomerine' flanges in the position that is occupied by the posterolateral expansions of the vomers in Typhlonectes, Nectocaecilia, and Chthonerpeton.

The vomers are separated medially by the parasphenoid process of the os basale. The degree of separation is variable in Chthonerpeton (Azpelicueta et al., 1987), and is variable also in Typhlonectes. In these forms separation may extend for the whole of the adentigerous portion or only for the posteriormost one third. Anteriorly, the vomers expand laterally, contributing to the anterior margin of the choanae and forming syndesmoses with the palatine shelves of the maxillopalatines. The vomers curve gently anteriorly into these lateral expansions except in Nectocaecilia and Atretochoana. In the former, there is a straight-sided deviation in the vomers about midway down their length with its anterior expansion forming a thin flange that partially conceals the choanal cavity. The lateral expansion in Atretochoana forms a steeper angle with the posterior projections of the vomers, giving the choanae a squarish anteromedial corner. In $\mathcal{T}$. natans, the maxillopalatine forms an elongate vomerine process at the posterior margin of its junction with the vomers. This process is present in other typhlonectids, but is more poorly developed. Potomotyphlus has an additional, weakly-developed, process of the maxillopalatine just posterior to the dentigerous ridge of the vomer, and thus the maxillopalatine notches into the vomer rather than bracing against its posterior margin.

In Atretochoana and Potomotyphlus, the palatal suture between the maxillopalatine and the nasopremaxilla of each side runs approximately transversely from the midline and then turns steeply anteriorly such that the maxillopalatine has a strong, ventrolateral, anterior, palatal process. In other typhlonectids, any anterior extension of the maxillopalatine is weak, and its junction with the nasopremaxilla ventrolaterally is more irregular. Potomotyphlus is distinctive in having the maxillopalatine forming a relatively large ventral cheek surface outside of the mouth.

Atretochoana shares with Potomotyphlus and Typhlonectes a maxillary arcade that is relatively straight in lateral view, curving much more gently than in Nectocaecilia and Chthonerpeton in which the arcade is concave. Atretochoana is the only caecilian in which the vomeropalatine teeth are clearly visible in lateral view. This is a reflection of a generally flatter palate than in other caecilians, which have the vomeropalatine teeth concealed laterally by the ventrolateral margin of the maxillopalatine, and in which the palate is weakly concave. The palatinal tooth row is distinctive in Nectocaecilia in forming an angle anteriorly with the vomerine teeth. In other typhlonectids, this tooth row is in line with the vomerine teeth anteriorly.

Anterior to the otic capsules, the lateral wall of the os basale within the adductor chamber is perforated by foramina for the passage of the rami of the trigeminal and facial nerves. These foramina are largely fused into a single antotic foramen in typhlonectids. Typhlonectes and Nectocaecilia have a small accessory foramen dorsal and posterior to the main foramen. In Chthonerpeton, the accessory foramen is partially 
fused with the antotic foramen and is indicated by a strong notch in the posterodorsal border of the antotic foramen, whereas in Potomotyphlus and Atretochoana, the fusion is complete with no indication of an accessory foramen.

Where the lateral wall of the os basale articulates with the sphenethmoid, just posterior to the orbit at the anterior end of the adductor chamber, there is a large orbital foramen which emarginates both bones and lies between the orbital and trabecular cartilages. A small foramen, the sphenethmoid canal for the passage of the opthalmicus profundus nerve, is present anterior to the orbital foramen and connected to it by a shallow groove in the sphenethmoid. This groove is relatively short in Typhlonectes, compared to other typhlonectids.

The nasal capsules are separated by a largely bony internasal septum. Typhlonectids lack olfactory eminentia (processus conchoides of some authors) dividing each of the main nasal cavities. Atretochoana and Potomotyphlus lack any bony projections into the anterior part of the nasal capsules, but other typhlonectids have a short, narrow, and nearly longitudinally oriented narial process of the nasopremaxilla which projects ventrally from the bony roof of each capsule very close to the narial aperture.

\section{Lower jaw}

The lower jaws of the two species of Typhlonectes were illustrated and very briefly described by Taylor (1977a). Peters (1879) illustrated, and Azpelicueta et al. (1987) illustrated and provided a terse description of, the lower jaw of Chthonerpeton indistinctum. The lower jaw of caecilians is composed of two elements, the pseudodentary and the pseudangular. The pseudangular extends anteriorly as a pointed triangular wedge on its medial side between dorsal and ventral medial processes of the pseudodentary. Laterally, a pointed triangular wedge of the pseudodentary extends posteriorly between dorso-and ventrolateral processes of the pseudangular. Teeth are present in two rows on the pseudodentary in typhlonectids, with the teeth of the inner row usually referred to as the splenials. The pseudangular bears a processus internus, an articular facet, and a deep articular groove associated with the jaw articulation. In addition, there is a large retroarticular process of the pseudangular and a large dorsally oriented canalis primordialis into which runs the mandibular branch of the trigeminal nerve and the mandibular artery. Dorsal, ventral, and lateral views of the lower jaws of Atretochoana, Potomotyphlus, and Typhlonectes natans are shown in Figures 11, 12 and 13.

In Chthonerpeton, the medial wedge of the pseudangular is relatively elongate, and the pseudodentary anterior to it is correspondingly smaller than in other typhlonectids. The dorsal margin of the medial wedge of Chthonerpeton is straight as it approaches the dorsal edge of the mandible in medial view and continues in a straight line across the dorsal edge to form the ventral margin of the dorsolateral process of the pseudangular. In Nectocaecilia, the dorsal margin of the medial wedge is expanded into a small dorsal process close to the dorsal margin of the mandible, which notches into the dorsomedial process of the pseudodentary. In Typhlonectes and Potomotyphlus, this dorsal process projects above the dorsal edge of the mandible and occupies the portion of the pseudangular directly anterior to the canalis primordialis and provides an additional surface for the insertion of the m. adductor mandibulae externus. The dorsal process of Atretochoana is not elevated, and it notches into the pseudodentary on the dorsolateral surface of the mandible. Thus, it is not visible in medial view. The 


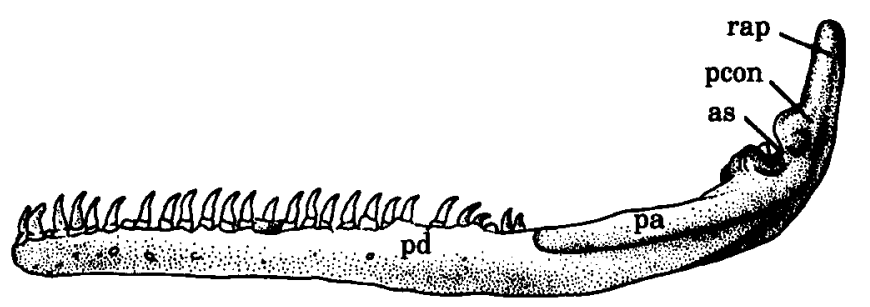

A

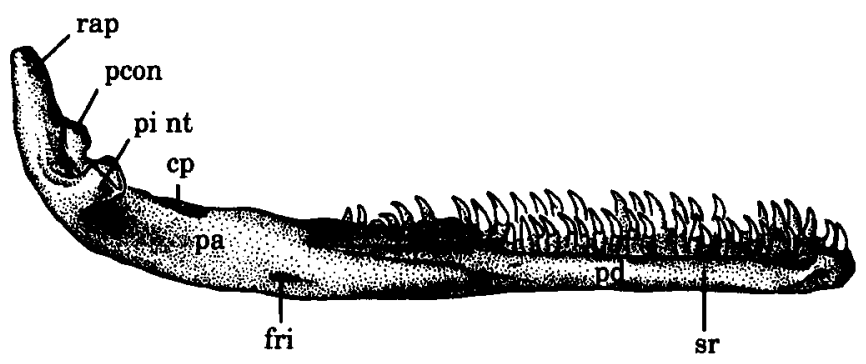

B

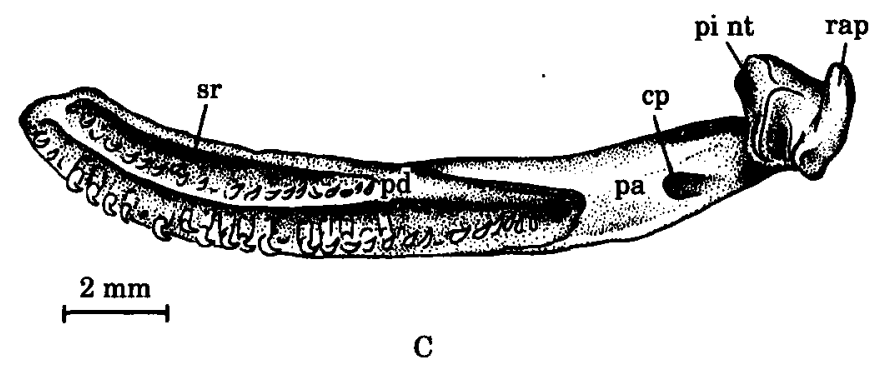

Figure 11. Lateral (A), medial (B) and dorsal (C) views of the lower jaws of NMW 9144, the holotype of Atretochoana eiselti. as =articular surface; $\mathrm{cp}=$ canalis primordialis; fri $=$ foramen for the ramus intermandibularis; $\mathrm{pa}=$ pseudangular; $\mathrm{pcon}=$ processus condyloides; $\mathrm{pd}=$ pseudodentary; $\mathrm{pint}=$ processus intermus; rap = retroarticular process; $\mathrm{sr}=$ splenial ridge. Scale $\mathrm{bar}=2 \mathrm{~mm}$.

region of the pseudangular anterior to the canalis primordialis is relatively elongate in Atretochoana.

The splenial ridge of the pseudodentary can be divided into three regions. The anteriormost region is dentigerous and is followed by a middle adentigerous region where the apex of the ridge is narrow and well defined. The posteriormost region has a more smoothly curved and less well defined apex. The dentigerous regions of Atretochoana and Potomotyphlus are more elongate than in other typhlonectids, particularly that of the former, and the middle region is also relatively elongate, especially in Potomotyphlus. Correspondingly, the posteriormost region of Potomotyphlus is relatively short, and in Atretochoana it is almost non-existent. The splenial ridge of Chthonerpeton fades out further anterior than in other typhlonectids. Typhlonectids have a subsplenial ridge, paralleling the splenial ridge and mesial to it. This is more elongate in Atretochoana and Potomotyphlus than in other typhlonectids, and, in 


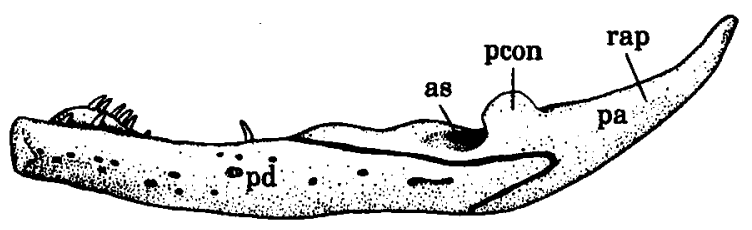

A

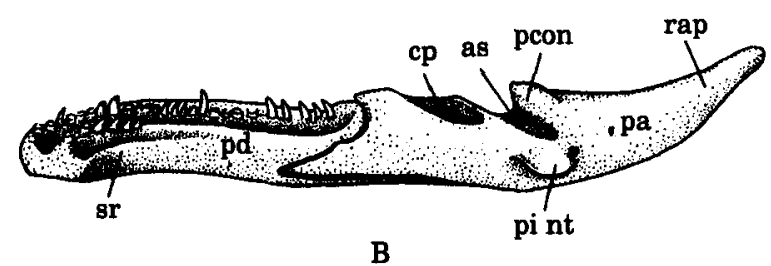

B
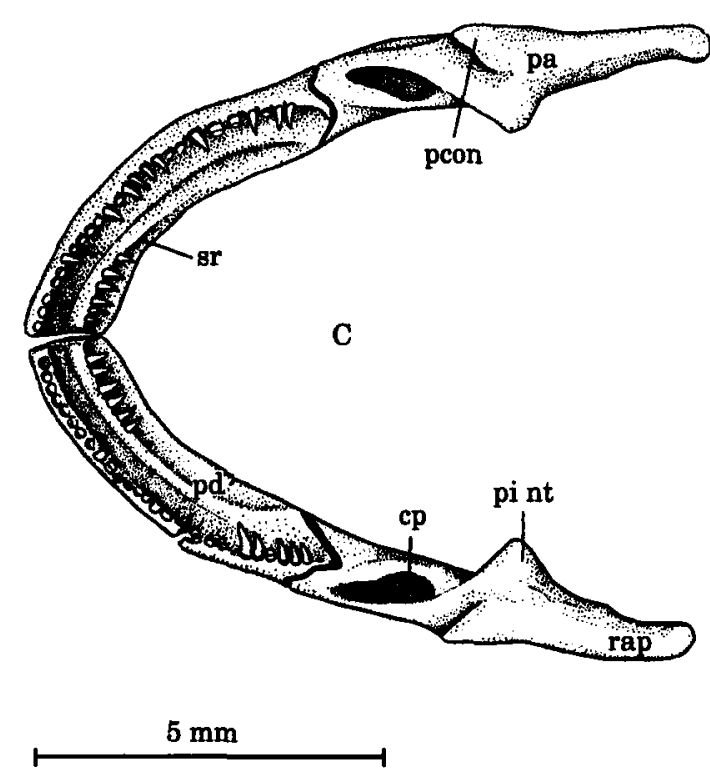

Figure 12. Lateral (A), medial (B) and dorsal (C) views of the lower jaws of UMMZ 211206, Potomotyphlus kaupii. Abbreviations as in Fig. 11. Scale bar $=5 \mathrm{~mm}$.

Potomotyphlus, it extends well posterior to the dentigerous region of the splenial ridge and then fades out. In Atretochoana and other typhlonectids, the subsplenial ridge expands dorsally close to the posterior margin of the splenial tooth series and merges with the splenial ridge forming a well defined splenial fossa between the two ridges, which is occupied by the pedicels of the splenial teeth. The fossa is well defined only anteriorly in Potomotyphlus. In addition, the dentigerous region of the splenial ridge is strongly elevated in Potomotyphlus and uniquely visible in lateral view above the lateral dorsal margin of the jaw. 


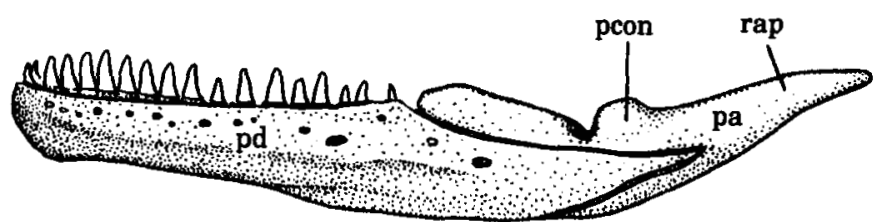

A

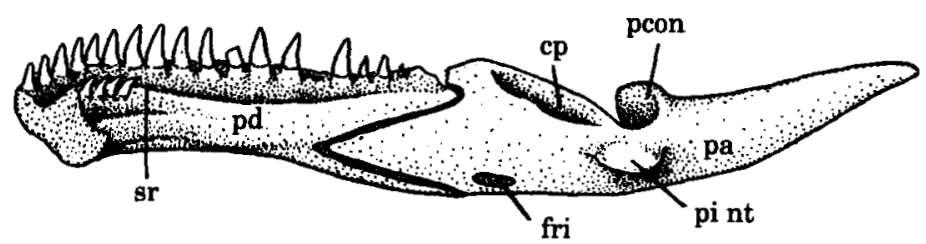

B

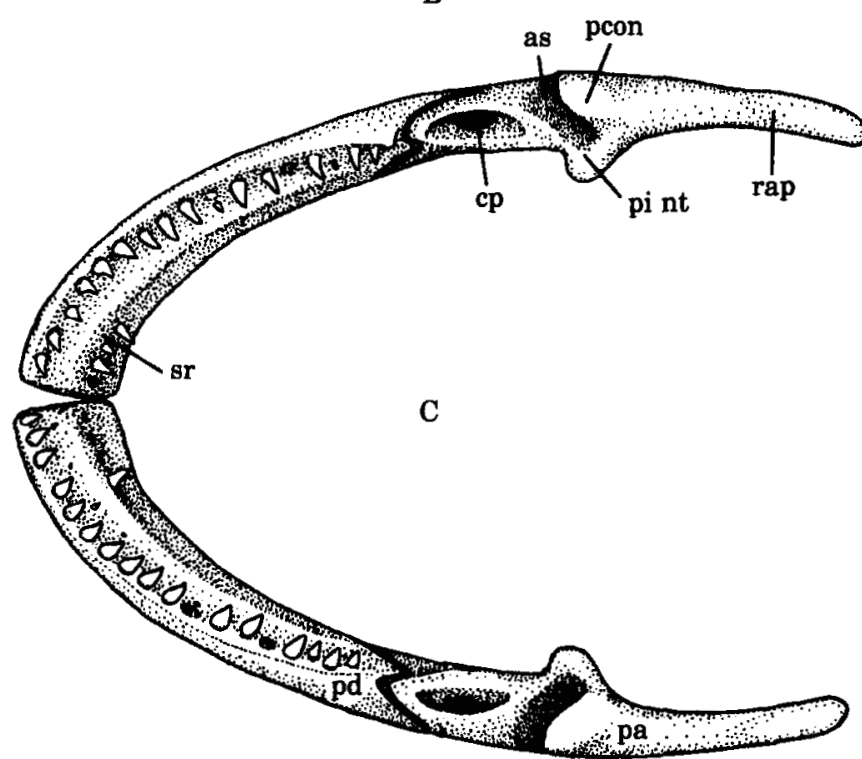

$5 \mathrm{~mm}$

Figure 13. Lateral (A), medial (B) and dorsal (C) views of the lower jaws of LACM 67454, Typhlonectes natans. Abbreviations as in Fig. 11. Scale bar $=5 \mathrm{~mm}$.

The ventrolateral process of the pseudangular is generally shorter than the dorsolateral process. This difference in the extension of the two processes is most pronounced in Atretochoana and Potomotyphlus, mainly as a result of relatively longer dorsolateral processes than in other typhlonectids, and is least pronounced in Nectocaecilia, which has a relatively elongate ventrolateral process. Atretochoana and Potomotyphlus have a somewhat squarish anterior tip to the pseudodentary. In other typhlonectids, the ventral margin of the pseudodentary curves gently upward to 
form a pointed anterior tip. Atretochoana alone has considerable flexibility between the two halves of the lower jaw at the mandibular symphysis.

The articular condyle of the pseudangular lies at the posterior edge of a deep articular groove which accommodates the articular foot of the posteroventral corner of the quadrate. In Chthonerpeton, the groove and the condyle are relatively transverse so that the face of the condyle is barely visible in medial view, whereas in Atretochoana and other typhlonectids the condyle and groove are more oblique, and the condylar surface is somewhat bent so as to expose the medial part of its surface in medial view. Atretochoana has a large, post-articular, dorsolateral tuberosity that is present also, but poorly indicated, in other typhlonectids. Ventral to the articular condyle is the processus internus of the pseudangular with an associated foramen presumably for the passage of blood vessels. The shape of the process is very variable in Typhlonectes natans as is the position of the foramen which may form only a groove notching into the ventral surface of the process.

Atretochoana has several unique features associated with the extreme elongation of the lower jaw. The pseudangular begins to bend dorsally anterior to the articular groove, which is thus directed more anteriorly. In other caecilians, the dorsal inflection is confined to the retroarticular process. The articular condyles and grooves are displaced posteriorly so that, in combination with the extreme elongation of the jaws anterior to the articulation, the retroarticular processes are both relatively and absolutely short. The retroarticular processes are strongly inflected dorsally, almost vertically, and have the strongest dorsal inflection yet observed in caecilians. There is little mesial inflection of the retroarticular processes in other typhlonectids, and the mandibles curve gently, but distinctly, toward the mandibular symphysis anteriorly. Atretochoana shares this anterior medial curvature, and also has a strong mesial inflection of the retroarticular processes, stronger than in any other caecilian. The lateral wedge of the pseudodentary does not extend posteriorly as far as the articular condyles in Atretochoana as it does in other typhlonectids. The distance between the canalis primordialis and the articular groove is large. In other typhlonectids, this distance is minimal, and the anterior edge of the articular groove contributes to the posterior border of the canalis primordialis.

\section{Dentition}

The adult tooth crown morphology of typhlonectids was surveyed by Wilkinson (1991). The teeth of Atretochoana, like those of Typhlonectes natans (Fig 14A) and all other typhlonectids, are monocusped, conical, recurved, and have lateral blade-like flanges. T. compressicauda (Fig. 14B) has distinctive spatulate or chisel-shaped tooth crowns (Greven, 1986). The tooth crowns of all other typhlonectids, including Atretochoana, are pointed. Potomotyphlus has relatively narrow teeth, often bearing an enlarged, lateral flange (Fig. 14G). Nectocaecilia has teeth that are relatively hypertrophied. The high tooth counts of Potomotyphlus and Atretochoana reflect both a relatively tight packing of the loci, especially in Potomotyphlus, and enlargement of the tooth-bearing areas, especially the splenial ridge in Atretochoana. The tooth crowns of caecilians are flexibly attached to their pedicels such that they can be displaced posteriorly or posteromedially (in the direction of prey transport in the mouth) about the pedicels, but resist displacement in other directions (Bemis, Schwenk \& Wake, 1983). The teeth of Atretochoana are exceptionally flexible in these directions and can 

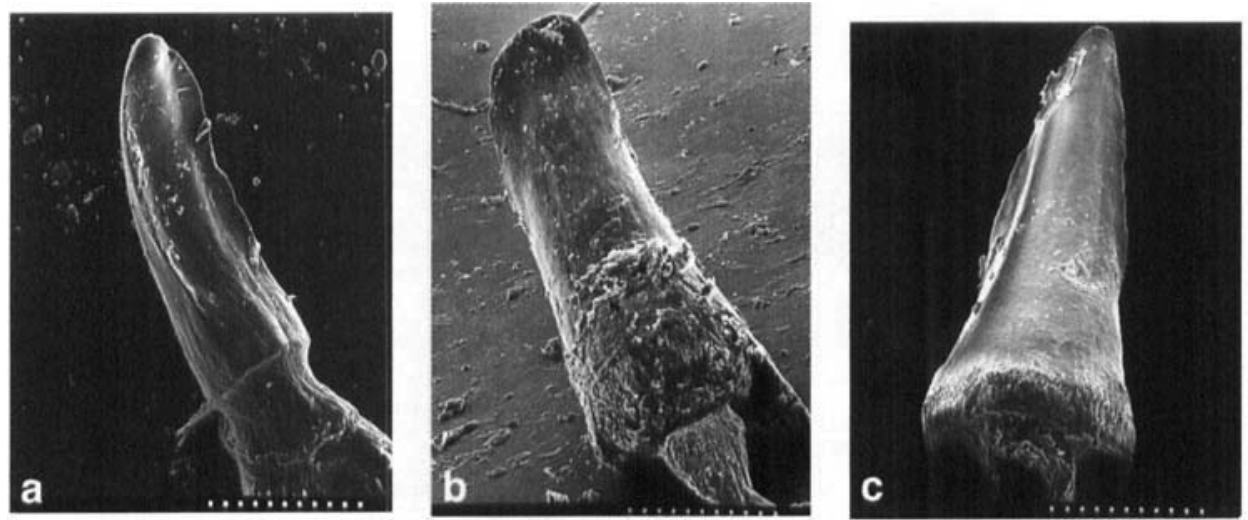

Figure 14. Scanning electron micrographs of anterior dentary teeth of (A) UMMZ 60881, Typhlonectes natans [Scale bar $=231 \mu \mathrm{m}$ ], (B) UMMZ 129649, T. compressicauda [Scale bar $=176 \mu \mathrm{m}$ ], and (C) CAS 10848 Potomotyphlus kaupii [Scale bar $=136 \mu \mathrm{m}]$.

TABLE 4. Numbers of teeth in skeletal preparations of adult typhlonectids. Numbers in each series are for a single side of the skull. Thus each specimen contributes two counts (right and left) with the exception of Atretochoana of which only one side of the skull was prepared. Figures in parentheses are data from Taylor (1969). $\mathrm{SS}=$ sample size, $\mathrm{N}=$ nasopremaxilla, $\mathrm{M}$ - maxilla, $\mathrm{V}=$ vomer, $\mathrm{P}=$ palatine $\mathrm{D}=$ dentary $\mathrm{S}=$ splenial

\begin{tabular}{lccccccc}
\hline & SS & N & M & V & P & D & S \\
\hline Chthonerpeton & 2 & $7-9$ & $9-10$ & 4 & $10-11$ & $13-16$ & $2-3$ \\
Nectocaecilia & 1 & 5 & 11 & $3-4$ & 11 & $10-13$ & 3 \\
Polomotyphlus & 1 & $12(10)$ & 15 & $5-6(4)$ & $19-21$ & 27 & 6 \\
Atretochoana & 1 & 9 & 18 & 6 & 14 & 29 & 21 \\
Typhlonectes natans & 14 & $6-9(10)$ & $11-16(20)$ & $4-6(8)$ & $12-18(23)$ & $14-19(21)$ & $2-6$ \\
Typhlonectes compressicauda & 4 & $8-11$ & $11-17$ & $5-7$ & $12-21$ & $14-21$ & $4-8$ \\
\hline
\end{tabular}

be displaced from their resting position into an almost horizontal plane. This may be an artifact of preservation. Variation in tooth counts from osteological specimens is given in Table 4 .

\section{Glossal skeleton}

Nussbaum (1977) and Azpelicueta et al. (1987) illustrated the glossal skeletons of Typhlonectes and Chthonerpeton respectively. Nussbaum (1977) noted that typhlonectids have a distinctive glossal skeleton in which the ceratohyals and first basibranchials form an M-shape and the fused third and fourth ceratobranchials are in the form of greatly enlarged plates. In adult non-typhlonectids, the paired cartilages of the ceratobranchials are continuous across the midline, and the cartilages of the basibranchials are continuous with those of the ceratohyals anteriorly and with the first ceratobranchials posteriorly. Similarly, foetal Typhlonectes natans have cartilage continuous across the junctions of the glossal elements, whereas in adults only the midline connection of paired fusions of the third and fourth ceratobranchials remain. Other articulations are replaced by non-cartilaginous connective tissue bridges that 


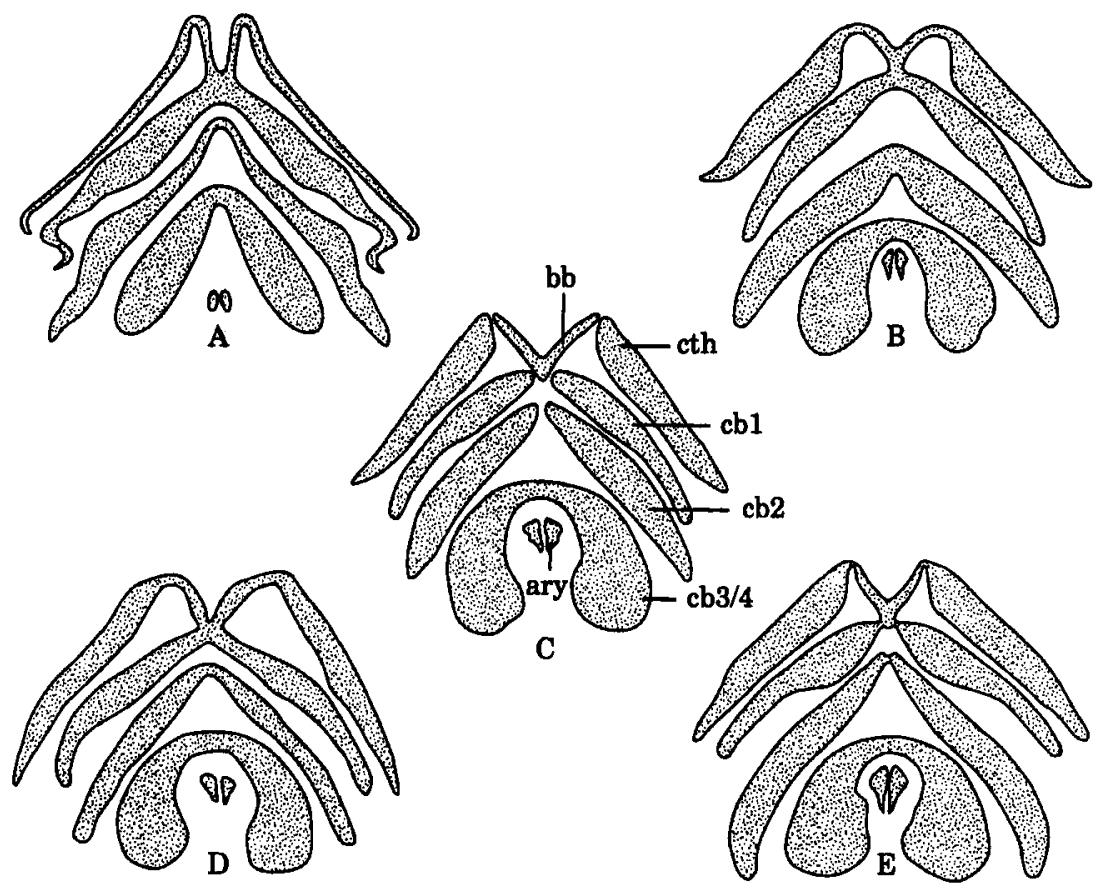

Figure 15. Semi diagramatic ventral views of the glossal skeletons of (A) Atretochoana, (B) Potomotyphlus, (C) Typhlonectes natans Adult, (D) Typhlonectes natans neonate, and (E) Nectocaecilia. ary = arytenoid; $b \mathrm{~b}=$ basibranchial; cb $1-3 / 4=$ ceratobranchials; $c$ th $=$ ceratohyal. Normally overlapping elements are shown displaced and separated. Not to scale.

provide greater flexibility between the cartilaginous elements. In typhlonectids other than Typhlonectes, cartilage is continuous across these articulations, but in Chthonerpeton and Nectocaecilia, the cartilaginous connections are very weak, approaching the condition in adult Typhlonectes. In Atretochoana and Potomotyphlus, and in foetal T. natans, the anterior tips of the ' $\mathrm{M}$ ' formed at the union of the basibranchials and ceratohyals are transversely elongate, straight in Atretochoana and curved in Potomotyphlus. In other adult typhlonectids, the tip is narrow and pointed. Potomotyphlus and Atretochoana are also similar in lacking the strong medial expansion of the distal fused third and fourth ceratobranchials characteristic of other typhlonectids (Fig 15). The Potomotyphlus examined by us is unique in having the tips of the normally cartilaginous tracheal cartilages ossified.

Atretochoana has several unique features of the glossal skeleton. The paired basibranchials are completely separated, whereas they are united posteriorly to form a V-shaped structure in Typhlonectes natans and a Y-shaped structure in other typhlonectids. The distal ends of the ceratohyals and first ceratobranchials are curved, medially in the former and first medially then laterally in the latter. These elements lack any distal curvature in other typhlonectids except for the dorsolateral curvature common to all caecilians. All of the elements are considerably narrower than in other typhlonectids, and the ceratohyals and first two pairs of ceratobranchials are relatively elongate. The fused third and fourth ceratobranchials lack the great size characteristic of other typhlonectids, and the two sides are connected between their medial edges by a very strong sheet of connective tissue, which we designate 
the laryngeal fascia. Typically, in typhlonectids and caeciliids, the arytenoid cartilages are located anteriorly, close to the union of the last ceratobranchials, and are composed of a subtriangular ventral plate with a projecting dorsal process that is continuous with the cartilaginous rings of the trachea. In Atretochoana, the arytenoids are far posterior, close to the posterior tips of the last ceratobranchials within the laryngeal fascia, and they are rod-like rather than subtriangular. Tracheal cartilages and the dorsal processes of the arytenoids appear to be absent in Atretochoana.

At rest, the first ceratobranchials are most superficial and partially overlay the second ceratobranchials medially and the ceratohyals distally (see Fig. 21). Profound expansion of the buccopharyngeal pump is achieved by posteroventral rotation of the ceratohyals and first ceratobranchials medially, and posterior sliding of the second and the fused third and fourth ceratobranchials. The sliding articulation of the first and second ceratobranchials is not seen in non-typhlonectids and is readily interpreted as a derived character supporting typhlonectid monophyly and associated with the elaboration of the buccopharyngeal pump.

\section{Vertebral column}

Peter (1894) described and illustrated vertebrae of Chthonerpeton in comparison to several non-typhlonectids. Estes \& Wake (1972) included Typhlonectes compressicauda among species for which they listed vertebral measurements. Taylor (1977b) illustrated and briefly described the anteriormost vertebrae of Typhlonectes. Wake (1980) illustrated vertebrae from several body regions and described regional variation within $T$. compressicauda (most probably T. natans) in comparison to those of Ichthyophis Fitzinger and the caeciliid Dermophis mexicanus. Azpelicueta et al. (1987) illustrated and commented on the vertebrae of Chthonerpeton indistinctum.

Chthonerpeton and Nectocaecilia are similar, and differ from other typhlonectids, in several features of their vertebrae. The two halves of the neural arch of the atlas are completely fused and continuous ventrally, whereas in other typhlonectids, the halves of the neural arch are separated medially by a strong diastema. This may well reflect ecology, because the genera with complete, and presumably stronger, neural arches are those that are semiaquatic and probably sometimes burrow in more compact substrates. Dorsally, with the exception of Chthonerpeton, the anterior edge of the neural arch of the atlas is roughly straight, and the posterior zygapophyses of the atlas are blunt and short. In Chthonerpeton, the anterior edge of the neural arch is distinctly convex, and the zygapophyses are more elongate and pointed. The neural arch of the atlas has a pronounced constriction just anterior to the posterior zygapophyses except in Chthonerpeton and Nectocaecilia. The posterolateral margin of the neural arch of the atlas and the anterolateral margin of the neural arch of the second vertebra are oriented anterodorsally, except in Typhlonectes, where the orientation is more vertical.

The parasphenes form distinct anterior projections from the centrum of the second vertebra except in Chthonerpeton and Nectocaecilia, and in all typhlonectids, the vertebrae posterior to the second, with the exception of some terminal vertebrae, have anteriorly projecting parasphenes. The parapophyses are developed on the lateral margin of the parasphenes where they overlap the centrum. With the exception of Chthonerpeton, a strong ventral ridge is evident on the parasphenes of trunk vertebrae, which isolates the parapophyses on a weak flange. 
The neural arches of Chthonerpeton and Nectocaecilia are characterized by strong nuchal crests, which are developed only very weakly in aquatic typhlonectids and generally are restricted to the anteriormost vertebrae. The vertebrae of the aquatic typhlonectids, including Atretochoana, are relatively elongate and narrow, whereas those of Chthonerpeton and Nectocaecilia are broad and short. The diapophyses of the second vertebra of Chthonerpeton and Nectocaecilia are notably distant from the anterior zygapophyses, and the diapophyses of trunk vertebrae are associated with a distinct thin flange of bone, more distinct in Chthonerpeton. In other typhlonectids, the diapophyses are always close to the anterior zygapophyses, and the trunk diapophyses lack any distinctive flanges of associated bone.

The anteriormost vertebrae of all typhlonectids bear either one or two foramina in the neural arches anterior to the diapophyses for the passage of the spinal nerves. After, at most, the fourth vertebra, the foramina are lost and the nerves exit intervertebrally, with the anterior margin of the neural arch distinctly emarginated, except in Chthonerpeton in which the foramina remain distinct and the neural arches lack emargination for the majority of the length of the trunk. The presence or absence of nerve foramina on trunk vertebrae of Atretochoana cannot be determined from our radiographs. Foramina are probably absent, because the anterior edges of the neural arches appear to be emarginated as in typhlonectids lacking foramina.

Typhlonectid ribs are characteristically dorsoventrally expanded on the anterior vertebrae. In Chthonerpeton and Nectocaecilia, these ribs remain broad throughout the majority of the trunk vertebrae. In Nectocaecilia, the distal tips of the ribs are broad and bluntly rounded, whereas in Chthonerpeton the tips are broad but more irregular and sometimes forked. The ribs also have a slight flexure close to midway along their length bending them posteriorly. In Typhlonectes, the ribs rapidly narrow along the trunk; their tips are slender points and the flexure is more proximal and less gentle. T. natans has unique ribs in which the capitulum is relatively elongate anteriorly. The ribs of Atretochoana and Potomotyphlus appear to remain broad throughout the trunk, flex proximally, and have narrow, pointed tips.

There is intra-and interspecific variation in the numbers of vertebrae (Table 2) and in the numbers of vertebrae occupying the nuchal and postcloacal region (Lescure, Renous \& Gasc, 1986; Wilkinson, 1989). Some variation may be attributable to preservation caused by shrinkage of soft tissues (Nussbaum, 1988). The holotype of Atretochoana is well preserved and has five nuchal vertebrae, more than other caecilians except Potomotyphlus, and five postcloacal vertebrae, within the ranges reported for other aquatic caecilians (Wilkinson, 1989). The presence of postcloacal vertebrae in typhlonectids is not accompanied by any external segmentation (annulation) of the body terminus. This and the absence of postcloacal vertebrae in most advanced caecilians (scolecomorphids and caeciliids) led Nussbaum \& Wilkinson (1989) and Wilkinson (1989) to argue that typhlonectid postcloacal annuli represent a pseudotail that is not homologous to the externally segmented tails of 'primitive' caecilians (rhinatrematids, ichthyophiids, and uraeotyphlids). Postcloacal extension of the vertebral column in typhlonectids may be related to their aquatic habits, providing support for the body terminus and the dorsal fin during swimming.

\section{Cranial muscles}

Nussbaum (1983) commented on the superficial cranial muscles of typhlonectids in relation to those of other caecilians. Azpelicueta et al. (1987) briefly described 


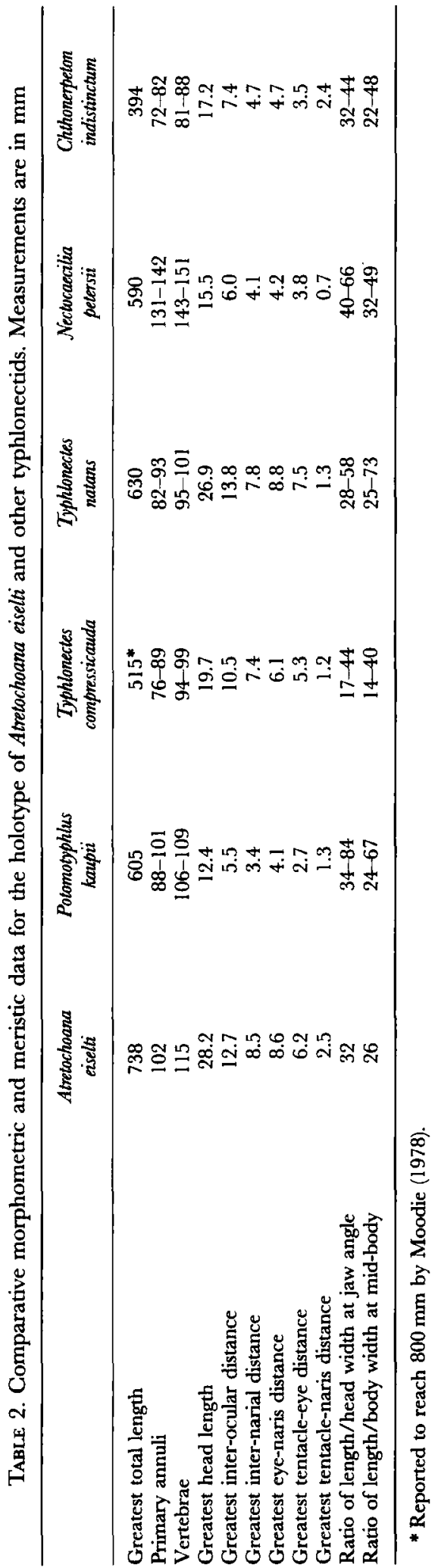


these same muscles in Chthonerpeton indistinctum, and Gronowski (1980) described the cranial muscles of this species based on serial sections.

\section{M. depressor mandibulae}

In typhlonectids, this is a fan-shaped muscle that, as in other caecilians, originates from the temporal region of the cranium and inserts mainly on the anterolateral, and to a lesser extent the anteromedial, edges of the retroarticular process, and serves to open the jaws. In Chthonerpeton, this muscle is relatively short, and its origin extends in an arc from the posterolateral corner of the parietal, anterolaterally across the strong fascia that stretches across the upper temporal fossa (here designated the temporal fascia), and then posteroventrally across the squamosal. Much of the squamosal remains exposed below the ventrolateral margin of the origin and also anteriorly, because the origin does not closely approach the orbit. Similarly, much of the temporal fascia remains exposed.

In Nectocaecilia, the muscle is longer, with the dorsomedial origin along the entire lateral margin of the parietal and anteriorly just overlapping the posterolateral margin of the frontal. Laterally, the origin is in a steep posteroventral line across the squamosal. Very little of the temporal fascia is exposed, and less of the squamosal ventral to the origin or dorsolaterally posterior to the orbit is exposed than in Chthonerpeton. Potomotyphlus is essentially similar to Nectocaecilia except that there is a more extensive anteromedial origin from the frontal, and less of the temporal fascia and the ventrolateral margin of the squamosal are exposed. The muscle in Typhlonectes (Fig. 16) most closely resembles that of Potomotyphlus except that no temporal fascia is exposed, and the lateral fibres extend further anteriorly, closely approaching the orbit and forming a more vertically oriented anterolateral origin. In Atretochoana, the muscle is relatively longer, due partially to its posteriorly displaced insertion onto the retroarticular process, but also reflecting the proximity of the origin of the lateralmost fibres to the orbit (Fig. 17). The muscle completely covers the ventrolateral margins of the squamosal and quadrate that delimit the lower temporal fossa, except for a small section of the latter immediately anterior to the jaw articulation. From its anteriormost lateral point the origin extends dorsally and posteromedially to contact only the posterolateral corner of the parietal, leaving much of the temporal fascia exposed as in Chthonerpeton.

In non-typhlonectids, this muscle is generally rather oblique and relatively short, resembling that of Chthonerpeton. In some caeciliids, such as Caecilia Linne, Oscaecilia Taylor, and Herpele squalostoma (Stuchbury), the muscle includes a distinct deep posterior unit. The fibres of this pars profundus originate from the dorsal body fascia and are oriented more vertically. They lie deep to the more oblique pars superficialis, or main body of the muscle, and may also be partly concealed by the origin of the m. cephalodorsosubpharyngeus. The pars superficialis and pars profundus have largely separate insertions on the anterolateral and anteromedial aspects of the retroarticular process respectively. Variation in the orientation of this muscle may be correlated to some extent with the orientation of the retroarticular process. The evolution of the strong dorsal inflection of the retroarticular process of Atretochoana has shifted the insertion of the $m$. depressor mandibulae dorsally, closer to the level of its origin and thereby contributed to the more horizontal orientation of its fibres.

\section{M. adductor mandibulae extermus}

This fan-shaped, jaw-closing muscle has a broad origin along the dorsolateral edge of the parietal and the junction of the parietal and os basale and extends 


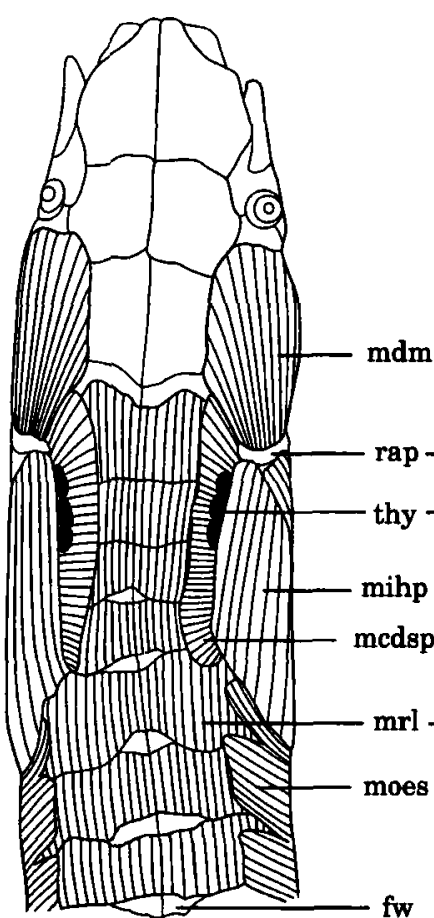

A

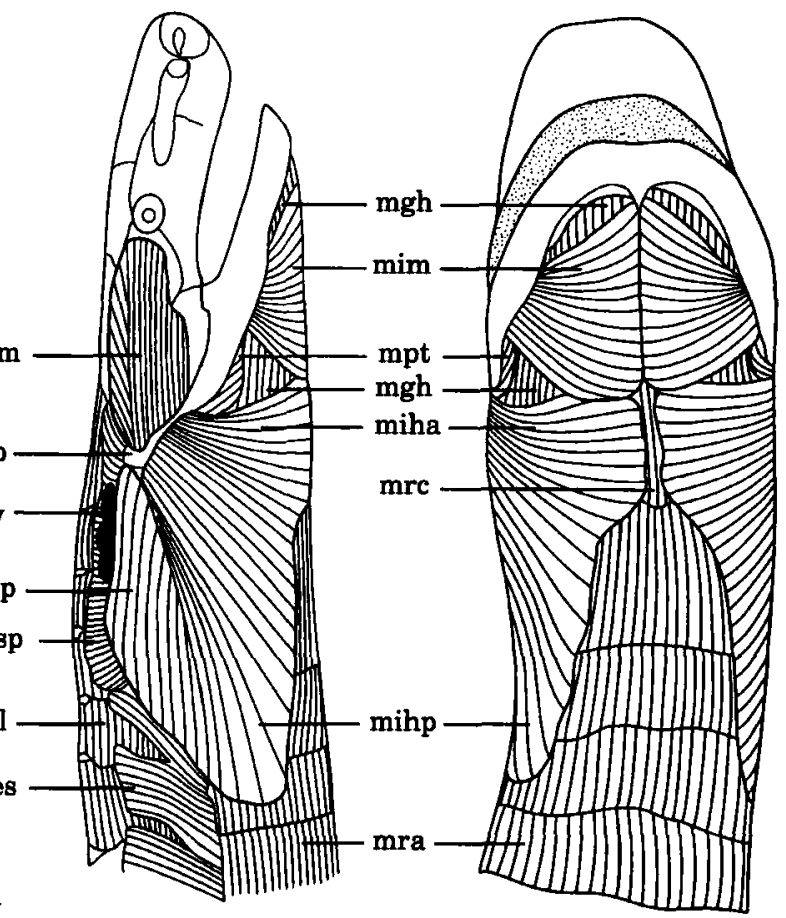

B

C

Figure 16. Lateral (A), Dorsal (B) and ventral (C) views of the superficial cranial muscles of UMMZ 182228, Typhlonectes natans. $\mathrm{fw}=$ fascial window; $\mathrm{mcdsp}=m$. cephalodorsosubpharyngeus; $\mathrm{mdm}=m$. depressor mandibulae; $\mathrm{mgh}=m$. geniohyoideus; $\operatorname{mim}=m$. intermandibularis; $\operatorname{miha}=m$. interhyoideus anterior, $\operatorname{mihp}=m$. interhyoideus posterior, moes $=m$. obliquus externus superficialis; $\mathrm{mpt}=m$. pterygoideus; $\mathrm{mra}=m$. rectus abdominus; $\mathrm{mrc}=m$. rectus cervicus; $\mathrm{mrl}=m$. rectus lateralis; thy $=$ thymus .

ventrally and posteriorly beneath the squamosal and through the lower temporal fossa to insert on the pseudangular, mostly anterior to the canalis primordialis. In Chthonerpeton, the origin is divided into parallel and widely separated superficial and deep bundles. In other typhlonectids, separate bundles, if present, are only narrowly separated. Atretochoana lacks this division entirely, but has a unique additional pars superficialis. This comprises a series of shorter fibres which originate not from the medial wall of the adductor chamber, but from the ventral surface of the squamosal and which form the most superficial part of the muscle. In Atretochoana, Chthonerpeton, and Nectocaecilia, the anteriormost fibres of the $m$. adductor mandibulae externus are more strongly anterodorsally oriented, reflecting a greater distance between the anterior extent of the origin and the insertion. This oblique orientation is extreme in Atretochoana (Fig. 17), where the origin of the main body extends anteriorly beyond the level of the eye medially, and the insertion is onto the dorsally curving region of the pseudangular proximal to the jaw articulation. In Atretochoana, the ventral portions of this muscle project laterally and posteriorly out from the lower temporal fossa so as to be visible superficially. In other typhlonectids it is almost completely hidden by the squamosal. In Typhlonectes (Fig. 16) and Potomotyphlus, the insertion is mainly onto the dorsal process of the pseudangular. In all typhlonectids, some of the anteriormost fibres insert into the soft tissue forming the corner of the mouth. 

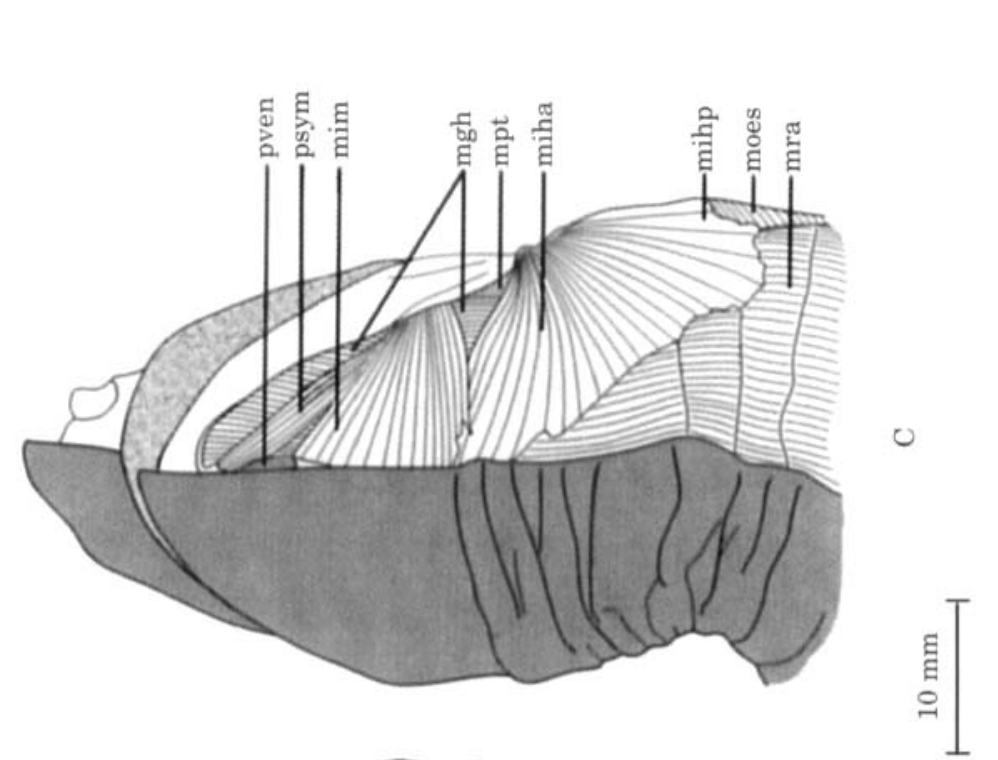

॥

ริ

范

赵

0

政.

की

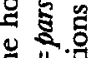

马 11.

ఫृ

T के

ऐै

娄范

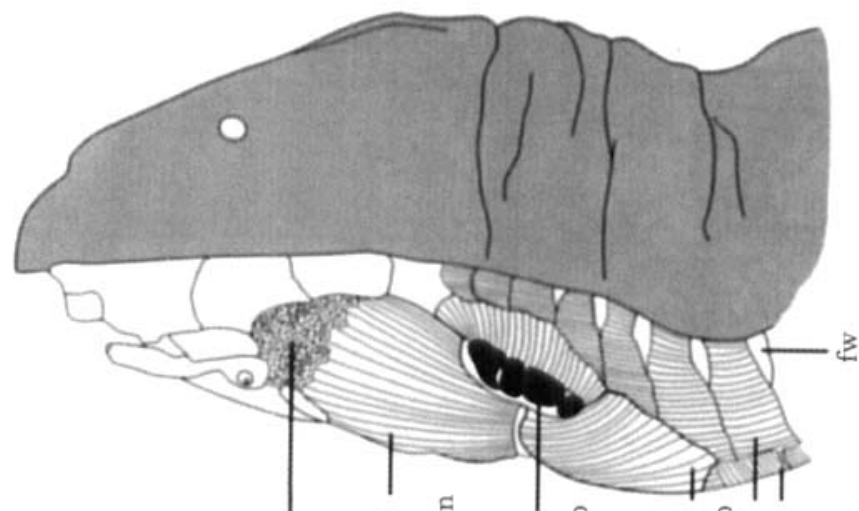

刍

苋密

过

ङ

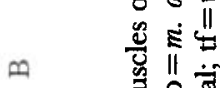

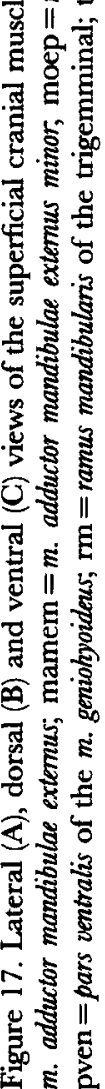


In rhintrematids, the $m$. adductor mandibulae externus extends dorsally, through the upper temporal fossa, to insert at the dorsal midline of the skull (Nussbaum, 1977). In stegokrotaphic caecilians, it is confined to the adductor chamber by the bony closure of the upper temporal fossa. In typhlonectids and other zygokrotaphic caecilians (e.g. Scolecomorphus Boulenger and Geotrypetes), the muscle resembles that of stegokrotaphic caecilians in being confined to the adductor chamber (not extending through the upper temporal fossa). That the adductor muscles do not extend dorsally through the upper temporal fossa in these forms can be interpreted as a legacy of a stegokrotaphic ancestry in which these muscles were confined within the adductor chamber, implying that their zygokrotaphy is secondary (Nussbaum, 1977). The orientation of this muscle in Atretochoana suggests that, in addition to closing the jaws, contractions will tend to pull the mandibles, and through them the suspensorium and cheek, medially. Such an action, though less pronounced, may occur in other typhlonectids also (see Discussion).

\section{M. adductor mandibulae externus minor}

This jaw-closing muscle is posterior to the $m$. adductor mandibulae externus from which it is derived embryonically (Edgeworth, 1935), and is separated from the latter by the mandibular ramus of the trigeminal nerve. Its origin is on the internal surface of the squamosal and ascending process of the quadrate, and it inserts closer to the jaw articulation posterior to the canalis primordialis. As with the $m$. adductor mandibulae externus, the muscle is mostly hidden by the quadrate-squamosal arch in all typhlonectids except Atretochoana in which it projects laterally from the lower temporal fossa (Fig. 17). Fibre orientation is more vertical in Chthonerpeton, Nectocaecilia, and Potomotyphlus, more obliquely anterodorsal in Typhlonectes, and extremely oblique in Atretochoana. As with the $m$. adductor mandibulae externus, the orientation of this muscle in Atretochoana sets it apart from other caecilians and partly reflects the dorsal inflection of its insertion.

\section{M. pseudotemporalis}

Where present, this jaw-closing muscle is separated from the m. adductor externus by the maxillary branch of the trigeminal and lies superficial to the ramus opthalmicus profundus of the same nerve (Fig 18). This muscle is absent in Chthonerpeton, and the two nerves which the muscle normally separates run forward together from the gausserian ganglion for some distance as a single unit, fused, at least superficially. Gronowski (1980) reported the presence of this muscle in Chthonerpeton and illustrated it, but noted that his sections were of poor quality. This muscle was reported as absent in the caeciliid genus Schistometopum Parker (Parker, 1941) and in Scolecomorphus uluguruensis (Barbour \& Loveridge) (Brand, 1956).

Edgeworth (1935) considered the $m$. pseudotemporalis to be a part of the $m$. adductor mandibulae externus, with which it shares a common embryonic origin, and reported that in caecilians the ramus maxilliaris passes through the muscle separating it into superficial and deep portions, but that the fibres of these portions run together dorsally and ventrally, so as to be indistinguishable. In adult typhlonectids that have a $m$. pseudotemporalis, it is completely distinct from the $m$. adductor mandibulae externus with no intermingling of their fibres. Where present, this muscle originates deep to the $m$. adductor mandibulae externus and extends parallel to it to insert on the pseudangular adjacent to, but more medially than, the latter muscle, mainly along the medial 


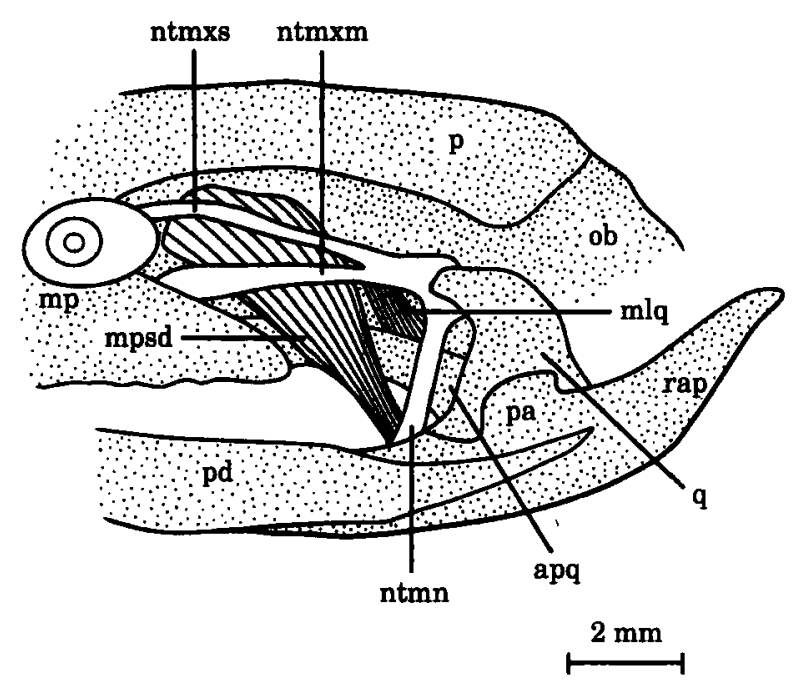

Figure 18. Deep muscles of the adductor chamber of UMMZ 190466, Nectocaecilia petersii. ntmxs $=$ trigeminal nerve maxillarary ramus (motor); $n$ tmxm = trigeminal nerve maxillarary ramus (sensory); $\mathrm{ntmn}=$ trigeminal nerve mandibular ramus; $\mathrm{mpsd}=m$. pseudotemporalis; $\mathrm{mlq}=m$. levator quadrat $;$ other abbreviations as in Figs. 7 \& 11 .

margin of the canalis primordialis. In Atretochoana, the muscle has a more extreme fan-shape, and the narrow insertion is by means of a long tendon. In Typhlonectes, a few of the anteriormost fibres of the $m$. pseudotemporalis originate from the surface of the $m$. compressor glandulae orbitalis which surrounds the eye.

\section{M. levator quadrati}

This muscle is found, among typhlonectids, only in Nectocaecilia in which it is very short (Fig. 18). Its origin is from the os basale, anterior to the gausserian ganglion and ventral to the ramus opthalmicus profundus and maxillary branches of the trigeminal nerve, and it inserts along the medial edge of the pterygoid process of the quadrate. Gronowski (1980) reported the presence of this muscle in sections of Chthonerpeton, but we have been unable to find it in our dissections. In Nectocaecilia, this muscle is oriented parallel and posterior to the $m$. pseudotemporalis from which it is probably derived. Its posteroventral orientation differs from the more transverse or anteroventral orientation of other caecilians, and its origin is far more ventral, below rather than above the gausserian ganglion (Lawson, 1965, pers. obs). Thus, the homology of this muscle in Nectocaecilia with that of other caecilians is in some doubt. Where present, this muscle is likely to be important in cranial kinesis, but its precise action awaits experimental investigation. Scolecomorphids lack a pterygoid or comparable pterygoid process of the quadrate, and, not surprisingly, they also lack a $m$. levator quadrati (Brand, 1956; Nussbaum, 1985a).

\section{M. pterygoideus}

In all typhlonectids, except Atretochoana, this muscle originates mainly from a broad and tough aponeurosis which extends across the ventral surface of the basipterygoid process and the mediopalatinal cavity to the posterior margin of the maxillopalatine. 


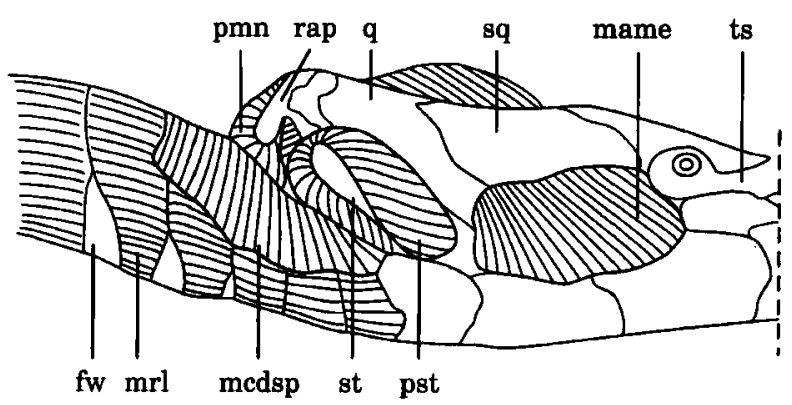

A

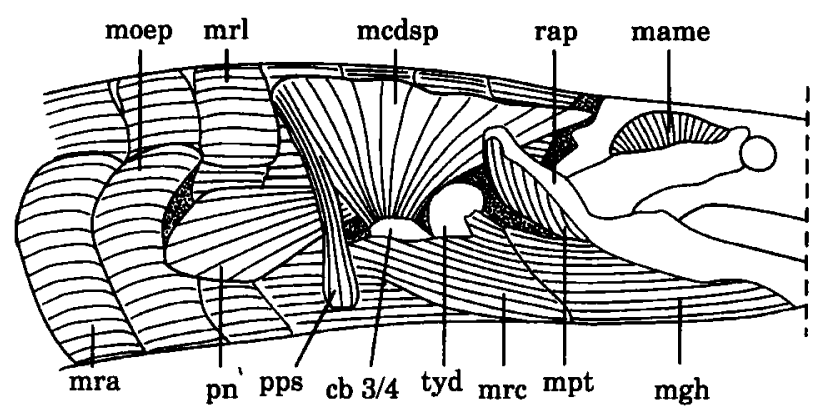

$\mathbf{B}$

Figure 19. Dorsal view of the cranial muscles of the left side of NMW 9144, holotype of Atretochoana eiselti (A), and lateral view of the right side of UMMZ 182228, Typhlonectes natans (B) after removal of the $m$. depressor mandibulae, $m$. interhyoideus, $m$. itermandibularis, and $m$. obliquus externus superficialis. $\mathrm{pmn}=$ pars mandibularis of the $m$. pterygoideus; $\mathrm{pn}=$ pars nuchalis of the $m$. obliquus extermus profundus; $\mathrm{pps}=$ pars posterosuperficialis of the $m$. cephalodorsosubpharyngeus; pst = pars stapedialis of the $m$. pterygoideus; ts $=$ tentacle sheath; tyd = thyroid; other abbreviations as in Figs 11, 15, 16 and 17.

From its origin ventral to the basipterygoid process the muscle runs posteriorly, with a number of short fibres inserting on the anterior margin of the processus internus of the pseudangular, but with the majority of its fibres running ventral to this process and curving dorsally to insert in two groups on the posteromedial and posterolateral aspects of the retroarticular process respectively (Fig. 19). A very few of the most medial fibres may insert in connective tissue associated with the stapes and foramen ovalis.

In Atretochoana, this muscle is differentiated into a pars mandibularis and a pars stapedialis (Fig. 19). Fibres of the two units diverge somewhat away from their adjacent points of origin from the aponeurosis, which is entirely posterior to the basipterygoid process rather than lying ventral to it. The pars mandibularis corresponds functionally to the $m$. pterygoideus of other caecilians and conserves the ancestral origin and insertion and function of this jaw-closing muscle, but with its lateralmost fibres especially short. From their origin, the fibres of the large pars stapedialis run posteromedially and bend dorsomedially to occupy much of the space between the posteriorly extended quadrate and the anterior axial musculature. Here they insert onto a connective tissue sheet, designated the stapedial sheath, that surrounds the majority of the stapes such that most of the stapes is embedded in muscle with only 
its most distal dorsal surface left exposed. This connective tissue sheet inserts directly onto the stapes only along its dorsolateral edge, but covers the entire convex medial and concave lateral surfaces of the stapes. Muscle fibres on the medial surface are arranged into two distinct layers distally, with fibres of the deeper layer incompletely hidden by those of the outer layer. Fibres of the outer layer appear to insert onto the surface of the deeper layer rather than onto the stapedial sheath. No comparable stapedial muscle is known in other tetrapods. Its disposition suggests a role in cranial kinesis (see Discussion).

\section{$M$. intermandibularis}

This superficial fan-shaped muscle extends from the medial surface of the mandible to join directly, or by a weak aponeurosis, along the midline with its opposite. The origin is broad in Chthonerpeton and in most non-typhlonectids, but is relatively narrow in all other typhlonectids (Fig. 16), especially so in Potomotyphlus. In Atretochoana, the anteriormost portion of this muscle forms a distinct narrow unit, or pars symphalis, which separates from the posterior fibres, or pars majoris, as they approach the midline (Fig. 17). In addition, a unique small pair of slips of the m. geniohyoideus (constituting a novel pars ventralis of this latter muscle) emerge from below the pars symphalis and extend posteriorly along the midline for a short distance to insert in fascia between the pars majoris and the skin. Contraction of the $m$. intermandibularis raises the floor of the mouth and functions in the buccal pump of lunged caecilians (Carrier \& Wake, 1995) and perhaps also in feeding. The pars ventralis and pars symphalis of Atretochoana are unique, and we can only speculate that they may be involved in controlling the relatively flexible mandibular symphysis of this species.

\section{M. interhyoideus}

There is no distinct separation of anterior and posterior units of this muscle in typhlonectids except that indicated by the passage of the external jugular vein which lies superficial to the anterior and runs deep beneath the posterior parts. The most superficial layers of fibres originate in fascia between the skin and trunk musculature. Deeper posterolateral fibres originate from a superficial continuation of a weak connective tissue septum that separates the first and second units of the $m$. obliquus externus profundus. As in all non-larval caecilians, the muscle inserts onto the posterolateral surface of the retroarticular process. The anteroventral fibres, corresponding to the $m$. interhyoideus anterior, insert on the posteroventral margin of the retroarticular process. Some fibres of the $m$. interhyoideus posterior insert directly onto the posterodorsal margins of the retroarticular process, but most insert indirectly via a tough connective tissue raphe just below the dorsal tip of the process so that most of the muscle is pectinate (Figs $16 \& 17$ ).

The dorsal margin of this muscle is free in Typhlonectes, Potomotyphlus, and Nectocaecilia. In Chthonerpeton and Atretochoana, the dorsal margin is not free, rather it is part of the origin. The muscle is especially thick in Atretochoana with many deep shorter fibres originating anterior to the superficial fibres, whereas in other typhlonectids the origin is narrow and the muscle has the form of a thin sheet. The $m$. interhyoideus anterior of all typhlonectids, except Typhlonectes, originates with its opposite along the midventral line. In Typhlonectes, the units from either side are often slightly separated midventrally and connected by an aponeurosis.

In most caecilians, the subspherical bodies of the thymus lie along the dorsal 
margin of this muscle and may have their ventralmost parts lying deep to it. In Chthonerpeton, there may be a reduced amount of thymus material in this typical position, but the majority lies far more ventral, deep to, and completely covered by, this muscle, in close association with the thyroid gland.

The m. interhyoideus, a muscle associated with the glossal skeleton in other tetrapods, is the novel component of the unique dual jaw-closing apparatus of caecilians (Nussbaum, 1977, 1983). The ancestral association of the $m$. interhyoideus anterior with the ceratohyal persists in larval caecilians and adult rhinatrematids, and, in larval rhinatrematids, the $m$. interhyoideus posterior shifts its insertion from the spiracular region to the retroarticular process at metamorphosis (Nussbaum \& Wilkinson, unpublished). All caeciliids we have examined have a distinctively derived condition in which the $m$. interhyoideus posterior narrows and extends much further posteriorly than in other caecilians. In Atretochoana, the strong dorsal inflection of the retroarticular process can be interpreted as compensating, to some extent, for the reduced length of the $m$. interhyoideus wrought by the posterior displacement of the suspensorium in the absence of any corresponding shift in its origin. The strong mesial inflection may have complex consequences for cranial kinesis. Contraction of the $m$. interhyoideus may tend to pull the suspensorium laterally as well as closing the jaws in all caecilians, and this action is expected to be enhanced in Atretochoana. Contraction of the anterior part of the $m$. interhyoideus also contributes to raising the floor of the mouth during buccopharyngeal pumping (Carrier \& Wake, 1995).

\section{M. cephalodorsosubpharyngeus}

The greater part of this muscle is covered by the $m$. interhyoideus. In typhlonectids, it is a fan-shaped muscle that originates from the fascia dorsalis covering the $m$. rectus lateralis, with fibres running ventrally to the pharyngeal region (Fig. 19). Due to their different forms of origin of the $m$. interhyoideus, the $m$. cephalodorsosubpharyngeus has most of its posterodorsal origin hidden in Chthonerpeton and Atretochoana, and exposed in other typhlonectids. There is much intraspecific variation in the extent to which the anterior fibres extend anterodorsally and thus to what extent the anterior of the muscle is concealed deep to the $m$. depressor mandibulae. This muscle was reported as absent in caecilians by Duellman \& Trueb (1986). Bemis et al. (1983) reported that in Dermophis it (their $m$. levator arcus branchialis) inserted onto the hyoid. We find that in ichthyophiids and rhinatrematids this muscle extends to the ventral midline, superficial to the $m$. rectus abdominus, to meet its opposite, and that in all caeciliids, including Dermophis, the insertion is mainly onto the anterolaterally expanded corner of the pharynx in the region of the distal tip of the last ceratobranchial. In typhlonectids, most of the $m$. cephalodorsosubpharyngeous inserts onto the lateral tip of the fused third and fourth ceratobranchials, but in Atretochoana the insertion extends from the lateral tip along the posterior edge and onto the laryngeal fascia. Because of the relatively posterior position of the jaw articulation in Atretochoana, a greater proportion of the anteriormost fibres of this muscle are covered by the $m$. depressor mandibulae, and less by the $m$. interhyoideus, than in other typhlonectids.

Typhlonectids also have a separate posterior slip of this muscle, here termed the pars posterosuperficialis, which, in all typhlonectids except Atretochoana, inserts in a weak fascia between the $m$. interhyoideus and the $m$. rectus abdominus. In Atretochoana, the insertion is onto a myoseptum between the lateral margins of the first unit of the $m$. rectus abdominus and the $m$. rectus cervicus which are composed of somewhat separate 
narrow bands of fibres. The pars posterosuperficialis is broad in Chthonerpeton but much narrower in other typhlonectids. A pars posterosuperficialis is also present in some (e.g. Caecilia) caeciliids where it resembles the broad unit of Chthonerpeton, and its position is reminiscent of that of the whole muscle in rhinatrematids and ichthyophiids. Functionally, the $m$. cephalodorsosubpharyngeus raises the glossal skeleton and the posterior floor of the mouth (Carrier and Wake, 1995). In species where it inserts close to the distal tips of the ceratobranchials, it is possible that it also anchors these so that the posterior pull of the contracting $m$. rectus cervicus is translated into posteroventral rotation of the ceratobranchials. The function of the pars posterosuperficialis is unclear.

\section{M. geniohyoideus}

This muscle lies deep to the $m$. intermandibularis and the anteroventral fibres of the $m$. interhyoideus (Figs 16 \& 17). It is composed of fibres that originate along the length of the internal surface of the mandible anterior to the jaw articulation. A basic pattern of insertion is common to all typhlonectids, in which the majority of fibres insert onto the posteroventral surface of the first ceratobranchials with some superficial fibres inserting onto a transverse connective tissue septum associated with the junction of the first and second ceratobranchials and the origin of the superficial fibres of the $m$. rectus cervicus. The lateralmost fibres of the $m$. geniohyoideus (those that originate posterior to the origin of the $m$. intermandibularis) extend further posteriorly and have irregular insertions on the lateral margins of the $m$. rectus cervicus and $m$. rectus abdominus, the tips of the second and the fused third and fourth ceratobranchials and connective tissue and blood vessels associated with the thyroid.

There is considerable intraspecific variation in the composition of the $m$. geniohyoideus in Typhlonectes natans. In a majority of individuals (and in all T. compressicauda examined), deep fibres, extending between the mandible and the ceratohyals, and superficial fibres, extending posteriorly to insert on the ventral surface of the $m$. rectus cervicus, are also present, but in some individuals they are completely absent. Our samples of other typhlonectid taxa are too small to assess how widespread such intraspecific variation is within the Typhlonectidae, but similar variation occurs in Ichthyophis glutinosus Linné (Nussbaum, pers. obs.). This muscle raises and pulls the floor of the mouth anteriorly during the upstroke of the buccopharyngeal pump (Carrier \& Wake, 1995).

\section{M. rectus cervicus}

This muscle represents the anterior continuation of the $m$. rectus abdominus (Fig. 16). With the exception of Typhlonectes, superficial fibres of this muscle extend directly between the septa separating this muscle from the $m$. geniohyoideus anteriorly and the $m$. rectus abdominus posteriorly. Deeper fibres arise from the ventral surface of the first ceratobranchial and extend posteriorly to insert on the ventral surfaces of the expanded plates of the fused third and fourth ceratobranchials laterally and along the posteroventral margin of the larynx medially. Medial fibres are oriented longitudinally, whereas lateral fibres have a more oblique posterolateral orientation.

As with the $m$. geniohyoideus, there is intraspecific variation in the form of this muscle in Typhlonectes natans. In this species (and in all T. compressicauda examined), most individuals have the muscle partially divided into a deep series of fibres corresponding to the form of the muscle described above, and a more superficial 


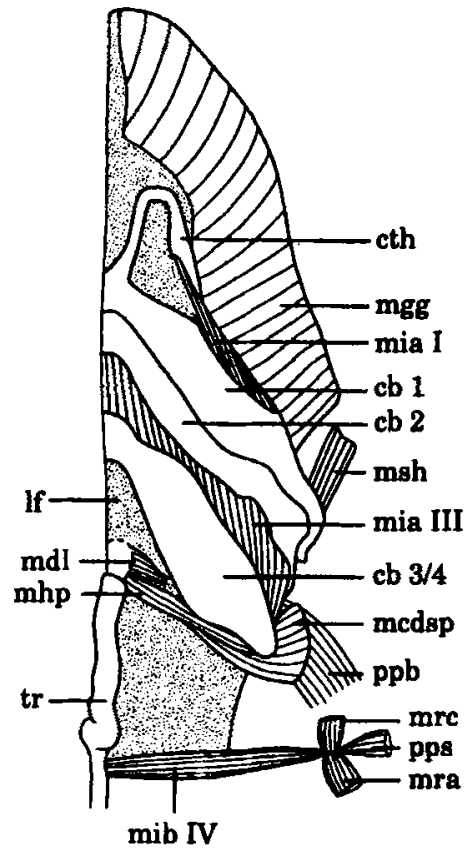

A

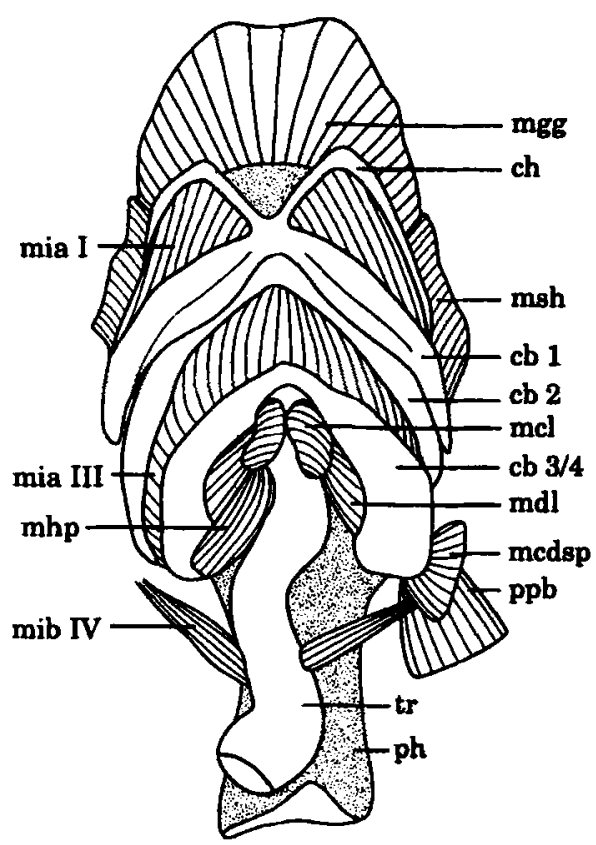

B

Figure 20. Ventral views of the glossal musculature of the left side of NMW 9144, holotype of Atretochoana eiselti (A) and of UMMZ 182228, Typhlonectes natans (B). If $=$ laryngeal fascia; $\mathrm{mcl}=m$. constrictor laryngeus; $\mathrm{mdl}=m$. dilator laryngeus; $\mathrm{mhp}=m$. hyopharyngens; $\mathrm{mia}=m$. interarcualis; mib $=m$. interbranchialis $\mathrm{IV} ; \mathrm{mgg}=m$. genioglossus; $\mathrm{msh}=m$. subhyoideus; $\mathrm{ph}=\mathrm{ph}$ arynx; $\mathrm{ppb}=$ pars pharyngeobranchialis of the $m$. obliquus internus; $\mathrm{tr}=$ trachea; other abbreviations as in Figs. 15,16 and 17.

set of shorter fibres with a stronger oblique orientation. Fibres of the superficial layers of either side separate shortly after their origin from a weak septum between them and the more elongate superficial fibres of the $m$. geniohyoideus, revealing the longitudinal medial fibres of the deeper layer. Contraction of this muscle pulls the glossal skeleton posteriorly and ventrally during buccal expansion (Carrier \& Wake, 1995).

\section{M. subhyoideus}

In typhlonectids and other caecilians, this muscle consists of a discrete narrow band or thin sheet of fibres extending from the distal tip of the ceratohyal to the medial surface of the mandible close to the jaw articulation (Fig. 20). This muscle is especially weakly developed in Atretochoana. Presumably, it contributes to the upstroke of the buccopharyngeal pump, and may also resist posterior displacement of the distal ceratohyals during the downstroke.

\section{M. subarcualis rectus $I$}

The fibres of this muscle extend from the posterior margin of the ceratohyal and the lateral edge of the basibranchial to the anterior margin of the first ceratobranchial deep to the $m$. geniohyoideus (Fig. 20). In most caecilians, it has the form of a broad 
sheet, completely filling the space between the cartilaginous arches. In some (e.g. Scolecomorphus) their may be a narrow medial gap between the ceratohyal and the first ceratobranchial along the basibranchial. The muscle in Atretochoana is a narrow slip extending obliquely from a point just distal to the anterior tip of the ceratohyal to the anterior edge of the first ceratobranchial.

\section{M. subarcualis rectus II and III}

The first of these muscles is not present in typhlonectids, as the space between the first and second ceratobranchials is obliterated by their novel sliding articulation. In all typhlonectids, the second of these muscles extends between the second and the fused third and fourth ceratobranchials as a thin sheet that occupies most of the space between these glossal elements (Fig 20). The subarcualis muscles presumably serve to pull the elements of the glossal skeleton together during the upstroke of the buccopharyngeal pump. Ancestrally, all three muscles are present and have the form of broad thin sheets that fill the space between the glossal elements. This arrangement is characteristic of rhinatrematids, ichthyophiids, uraeotyphlids, and scolecomorphids. Most caeciliids are like typhlonectids in lacking an m. subarcualis rectus II and many (e.g. Dermophis, Gymnopis Peters, Siphonops, and Herpele Peters) have a $m$. subarcualis rectus III that is developed only medially.

\section{M. genioglossus}

This muscle is composed of fibres that originate from the medial surface of the mandible anterior to the jaw articulation, deep to the origin of the m. geniohyoideus, and enter the tongue (Fig. 20). As determined by gross dissection, the muscle has its simplest form in Chthonerpeton where it consists of only a single thick layer of fibres converging in a radial pattern toward, but not reaching, the middle of the tongue. Nectocaecilia, Potomotyphlus and Atretochoana are similar to Chthonerpeton, but have two short sets of additional deeper fibres, one anterior and one posterior, which enter the narial plugs rather than extending towards the tongue's centre. In Typhlonectes, the muscle is more complex. Its fibres are arranged in three layers separated by the passage of blood vessels. The deepest (dorsalmost) layer is a thick sheet of fibres with the radial orientation typical of the entire muscle in Chthonerpeton. The most superficial (ventralmost) layer is a thin sheet of fibres with this same orientation. Sandwiched between these, the middle layer is also a thin sheet of fibres, but the fibres are parallel, anteromedially oriented, and the origin is less extensive. In addition, there are separate anterior and lateral thickenings of the deepest fibres of the deep layer which appear to run into the narial plugs and probably correspond to the more distinct deep bundles of Nectocaecilia, Potomotyphlus and Atretochoana. In Atretochoana, left and right halves of this muscle are separated by connective tissue stretching between the glossal skeleton and the mandibular symphysis.

As noted earlier (p. 48), discrete bundles of fibres of this muscle that insert into the narial plugs are evident in sections of the caeciliids Grandisonia alternans, Hypogeophis rostratus, and Geotrypetes seraphini. Similarly, narial plug muscle units are evident in all typhlonectids, with the possible exception of Chthonerpeton. Absence in Chthonerpeton is uncertain: the complexity of the muscle and small size of the narial plug muscle units makes it necessary that they be studied in sections. Contraction of this muscle is expected to depress the tongue and retract the narial plugs. Experimental studies 
are needed to determine whether the narial plug muscle units act independently of the rest of the muscle.

\section{M. constrictor laryngis}

This comprises a sheet of muscle extending across the posterodorsal surfaces of the arytenoids posterior to the glottis and running ventrally and medially on either side to insert ventrolaterally on the arytenoids anterior to the insertion of the $m$. hyopharyngeus (Fig. 20). We were unable to distinguish the various separate components of this muscle described by Edgeworth (1935). This muscle is absent in Atretochoana, but present in other caecilians, where it is presumed to close the larynx during the downstroke of the buccopharyngeal pump.

\section{M. dilator laryngis}

In all typhlonectids, with the exception of Atretochoana, this is a short fan-shaped muscle that has a broad origin from the posteromedial margins of the fused third and fourth ceratobranchials and extends medially and slightly anteriorly to insert onto the dorsal process of the arytenoid cartilage (Fig. 20). In Atretochoana, this muscle is very short and transversely oriented with its origin from the laryngeal fascia and a more superficial insertion onto the lateral surface of the arytenoid cartilage. Given its presumed action of opening the glottis, the retention of this muscle in Atretochoana seems anomalous.

\section{$M$. hyopharyngeus}

This muscle runs as an elongate thin strip from the posterodistal margin of the fused third and fourth ceratobranchials to the posterolateral margin of the arytenoid cartilage (Fig. 20). It is oriented more transversely in Atretochoana than in the other typhlonectids because of the more posterior position of the arytenoids relative to the ceratobranchials. Typhlonectids lack a $m$. hyopharyngeus intermus.

\section{M. interbranchialis IV}

All typhlonectids have a peculiar muscle slip that arises, one on each side, from the trachea some distance posterior to the glottis deep to the $m$. transversus, and extends anterolaterally to insert in connective tissue associated with the carotid artery (Fig. 20). In Atretochoana, the orientation of the muscle is more transverse and the insertion is at the lateral margin of the septum between the m. rectus cervicus and the $m$. rectus abdominus. This muscle probably corresponds to the $m$. interbranchialis IV of Norris \& Hughes (1918) and appears to be widespread in caecilians. Its function is unclear.

\section{Trunk musculature}

Nussbaum \& Naylor (1982) surveyed the variation in caecilian trunk muscles. Among typhlonectids, they examined representatives of Typhlonectes and Potomotyphlus. The trunk musculature of all the typhlonectids we have examined conform to these forms as reported by these authors, except for several notable variations reported below. We also describe some characteristics of the anterior trunk musculature 
which these authors did not consider. All typhlonectids share a unique and presumably derived condition of the subvertebral muscle, in which the m. subvertebralis pars ventralis originates from fascia lateral to the centra with distinctly scalloped origins (Naylor \& Nussbaum, 1980).

\section{M. rectus lateralis}

This muscle is the most dorsal component of the external muscular sheath. It is present in all caecilians with the notable exception of Chthonerpeton in which there is no trace. In other typhlonectids, each unit narrows dorsally as it nears the midline so that adjacent units are not contiguous, but are separated by a longitudinal fascial window extending between their margins (Figs $16 \& 17$ ). The separation is less evident anteriorly. In all caecilians that have it, this muscle overlies the $m$. dorsalis trunci throughout the length of the body except immediately posterior to the head. Here, the anteriormost unit attaches dorsally to the parietal by a broad thin aponeurosis that overlies, and is tightly bound to, the anteriormost specialised unit of the $m$. dorsalis trunci (see neck muscle I, below). The lateralmost fibres of the anteriormost unit of the $m$. rectus lateralis appear to insert onto the surface of the $m$. dorsalis trunci.

\section{M. obliquus externus superficialis}

In typhlonectids, the units of this muscle have transverse 'septa' congruent with adjacent myosepta (Nussbaum \& Naylor, 1982). Fibres run ventrally and slightly posteriorly from their origin in the fascia dorsalis. The posteriormost fibres of each unit are more obliquely posteroventral, and, at their ventral margin, are incompletely separated from the fibres of the adjacent posterior unit. As a consequence, the septal space is larger dorsally and narrows, eventually disappearing, ventrally. In Atretochoana, the oblique posteriormost fibres are short, about half the length of the other fibres and, sharing the same ventral margin, do not extend as far dorsally.

In all typhlonectids, the anteriormost unit of this muscle partially overlies the posterolateral origin of the $m$. interhyoideus posterior, a pattern that is seen in most nontyphlonectids (Figs $16 \& 17$ ). There is much variation in the form of this anteriormost unit in Typhlonectes natans. In this species, it may be shorter, longer, narrower, wider, and dorsally or ventrally displaced relative to more posterior units, and often differs on either side. In other typhlonectids, similar variation occurs between individuals and between sides of the body within individuals, but, presumably due to the smaller samples examined, the observed variation is not as extensive as in $T$. natans. In nontyphlonectids, there is also considerable intraspecific variation in the disposition of the anteriormost units of this muscle, and some notable interspecific differences. In caeciliids, the anterior units of this muscle generally become smaller as the elongate $m$. interhyoideus posterior becomes broader. In contrast, the caeciliid Geotrypetes has an unusual arrangement in which the muscle extends further anteriorly and its anteriormost units are completely superficial to the body of the $m$. interhyoideus posterior.

\section{M. obliquus externus profundus}

In all typhlonectids, the anteriormost unit of this muscle is relatively elongate and fan-shaped. It extends anteriorly and slightly dorsally from the level of the posterolateral origin of the $m$. interhyoideus posterior and parallel but deep to the latter muscle. It inserts deep to the m. cephalodorsosubpharyngeus onto the posterior surface 


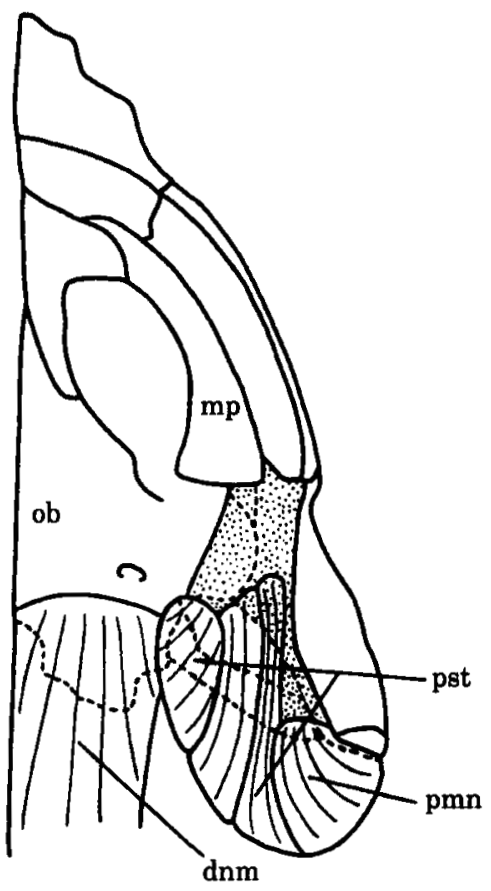

A

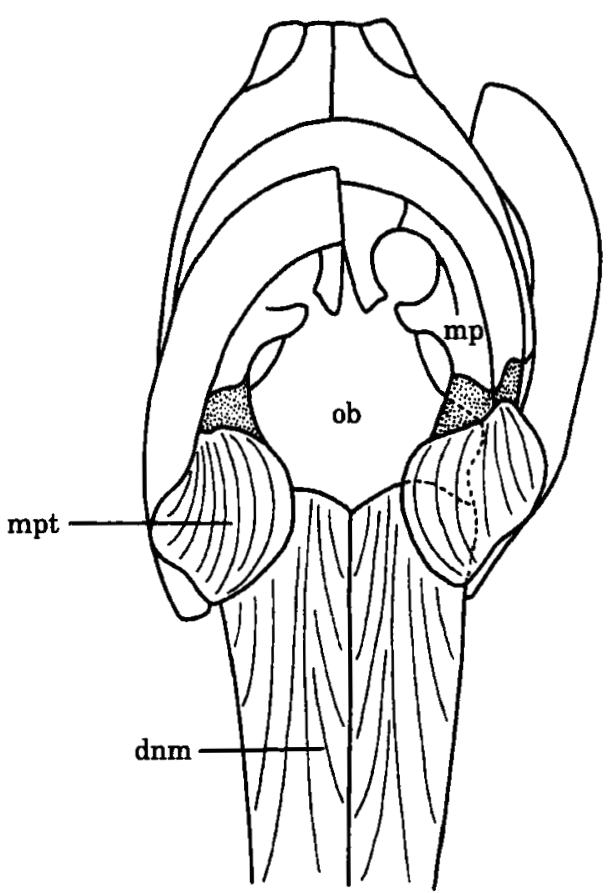

B

Figure 21. Ventral views of the m. pterygoideus of the left side of NMW 9144, holotype of Atretochoana eiselti (A) and of UMMZ 182228, Typhlonectes natans, with the left lower jaw displaced laterally (B). Stippling indicates aponeurosis; dnm $=$ deep neck muscle III. Other abbreviations as in Figs 7, 16 and 17.

of the distal tip of the rib of the second vertebra (Fig. 19). We refer to this unit as a pars nuchalis. Because the fibres of the $m$. rectus abdominus are continuous with those of the $m$. obliquus externus profundus, the two muscles are not clearly distinguishable, and some of the ventral fibres of the pars nuchalis are probably serially homologous with the $m$. rectus abdominus. The pars nuchalis is also present in some caeciliids (e.g. Herpele and Siphonops) and may correspond to the $m$. rectus abdominus lateralis of Norris \& Hughes (1918). It is presumed to flex the 'neck'.

\section{M. obliquus internus}

In all typhlonectids, the anteriormost unit of this muscle is fan-shaped and also arises close to the level of the posterolateral origin of the m. interhyoideus posterior. It extends anteriorly and slightly ventrally deep to the pars nuchalis of the $m$. obliquus externus profundus and inserts mainly on the distal tip of the fused third and fourth ceratobranchials. A few fibres insert in connective tissue associated with the tips of the latter and the second ceratobranchials. In Atretochoana, the insertion is mainly in this connective tissue, with some fibres inserting also onto the adjacent lateral margin of the laryngeal fascia (Fig. 21). In non-typhlonectids, the insertion is more directly onto the posterolateral corners of the anterior pharynx and is only indirectly associated with the glossal skeleton. The form of this anterior unit, which we designate as the pars pharyngeobranchialis, has apparently not been previously reported, 
but appears to be widespread in caeciliids. Functionally, it is presumed to assist the $m$. rectus abdominus and $m$. rectus cervicus in posterior displacement of the glossal skeleton during the downstroke of the buccopharyngeal pump.

\section{M. transversus}

In all caecilians, the anteriormost fibres of this continuous sheet of muscle insert onto the lateral margins of the trachea. A short distance posterior to the glossal skeleton its fibres become less extensive ventrally and appear to insert directly onto the lateral surfaces of the carotid arteries. They then gradually shorten as these arteries curve laterally toward the distal tips of the fused third and fourth ceratobranchials and eventually fade out without reaching the level of the glossal skeleton.

\section{Deep neck musculature}

Deep to the external muscular sheath is a series of vertebral muscles. Anterior serial homologues of these muscles insert on the posterior aspects of the cranium and probably serve in flexion of the head and anterior vertebrae. There exists a variety of names that have been applied to both the trunk and neck muscles of caecilians (Nishi, 1916; Lawson, 1965), but there has been no definitive treatment. In the most recent treatment of the trunk musculature, Naylor \& Nussbaum (1980) and Nussbaum \& Naylor (1982) employed a workable system of names based mainly on the work of Maurer (1892, 1911), and they provided a partial list of synonyms. The various names that have been applied to the anterior serial homologues of the trunk muscles are not, however, consistent with this system. To avoid confusion, we designate these muscles in typhlonectids by numerals and identify, where possible, the vertebral muscles with which they are serially homologous.

Muscle $I$ is the anterior continuation of the $m$. dorsalis trunci, and, like this latter muscle, it is thick bodied. It originates mainly from the hypapophysis and body of the neural arch of the second vertebra, with some lateral fibres originating from the diapophysis. It has a broad insertion onto the occipital region of the skull that extends laterally from the dorsal midline to the supraotic shelf. This muscle is the $m$. rectus capitis superior of Lawson (1965).

Muscle II is the anterior continuation of the hypapophyseal muscle. It lies deep to and is slightly less thick than I. It arises from the dorsal body and hypapophysis of the neural arch of the atlas and inserts upon the occipital region deep to the insertion of I. In Atretochoana, this muscle is composed of a complex set of pearshaped bundles of fibres arranged in an anterior and a posterior series. The narrow apices of the bundles of each series interdigitate across the belly of the muscle. In other caecilians the fibres of this muscle form a simple fan-shaped sheet.

Muscle III has a deep and a superficial part. The superficial portion comprises fibres that arise from the ventral surface of the basapophyseal muscles of the third to eleventh vertebrae close to the midline. The fibres of this part run anteriorly and insert onto the ventral occipital region by an aponeurosis superficial to the deeper part. The deeper part represents an anterior expansion. It has a broader origin from the ventral surfaces of the basapophyseal muscles and the parasphenes of the second and third vertebrae and from the ventral margin of the rib of the second vertebra. This part of the muscle is very well-developed, and its insertion occupies 
most of the occipital region of the skull ventral to the occipital condyles including much of the posterior aspects of the otic capsules (Fig. 21). Thickened bony ridges of the os basale delimiting the anterior extent of this muscle can be seen on most caecilian skulls (e.g. Figs 7, 8 \& 9). The anterior expansion of this muscle begins where the pars ventralis of the $m$. subvertebralis fades out. This muscle appears to be uniform within the Typhlonectidae and is the $m$. subvertebralis of Norris \& Hughes (1918), the $m$. intertransversarius capitis inferior of Lawson (1965), and the $m$. longus capitus of Bemis et al. (1983).

Muscle IV arises from the distal anterior face of the rib of the second vertebra and runs anteriorly to insert onto the posterolateral wall of the otic capsule between the insertions of I and II. It has a rather cylindrical form and is separated from I and from III by the dorsal and ventral spinal nerves of the second vertebra respectively. Anterior and posterior to the passages of these nerves, fibres of this muscle are difficult to separate from the adjacent muscles. This muscle appears to be uniform within the Typhlonectidae. Topologically it lies in series with the pars nuchalis of the $m$. obliquus externus profundus, but it is probably a derivative of I or III.

\section{Respiratory structures}

The foetal gills of Typhlonectes compressicauda were described by Peters (1875), and those of Chthonerpeton viviparum Parker \& Wettstein by Vavra (1907). The gills of T. natans and Nectocaecilia have since been briefly described (Wilkinson, 1989). The lungs and skin of Potomotyphlus and Typhlonectes were described by Fuhrmann (1914). Gaymer (1971) briefly reported on the histology of the skin of T. natans in comparison with several non-typhlonectid taxa. Wake (1974) and Wilkinson (1989) described variation in lung size among typhlonectids. Grinkaut (1949) described the tracheal lungs of $T$. compressicauda. Nussbaum \& Wilkinson (1995) illustrated and described sections of the skin of Atretochoana.

All typhlonectids, except Atretochoana, have the trachea expanded into a tracheal lung. Elsewhere among caecilians, tracheal lungs are found in ichthyophiids and uraeotyphlids. Phylogenetic analysis indicates that the tracheal lungs of the latter probably originated independently from those of typhlonectids (Wilkinson \& Nussbaum, 1996). Respiratory epithelium and internal septa are absent from the trachea where it narrows dorsal to the heart in typhlonectids, but not in uraeotyphlids and ichthyophiids. In Chthonerpeton, the right lung is relatively short and extends posteriorly to just past the posterior tip of the liver without closely approaching the posterior end of the coelom. In all other typhlonectids, except Atretochoana, the right lung is very long and extends well past the liver to closely approach the cloaca at the end of the coelom. Wilkinson (1989) erroneously reported the left lung to be well-developed in Nectocaecilia. Wake (1974) reported the left lung of Chthonerpeton as approaching $50 \%$ of the length of the right lung. In all specimens of both these genera that we have examined the left lung is vestigial as it is in most caecilians. In Typhlonectes compressicauda, the left lung is as long as, or slightly shorter than, the right. In $T$. natans the left is shorter than the right, but still well-developed, and typically extends to just past the posterior tip of the liver. In Potomotyphlus, the left lung is a little shorter, not reaching the posterior tip of the liver, and, as first noted by Fuhrmann (1914), it is exceptionally broad and sac-like. This expanded left lung is also completely devoid of the incomplete ring-like cartilages that are present 
throughout the length of the trachea and lungs of other typhlonectids, and its more typical right lung. Atretochoana lacks any indication of lungs, and the very narrow trachea, which ends blindly at the level of the heart, lacks respiratory epithelium and is essentially vestigial.

The gills of foetal typhlonectids are in the form of a pair of expanded bladderlike sacs between one half and two thirds the length of the foetus and typically wrapped around the body of the foetus in utero. Wake (1992) described Potomotyphlus as viviparous, as evidenced by foetuses. However, as far as we can determine, foetuses of Potomotyphlus are unknown. Foetuses are known for only five, and foetal gills for only four of the 12 typhlonectid species, but viviparity and the peculiar gill form are probably typical of the family. The bases of the gills attach dorsally and are fused together in Typhlonectes, attach dorsolaterally in Nectocaecilia with a slight medial separation, and attach laterally with a strong separation dorsally in Chthonerpeton viviparum. The latter is most similar to non-typhlonectids in this respect (Wilkinson, 1989). The form of the gills is unknown in Atretochoana and Potomotyphlus.

The skin of typhlonectids consists of a compact epidermis and a thicker and more diffuse dermis. The epidermis is differentiated into three regions, the basal, intermediate and cuticular layers of Gaymer (1971). The basal region comprises a single layer of cells that rest on the basement membrane and are otherwise distinguished from cells of the intermediate region only by their slightly more regular cuboidal shape. The cuticular region is the most superficial part of the epidermis and is composed of keratinized squamous cells. There is considerable variation in the depth of the cuticular layer. In our sections, Atretochoana, Potomotyphlus, Typhlonectes natans and Chthonerpeton have mostly a single layer of cuticular cells, with some irregular thickenings due to the partial keratinization of underlying cells. In $T$. compressicauda and Nectocaecilia, there is a double layer of cuticular cells, thickened into a triple layer in places in Nectocaecilia. Gaymer (1971) reported a triple layered cuticular region in T. natans. The observed variation may reflect different stages of the moulting cycle. T. natans sheds its 'skin' in a single piece (Wilkinson, 1980), probably resulting in the sudden loss of the outermost cuticular layer, and the cuticle may alternate between a single and bilayered composition. Unevenness in the development of the second, or third, layers may represent regional variation in the rate of development of replacement layers.

The intermediate region consists of a mass of irregular cells sandwiched between the basal and cuticular regions. This region is five or six cells thick in Chthonerpeton, but thinner in other typhlonectids (3-4 cells). Fuhrmann (1914) reported dermal capillaries indenting the basal layer of the epidermis in Typhlonectes natans, though Gaymer (1971), working with the same species, did not report this in his sections. We find that in skin from the dorsal surface of the head, capillaries are entirely dermal and there is no modification of the epidermis, except in Atretochoana where the capillaries remain dermal but notch into the basal region of the epidermis. In skin from the dorsal surface of the mid-body region, capillaries are also dermal except in Atretochoana, Potomotyphlus, and large T. natans. Here the capillaries perforate the epidermis and are separated from the outside by only the cuticular region and a single narrowed layer of cells of the intermediate region. They are especially numerous in Atretochoana (see Nussbaum \& Wilkinson, 1995: Fig. 2.). In skin from smaller T. natans, no epidermal capillaries are present, and in $T$. compressicauda there is no apparent development of epidermal capillaries in either small or large 
specimens, though sample sizes are small, and further studies are needed to test these generalizations.

The dermis is richly supplied with both mucus and granular glands located just below the epidermis. Capillaries are the only blood vessels found in the superficial glandular layers of the dermis, with larger vessels, both venous and arterial confined to the dermis deep to the glands. Associated with increased vascularization, the dermal glands are less numerous in Atretochoana, and larger blood vessels can also be seen in the loose connective tissue between the skin and the underlying muscle and bone. In Atretochoana, vascularization of this layer is extreme so that the cranium and its muscles are surrounded by a plexus of blood vessels embedded in thick pads of connective tissue. Similarly, the connective tissue of the dorsal 'fin' of Atretochoana is invaded by strikingly numerous blood vessels. The dense capillary network close to the surface of Atretochoana must enhance the rate of gas exchange across the skin. It is also expected to have consequences for osmotic regulation.

\section{Circulatory system}

Aspects of the heart and circulatory system of Chthonerpeton indistinctum were described by Acolat (1939). Sawaya (1948) and Toews \& Macintyre (1978) described the heart and aortic arches of adult Typhlonectes compressicauda, and Peters (1875) described these structures in a foetal specimen of this species. Wilkinson (1992) described aspects of the circulation of $T$. natans.

The aortic arches of typhlonectids arise from the elongate truncus arteriosus. A single common pulmonary artery, when present, arises from the right side of the truncus arteriosus just anterior to the limit of the pericardium and bends dorsally and posteriorly (Fig. 22). Close to its origin it gives rise to a tracheal artery from its dorsal surface which splits into anterior and posterior branches as it contacts the trachea. Further posteriorly, the common pulmonary trunk divides into left and right pulmonary arteries which run into the left and right lungs respectively. The relative sizes of these are positively correlated with the relative sizes of the lungs that they supply. The systemicocarotid trunk continues anteriorly a short distance before a single common carotid artery arises and runs anteriorly from its anterior surface. It then curves dorsally and posteriorly as the systemic arch, gives off several anterior vertebral arteries and continues posteriorly along the midline as the single dorsal aorta. The common carotid artery bifurcates into left and right carotids just posterior to the glossal skeleton, and these bend laterally to cross the ventral distal surface of the fused third and fourth ceratobranchials before giving rise to the major vessels of the head and neck.

In Typhlonectes, Chthonerpeton and Nectocaecilia, the arterial pulmonary circulation is separated from the systemic circulation by a complete septum in the truncus arteriosus, which begins proximal to the conus arteriosus and extends anteriorly to the origin of the common pulmonary artery. The septum, which is slightly less thick in Nectocaecilia, is oriented horizontally at its proximal end, dividing the truncus arteriosus into dorsal pulmonary and ventral systemic chambers. Distally, the septum rotates so as to be vertical with right pulmonary and left systemic chambers. The pulmonary and systemic chambers within the truncus are of approximately equal sizes. A much smaller third division of the truncus is present in Nectocaecilia and Typhlonectes in the initially right lateral and, subsequent to rotation, dorsal wall of the truncus at the 


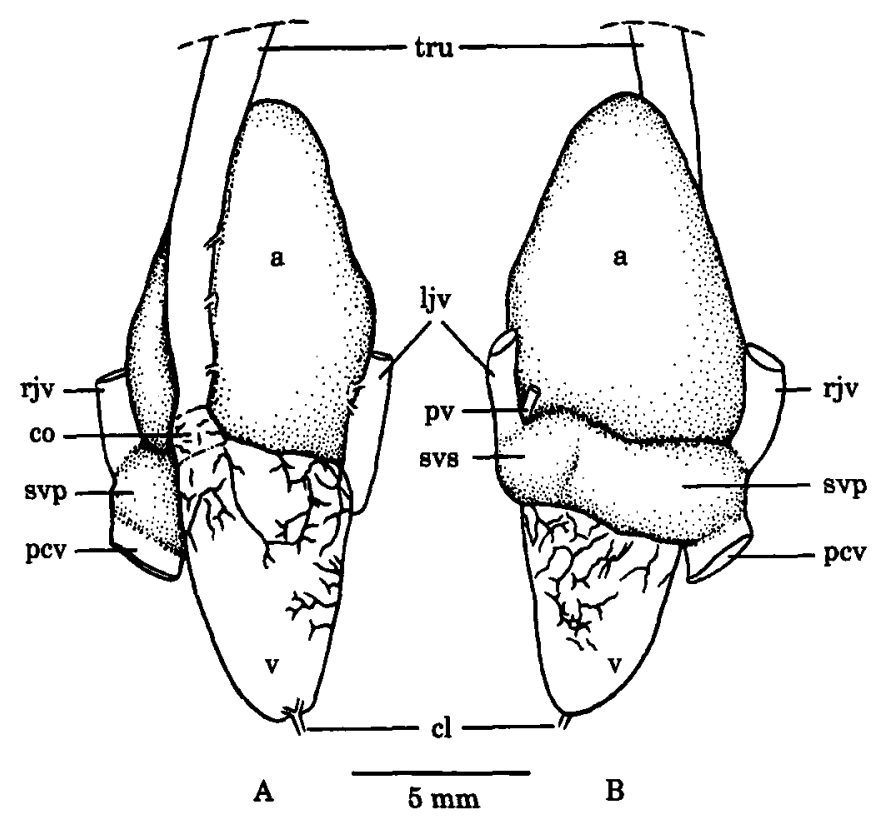

Figure 22. Ventral (A) and dorsal (B) views of the heart of LACM 67502, Typhlonectes natans. $a=a$ atria; $\mathrm{cl}=$ cardiac ligaments; $\mathrm{co}=$ conus arteriosus; $\mathrm{ljv}=$ left jugular vein; $\mathrm{pv}=$ pulmonary vein; $\mathrm{pvc}=$ posterior vena cava; rjv = right jugular vein; $\mathrm{svp}=$ sinus venosus principale; svs $=$ sinus venosus sinistra; tru $=$ truncus arteriosus; $v=$ ventricle; dashed line $=$ anterior limit of the pericardium.

base of the main septum. This chamber communicates proximally with the pulmonary chamber and distally narrows to the point where it can no longer be traced. It probably supplies the intrinsic musculature of the truncus. In Atretochoana and Potomotyphlus, the truncus arteriosus is completely undivided. In the former there is no trace of any pulmonary or tracheal arteries, and in the latter the common pulmonary artery is present and well-developed but considerably smaller than in other typhlonectids. While the pattern of aortic arches of typhlonectids is distinctive among caecilians (most other caecilians have paired pulmonary and systemic arches), it is similar to that of the caeciliids Caecilia and Oscaecilia that are thought to be closely related to typhlonectids on the basis of DNA sequence data (Hedges, Nussbaum \& Maxson, 1993). A major difference is a partial distal fusion of the pulmonary and systemic arches in these caeciliids (Wilkinson, pers. obs.).

Caecilians have a common pattern of veins draining into the heart. The right side of the sinus venosus receives the right jugular vein and a large postcaval vein returning blood from most of the posterior body via the liver. In addition, the renal vein carries blood from the posterior ventral body wall and joins the right jugular close to the sinus venosus. On the left side the only systemic vein is the left jugular. The common pulmonary vein is formed by the union of left and right veins, even when the left lung is vestigial, and receives a tracheal vein close to the sinus venosus. It maintains a separate entrance directly into the atrium with only its ventral wall passing through the sinus venosus. Pulmonary and tracheal veins are completely absent in Atretochoana.

Typhlonectid hearts have a single row of valves in the conus arteriosus and a highly trabecular ventricle showing no indication of intraventricular septation. Within the 
atrium there is a horizontal, almost complete interatrial septum, the posterior margin of which bisects the space directly anterior to the atrioventricular aperture and its paired valves. The ancestrally 'left' and 'right' atrial chambers are thus rotated with the left lying ventral and the right dorsal. To the right of the atrioventricular aperture, the septum is attached to the atrial wall by a particularly sturdy connective tissue cord. On its right anterior side, this cord is continuous with a plexus of connective tissue strands that extend anterolaterally along the dorsal wall of the atrium, ramifying somewhat, but mostly forming an incomplete division of the 'right' dorsal atrial chamber into left and right halves. This plexus is raised into a septumlike ridge close to the sturdy cord, and, as the branches of the plexus approach the right wall of the atrium, they become continuous with a system of trabeculae that occupies this region. Anteriorly, the interatrial septum connects with some of the trabecular strands at their dorsal margins such that there are channels connecting the 'left' atrial chamber with the lumena of the trabecular region of the 'right' atrial chamber.

The septum itself is a thin sheet of connective tissue with an irregular network of thicker strands that is perforated by numerous pores. In Chthonerpeton, Nectocaecilia and Typhlonectes, the pores are extremely small, and the septum probably forms an effective barrier to blood flow. Blood from the sinus venosus enters the 'right' atrial chamber through a single large unguarded sinuatrial aperture adjacent and to the right of the raised septum-like portion of the connective tissue plexus. The pulmonary vein (if present) enters the 'left' atrial chamber adjacent to the sinuatrial aperture, but is separated from it by the interatrial septum and the septum-like ridge.

The sinus venosus comprises a sinus venosus sinistra, which has the appearance of a posterior expansion of the left jugular vein, and a much larger, transversely oriented sinus venosus principale. In Typhlonectes and Nectocaecilia, there is a raised, sagitally oriented, partial septum on the posterior wall of the sinus venosus, directly opposite the midline of the sinuatrial aperture. If this weak septum marks the limits of the sinus venosa, then the sinuatrial aperture is half in each chamber. The sinus venosus is oriented transversely in typhlonectids, and in this respect resembles that of caeciliids. Other caecilians have a more oblique, longitudinally oriented sinus venosus (Wilkinson, 1996c).

In Atretochoana and Potomotyphlus, the interatrial septum is present but degenerate with larger and more irregular pores, especially in the former, and is a generally more flimsy structure lacking the sturdy chord seen in other caecilians. In Potomotyphlus, it retains the same extension as in other typhlonectids, but, in Atretochoana, it occupies far less of the atrial length and does not closely approach the atrioventricular aperture.

\section{DISCUSSION}

\section{Phylogenetic position of Atretochoana}

A well supported phylogenetic hypothesis for the then recognised genera of typhlonectids caecilians was proposed by Wilkinson (1989). In it, the aquatic caecilians Potomotyphlus and Typhlonectes (including Atretochoana), comprised a clade with Nectocaecilia and Chthonerpeton successively more distant relatives. A number of 


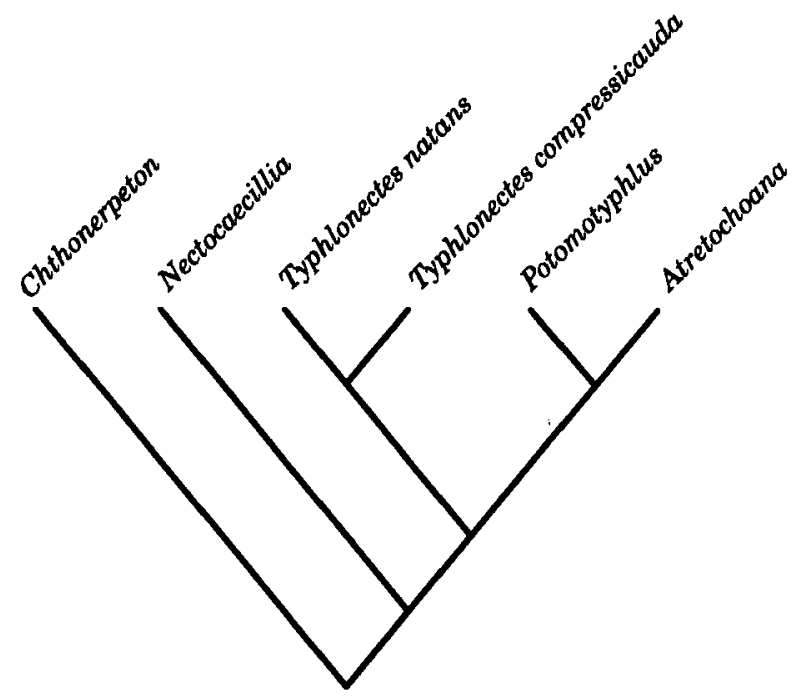

Figure 23. Cladogram showing hypothesised phylogenetic relationships within the Typhlonectidae (after Wilkinson, 1989; Wilkinson \& Nussbaum, in prep).

shared derived features suggest that Atretochoana is most closely related to Potomotyphlus (Fig. 23), including: a degenerate interatrial septum; undivided truncus arteriosus; dorsoventral compression of the skull; large choanae; superficial choanal valves; fusion or partial fusion of choanal valves; no medial expansion of the distal fused third and fourth ceratobranchials; and reduced or absent postchoanal processes. Detailed analysis of the phylogenetic relationships of Atretochoana will be presented elsewhere.

\section{Uniqueness of Atretochoana}

Atretochoana is an exceptional caecilian and an exceptional tetrapod in several respects. It is the only known tetrapod in which the internal nares are secondarily sealed. Furthermore, it is the only tetrapod exhibiting complete lunglessness outside of the Caudata, and it is by far the largest lungless tetrapod. The next largest lungless tetrapod, the comparatively slender plethodontid salamander Pseudoeurycea belli, attains a total length of up to $325 \mathrm{~mm}$ (less than half the length of Atretochoana). The complete loss of pulmonary vessels is also unique among tetrapods. Plethodontids retain the pulmonary arch which gives rise to arteries supplying the oesophagus (Darnell, 1949). In addition, Atretochoana has a suite of derived features involving reduction in the glossal apparatus, major modification of the jaws, and unique and radical modification of the stapes and the adductor musculature. Considering the constancy of the form and position of the jaw articulation in other caecilians and the co-occurrence of these modifications and lunglessness in Atretochoana, it would be surprising if there were not either some causal relation between them during their evolution, or some common causal factors affecting their evolution.

Unfortunately, because these unique features are restricted to Atretochoana, with precursors of relatively few of the novel characters occurring in the sister genus 
Potomotyphlus, phylogenetic analysis provides little information on the likely sequence of events in the morphological evolution of Atretochoana, in particular whether pulmonary modification preceded, was contemporaneous with, or occurred after, the modification of the jaws. The diversity of caecilians is, as is dramatically evidenced by this investigation of Atretochoana, poorly known, and so there is some hope that future discoveries might provide taxa intermediate in some regards between Potomotyphlus and Atretochoana. The continuing destruction of tropical ecosystems means, however, that time for any such discoveries, and for the discovery of live specimens of Atretochoana that could be investigated physiologically and from the perspective of functional morphology, may be running out. The discovery of the unique and radically divergent morphology of Atretochoana represents a major increase in the degree of morphological diversity (disparity) within the Gymnophiona. Gould (1989) has argued for a general evolutionary pattern in which maximal disparity occurs early in the evolution of a group. The origin of Atretochoana within the small and presumably late radiation of relatively advanced caecilians that comprise the Typhlonectidae does not fit this pattern and demonstrates the unpredictability of evolution. In the following sections we provide an extended discussion of the evolution of Atretochoana much of which is of necessity highly speculative.

\section{Evolution of lunglessness}

Amphibians are preadapted to lunglessness or lung reduction because their skin provides an important additional surface for respiratory gas exchange (Nussbaum \& Wilkinson, 1995, and references therein). Other lungless tetrapods are found only among the salamanders, in which one family, the Plethodontidae, and some hynobiids are lungless. In addition, there are salamandrids, ambystomatids, and several anurans that have greatly reduced lungs. The Plethodontidae is the most speciose group of salamanders (comprising well over half of all salamander species) and the only group represented in the tropics. The classical hypothesis of Wilder \& Dunn (1920) and Dunn (1926) concerning the origin of lunglessness in the Plethodontidae has, until recently, never been challenged. The hypothesis postulates that lunglessness evolved in an environment of fast-flowing, montane streams in which lungs provided disadvantageous buoyancy. Lunglessness is thus a rheotactic adaptation.

This hypothesis drew support from three sources. Firstly, the observation that most other lungless forms and forms with reduced lungs are inhabitants of montane streams, at least during the breeding season or as larvae. Secondly, from the observation that, although many plethodontids are terrestrial, forms considered to have primitive morphologies and life histories are semi-aquatic and mostly associated with mountain streams and seepages. Thirdly, the greatest diversity of non-terrestrial plethodontids is found in the Appalachian Mountains in southeastern North America which has been assumed to be the area of origin of the group. In addition, Noble (1925) pointed out that because montane waters are cold their capacity for dissolved oxygen is great, and that this would facilitate an increased dependence on cutaneous respiration.

Ruben \& Boucot (1989) recently challenged this classical scenario and provided an alternative. They claimed that the topography and climate of Appalachia during the middle to late Mesozoic (the presumed period of plethodontid origin) would have supported only oxygen-poor, warm, lowland waters, and not the mountain 
stream environment central to the classic hypothesis. As an alternative, Ruben \& Boucot (1989) suggested that lunglessness evolved in terrestrial protoplethodontids as a consequence of reduction in head size. This reduced the capacity of the buccopharyngeal force pump and thus the degree and efficiency of lung ventilation, and hence the effectiveness of pulmonary function, leading to an increased dependence on cutaneous gas exchange (Schmalhausen, 1957, cited in Szarski [1962]; Szarski, 1962; Whitford \& Hutchinson, 1966).

Although developed to explain the evolution of lunglessness in plethodontids, the rheotactic and buccopharyngeal pump efficiency (BPE) hypotheses represent alternative general explanations of the evolution of lunglessness or reduced lung size in amphibians. Here we argue that the evolution of lunglessness in Atretochoana is better explained by the rheotactic hypothesis than by the BPE hypothesis. We also suggest that the latter is an unconvincing explanation of the origin of lunglessness in any amphibians, a view we shall develop more fully elsewhere (Nussbaum \& Wilkinson, in prep).

Considered in isolation, the evolution of lunglessness in Atretochoana, with its exceptionally large mouth compared to other caecilians, does not fit the BPE hypothesis. However, Potomotyphlus, which is hypothesised to be the closest relative of Atretochoana, may seem to better fit this model. Potomotyphlus is unusual in its reduced relative head size in comparison to other caecilians, and concomitant reduction in the capacity of its buccopharyngeal force pump. In this form, there is no septum in the truncus arteriosus, a reduction of the size of the common pulmonary artery, and partial degeneration of the interatrial septum. All these features indicate that there has been a loss of the ability to maintain a high degree of separation of pulmonary and systemic circulation, and are consistent with a reduction in the importance of pulmonary gas exchange.

Toews \& Macintyre (1978) experimentally demonstrated a capacity for the maintenance of largely separate oxygenated and deoxygenated blood streams through the heart and aortic arches in Typhlonectes compressicauda despite the undivided condition of its ventricle, and Sawaya (1947) reported that most oxygen uptake $(94 \%)$ in this species is pulmonary. Given the similarity of the structure of the heart in other typhlonectids (with the exceptions of Atretochoana and Potomotyphlus) to that of $T$. compressicauda, the physiological correlates of this structure observed by Toews and Macintyre are probably primitive for the Typhlonectidae. Thus a parallel can be drawn between Potomotyphlus and ambystomatid salamanders in which reduction of the size of the buccopharyngeal force pump is correlated with increased reliance upon cutaneous gas exchange (Whitford \& Hutchinson, 1966). However, the lungs of Potomotyphlus are, in comparison to the majority of other caecilians, very well developed. The left lung is unusual in being developed into an especially broad saclike structure lacking any respiratory epithelium. It presumably serves as a hydrostatic organ, more important in the control of buoyancy than in respiration. The loss of cartilages from this lung would facilitate major changes in its degree of expansion consistent with a hydrostatic function. In contrast, the elongate right lung has a more typical pulmonary structure suggesting that, as in Typhlonectes compressicauda, it is important as a surface for gas exchange. Thus, the anatomical data indicate a reduced importance for pulmonary gas exchange in Potomotyphlus correlated with reduced head size and thus consistent with the BPE hypothesis. However, despite the reduction in the size of the buccopharyngeal pump and any concomitant increase in the cost of pulmonary ventilation, the structure of the large right 
lung implies that pulmonary gas exchange remains of considerable importance in Potomotyphlus and that the buccopharyngeal pump remains adequate to the task of filling the large lungs.

In both caecilians and salamanders, we would not expect the size of the buccopharyngeal pump to be a limiting factor in the magnitude of pulmonary ventilation, and hence lung size, because it is not a single pulse, but repeated contractions of the buccal floor that fill the lungs. Lung size in caecilians does not correlate with relative head size. Limited observations indicate that it may correlate with the number of buccal pulses occurring during ventilation. In the aquatic, large-lunged Typhlonectes natans, ventilation usually involves as many as thirty buccal pulses (Wilkinson, 1980), whereas in the terrestrial, small-lunged Ichthyophis bannanicus Yang, ventilation is typically accomplished by between four and seven buccal pulses (pers. obs.). Thus, reduction in the capacity of the buccopharyngeal pump through the evolution of reduced head size could be compensated for by increase in the number of pulses used to fill the lungs. This might make pulmonary ventilation more expensive energetically, and could potentially increase the advantage of alternative non-pulmonary gas exchange. However, considering the greatly reduced head size of Potomotyphlus and its large lungs, it does not seem likely that the inefficiency of pulmonary ventilation would be a sufficient cause of either major reduction or complete loss of lungs.

The BPE hypothesis identifies the cost of lungs as the energy expended in their ventilation: if the buccopharyngeal pumping required to fill the lungs uses more oxygen than is taken up by the lungs (an efficiency threshold), then lung reduction would be selectively advantageous (Whitford \& Hutchinson, 1966). Ruben \& Boucot (1989) hypothesize that BPE is reduced beyond the efficiency threshold by selection for reduced head size. However, there are tremendous advantages associated with even an extremely limited potential for pulmonary respiration (as evidenced by the numerous convergent developments of accessory respiratory structures for exploiting atmospheric oxygen in fishes). Thus, changes in head size that would push BPE beyond the efficiency threshold are expected to face strong counter selection. We consider that the complete loss of lungs is to be expected only where there is (a) some major disadvantage associated with their possession, and/or (b) some major advantage associated with a feature (such as small head size) that is incompatible with lungs. The rheotactic hypothesis identifies a plausible potential disadvantage of lungs associated with montane aquatic habitats. It is strongly supported by the association of lunglessness or reduced lungs with such habitats in a variety of amphibian lineages and by parallel patterns in the reduction or loss of swim bladders in fishes (Bridge \& Haddon, 1893). Limited experimental evidence also demonstrates that lung size affects the ability of amphibians to resist a current (Wilder \& Dunn, 1920; Bruce et al. 1994). In contrast, the BPE hypothesis identifies one possible feature that is incompatible with lungs (small head size), but fails to identify strong selection pressures that would reduce BPE sufficiently to render lung loss advantageous in the face of the expected counter selection for maintenance of a potential for pulmonary gas exchange. Thus we consider the BPE hypothesis an inadequate explanation of the evolution of lunglessness in amphibians.

Can the more satisfactory rheotactic hypothesis account for the evolution of lunglessness in Atretochoana? Unfortunately, we have no information on the habitat of Atretochoana, and are forced to make inferences from its morphology. It is clear that Atretochoana is aquatic. Furthermore, the lack of lungs and increased 
vascularization of the skin indicate that the skin has become the chief respiratory organ. This, combined with its large size, indicates that it must live in waters of high oxygen content, i.e., cool flowing waters. Only an environment like this could support such a large organism reliant on cutaneous gas exchange. The extreme dorsoventral compression of the head is typical of lower vertebrates that are bottom dwellers in fast flowing water (e.g. Cryptobranchus and loricariid catfish), and thus provides some corroboration for our interpretation. It is suggested, then, that lunglessness in Atretochoana is probably the result of adaptive evolution for reduced buoyancy accompanying the invasion of montane aquatic habitats.

Noble (1925) described various modifications of the skin and heart of amphibians, notably the perforation of the epidermis by capillaries and the fenestration of the interatrial septum, which are associated with increased cutaneous respiration. Epidermal capillaries occur in Atretochoana and to a lesser degree in Potomotyphlus, in conjunction with modifications of the heart and arterial system, paralleling the morphological modifications reported by Noble for other taxa. Compared to other caecilians, the epidermal capillaries of Atretochoana are more dense, dermal glands less dense, and epidermal vascularization more extensive, occurring on both the head and body, in keeping with the complete loss of lungs. However, epidermal capillaries also occur in the skin of large Typhlonectes natans. This species has very well-developed lungs and has none of the circulatory modifications seen in Potomotyphlus and Atretochoana or reported by Noble (1925) for other amphibians. Lacking any other indications of decreased dependence on pulmonary gas exchange, the presence of epidermal capillaries in $T$. natans is anomalous.

The apparent reduction in the significance of pulmonary respiration in Potomotyphlus indicates that some reduction had probably occurred in the lineage ancestral to Potomotyphlus and Atretochoana. Unfortunately, we have almost no knowledge of the ecology of Potomotyphlus, and no information on its physiology. An early physiological study of Typhlonectes compressicauda showed that most oxygen uptake (94\%) is pulmonary (Sawaya, 1947). Toews \& Macintyre (1978) interpreted the respiratory properties of this species as adaptations to life in environments that may frequently be hypoxic. This species is distributed throughout warm lowlands in slow-moving waterways of the Amazon Basin and Guianan Shield, and it has been recovered from underwater mud burrows (Moodie, 1978) in which hypoxia is likely to be an important environmental factor. The modified body shape of Potomotyphlus, with its small head and large specialised hydrostatic organ, are not consistent with the idea that this species is a burrower, and it has not been reported from mud burrows. The only ecological information known to us for this species accompanies two specimens in the Carnegie Museum which were found beneath rocks in shallow water. If the evolution of the lineage ancestral to Potomotyphlus and Atretochoana involved (i) the emergence from mud burrows, (ii) the development of a reduced head size, and (iii) the elaboration of one of the lungs as a hydrostatic organ, this would have had three corresponding consequences that could have led to a reduction of pulmonary gas exchange to the degree seen in Potomotyphlus. Firstly, the emergence from an hypoxic burrow environment would reduce the demand for effective pulmonary gas exchange. Secondly, reduction of head and buccopharyngeal pump size would reduce the efficiency of the ventilatory mechanism and increase the cost of pulmonary gas exchange as suggested by Szarski (1962), and thirdly, the transformation of a lung into a hydrostatic organ lacking extensive respiratory epithelia would reduce the surface area available for pulmonary gas exchange. 
Ruben \& Boucot's (1989) interpretation of the geological history of Appalachia led them to suggest a terrestrial origin of lunglessness in plethodontids. Beachy \& Bruce (1992) have criticised their interpretation of the Mesozoic topography of Appalachia, and, as Ruben \& Boucot (1989) note, it is also conceivable that lungless plethodontid ancestors evolved in an aquatic environment elsewhere and subsequently invaded Appalachia. To further support a hypothesised terrestrial origin of plethodontid lunglessness, Reagan \& Verrell (1991: 1305) argued that "the presence of a more or less stationary boundary layer adjacent to the skin of an aquatic protoplethodontid would offer considerable resistance to gas exchange." Similarly, Ruben, Reagan, Verrell \& Boucot (1993: 1044) consider that "lunglessness is unlikely to ever have evolved in any thoroughly aquatic tropical salamander, even a stream dweller." The evolution of lunglessness in Atretochoana casts considerable doubt on the validity of the latter arguments for a terrestrial origin of lunglessness in plethodontids. The limited locality data for Atretochoana and its morphology (possession of a fin), indicate that, like its closest relatives, Typhlonectes and Potomotyphlus, it is a fully aquatic, Neotropical amphibian. It is implausible and unparsimonious that lunglessness in Atretochoana evolved in a terrestrial environment. Thus, the discovery of lunglessness in Atretochoana provides the strongest evidence yet available that, contra Reagan \& Verrell (1991) and Ruben et al. (1993), aquatic environments do not prevent the evolution of lunglessness in amphibians.

\section{Evolution of the choanae and the buccopharyngeal pump}

Compared with other caecilians, the buccopharyngeal pump of typhlonectids is particularly well-developed, with enlargement of the fused third and fourth ceratobranchials, bellows-like articulation of the first and second ceratobranchials, increased flexibility in the articulations between more anterior glossal elements, and the novel attachment of muscles ( $m$. cephalodorsosubpharyngeus and $m$. obliquus internus pars pharyngeobranchialis) to the glossal skeleton. Such a well-developed buccopharyngeal pump may be required to fill the elongate lungs of typhlonectids and to compensate for the increased resistance to displacement of the external medium (water rather than air) by the floor of the mouth and the body.

Accompanying lung loss in Atretochoana, there is some reduction of the ancestral, well-developed, typhlonectid buccopharyngeal force pump. In particular, the fused third and fourth ceratobranchials are smaller, the ceratohyal narrower and more delicate, and the $m$. interarcualis $I$ is reduced to a narrow band. These modifications are unlikely to have occurred prior to the shift from pulmonary to cutaneous gas exchange and the loss of functional lungs; and dependence on active pulmonary gas exchange is expected to constrain modification of the ventilatory apparatus. Similarly, the closure of the choanae in the evolution of Atretochoana could only have been possible with the loss of pulmonary gas exchange and the loss of the need for choanae that served as intake channels for the buccopharyngeal force pump. The choanal valves of Potomotyphlus foreshadow this closure in a form with well-developed lungs and a functional buccopharyngeal force pump. Thus, the beginnings of choanal valve fusion may have occurred independently of any significant reduction in lung size. However, despite lunglessness, the buccopharyngeal pump of Atretochoana is far from vestigial; it retains the sliding articulation between the first and second ceratobranchials, and the narial plugs are well-developed and of similar size to the 
choanal valves, paralleling a presumed functional relationships between these in lunged caecilians.

All typhlonectids, but particularly the three genera of fully aquatic typhlonectids, Typhlonectes, Potomotyphlus, and Atretochoana, have enlarged choanae and enlarged choanal valves compared to terrestrial caecilians. The choanae are smallest and the valvular apertures largest in Typhlonectes; Potomotyphlus has larger choanae with smaller and concealed valvular openings; and the large choanae of Atretochoana are covered with sealed valves. Typhlonectid choanae are also more superficial than in terrestrial caecilians, nearly level with the roof of the mouth in Typhlonectes and Potomotyphlus, and projecting into the mouth in Atretochoana, such that they are readily deformed by vertical movement of the tongue and the correspondingly large narial plugs. Functionally associated with the enlarged choanae and valves of aquatic typhlonectids, we believe, are the enlarged external nares and the reduced size of the tentacular apertures and the non-protrusible tentacles. We suggest that the switch from the aerial to the aquatic medium led to the evolution of these correlated morphological features, which are associated with changes in the chemosensory mechanism.

Well-developed, protrusible tentacles apparently are useful as chemosensory organs only in the terrestrial-aerial environment. The appearance of tentacles in terrestrial caecilians with aquatic larvae is either a metamorphic (Rhinatrematidae, Ichthyophiidae) or late premetamorphic event (Uraeotyphlidae, Caeciliidae) and thus accompanies the transition from the aquatic to the terrestrial environment. The decrease in size and loss of protrusibility of tentacles in the secondarily aquatic typhlonectids suggests reduction, or loss, or some other modification of the chemosensory function of the tentacles, which presumably were morphologically and physiologically adapted for chemosensory function in the terrestrial environment, and specifically in burrows where the protruded tentacle could be placed in direct contact with the wall of the burrow or potential prey, predators, and mates. In addition to "tasting" with their tentacles, terrestrial caecilians presumably can smell by drawing air into their nasal cavities.

Chemosensory perception in the aquatic environment by typhlonectids may be accomplished with taste buds (Wake \& Schwenk, 1986) and also by moving water into and out of their sensory nasal cavities. Water is denser and more viscous than air, and requires more force and larger passageways for its transit. The large external nares facilitate movement of water into and out of the nasal cavities, and the enlarged choanae and their superficial, flexible, membranous valves are integral parts of a powerful pump that effects this movement. Enlarged lower choanal passageways allow larger stroke volumes of water, and the flexible valves serve as water and pressure barriers between the nasal and buccal cavity. Water is drawn into the nasal cavities by negative pressure in the buccal cavity, which is created by lowering the throat and tongue while the mouth and choanal valves are sealed. Negative pressure in the buccal cavity is transmitted to the nasal cavities by pulling down on the shut (Typhlonectes, Potomotyphlus) or permanently sealed (Atretochoana) choanal valves resulting in the inflow of water through the nares. The stroke volume is proportional to the surface area of the choanal valves and their flexibility, or the degree to which they can be deformed. This action is expected to be similar to that used in filling the buccal cavity with air during the intake stroke of the pulmonary buccopharyngeal pump in breathing, except that the choanal valves are sealed. Positive pressure needed for forcing water out of the nasal cavities is created by 
raising the tongue and pushing the narial plugs against the choanal valves and into the lower choanal passageways.

This scenario, if correct, would explain the seemingly anomalous coevolution of enlarged lower choanal passageways in Potomotyphlus and Atretochoana and the partial or complete closure of their choanal valves. If enlarged choanae had evolved to facilitate passage of air through the choanae into the buccal cavity for lung ventilation, then the concurrent evolution of large, nearly or actually sealed, valves placed over the openings of the choanae is counterintuitive. It is understandable, however, if the enlargement of both the choanae and the covering valvular membranes are part of a large-volume water pump for 'water-smelling' in the nasal cavities. The partially fused valves of Potomotyphlus are presumably more efficient for moving water than those of Typhlonectes, but tiny valvular openings are needed in Potomotyphlus for the occasionally servicing of the lungs. With loss of lungs, Atretochoana presumably evolved the more efficient condition of permanent closure of the valves. Both the choanae and the covering membranes remain large in Atretochoana, even though it is no longer possible for air or water to pass between the nasal and buccal cavities, possibly attesting to the functionality of the large choanae and valves in movement of water into and out of the nasal cavities.

Terrestrial caecilians and many other amphibians display two kinds of buccopharyngeal pumping. Ventilation of the lungs involves a high-amplitude, lowfrequency cycle. A second pattern of activity involves low-amplitude, high-frequency fluttering of the floor of the mouth. This second pattern of activity has been interpreted as flushing air in and out of the buccal cavity, either for buccopharyngeal respiration (Noble, 1925), or as a precursor to lung ventilation (the oscillatory cycle of Gans [1974]). Given that fluttering also moves air through the nasal cavities, it is probable that is serves in olfaction also (Foxon, 1964). The terrestrial caecilian Boulengerula taitanus, shows increased rates of fluttering and tentacle protrusion when approaching food (Wilkinson, pers. obs.). Fluttering is also seen in submerged Typhlonectes (clearly not as part of their air breathing cycle), and also increases when prey has been introduced into aquaria (pers. obs.). While these behavioural observations are limited, they are consistent with our interpretation of aquatic caecilians having evolved a water-smelling system from an ancestral air-smelling system of terrestrial caecilians.

\section{Evolution of the skull}

The evolution of Atretochoana has involved a profound increase in the size of the gape. The situation loosely parallels that of advanced snakes in which the quadrate is elongate and projects posteriorly and ventrally from its articulation with the supratemporal, resulting in a posterolaterally displaced jaw articulation and widened gape. In Atretochoana, posterior and lateral displacement of the jaw articulation is also primarily achieved through elongation of the quadrate, and to a lesser extent the squamosal, while the form of the articulation with the pseudangular is conserved. Presumably, the increased gape allows larger prey items to be exploited, and selection probably acted so as to modify the jaws for this reason in both Atretochoana and in snakes. In Atretochoana, shift in prey size may be associated with the invasion of its inferred lotic habitat, where there is a greater frequency of larger prey compared to lentic habitats (Nussbaum, 1985b). 
Two major differences in the form of the suspensorium of Atretochoana from that of snakes are the articulation of the quadrate ventrolaterally, forming a sliding synovial joint with the laterally expanded basipterygoid process of the os basale, and the anterior connection of the quadrate to the squamosal dorsally and maxillopalatine ventrally. In Atretochoana, the elongate ascending and pterygoid processes of the quadrate, which form most of the lower temporal fossa, have been rotated dorsomedially so that the fossa is oriented more laterally. The orientation of the adductor musculature is far more oblique, and these muscles project laterally and posteriorly to insert on the pseudangular close to the jaw articulation.

The idea that the caecilian skull is kinetic is as old as the concept of kinesis itself. The presence of a well-developed synovial joint between the pterygoid process of the quadrate and the basipterygoid process of the os basale was taken by Versluys (1912) to indicate the mobility of the quadrate. Since then, many authors have considered the question of kinesis in caecilians, producing a variety of interpretations based mainly on reconstructions from serial sections of the skulls of a number of different species. The existing literature is full of contradictory reports, and it is not possible to be sure how much of this is due to real morphological differences between taxa and how much to differing inferences of the investigators. The literature on caecilian cranial kinesis has recently been summarized by Wake \& Hanken (1982). These authors reported mobility in the quadrate of freshly killed adult Dermophis. Surprisingly, this is the only report of the possibility of cranial kinesis based on manipulation, rather than on interpretation of static morphological preparations.

While being aware of the grave difficulties of making accurate functional interpretations from morphology, we believe that most caecilians share a common form of cranial kinesis that has never been adequately characterized and that this form of kinesis has been elaborated dramatically in the evolution of Atretochoana. In other typhlonectids, the quadrate, squamosal, and maxillopalatine form a distinct 'cheek' unit that articulates with the rest of the 'median' skull at several points (see Fig. 24): (1) the maxilla braces against the nasopremaxilla anteriorly, and with the adjacent vomers on the palate; (2) the maxillopalatine and the squamosal abut against median paired elements dorsally (nasopremaxillae anteriorly and frontals posteriorly); (3) the postchoanal process of the maxillopalatine braces against the os basale and posterior tips of the vomers; (4) the pterygoid process of the quadrate articulates with the basipterygoid process of the os basale; and (5) the quadrate (processus oticus when present) articulates with the stapes. None of these points of contact is a fusion, 4 and 5 are sliding joints, 1 and 2 are flexible syndesmoses, and 3 is a flexible juxtaposition with relatively little connective tissue. Thus, the 'cheek', as defined here, is an independently movable unit. Manipulation of both macerated glycerine, formalin-fixed, alcoholic and freshly killed specimens confirms the potential mobility of this element relative to the rest of the cranium. This pattern of articulation is also seen in non-typhlonectid caecilians, although in stegokrotaphic forms there is a much more extensive articulation of the squamosal with the skull roof (frontals and parietals) that must further limit the mobility of the cheek, and, in those caecilians that retain a separate pterygoid (rhinatrematids, ichthyophiids, and uraeotyphlids), there is likely to be additional mobility, within the cheek, of the pterygoid relative to other components.

We propose that in active feeding, contraction of the internal adductor musculature not only aids in the adduction of the lower jaw, but also, when the jaws are closed, transmits forces through the jaw articulation to the cheek. The orientation of the 


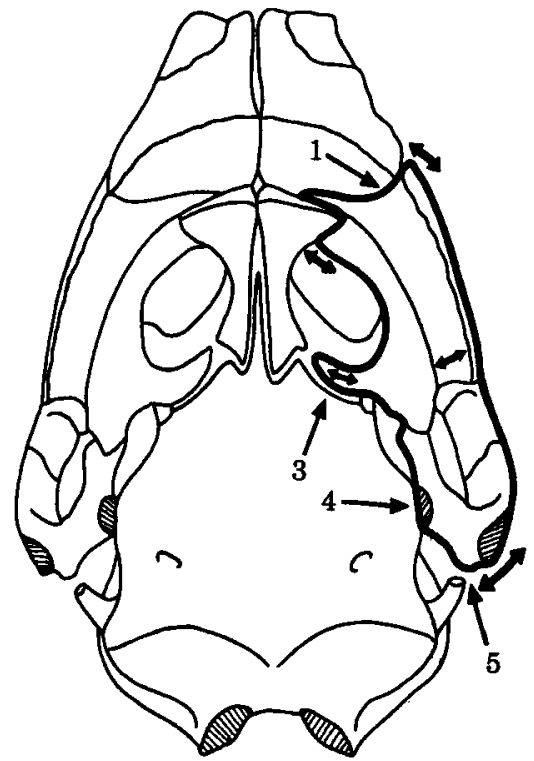

Figure 24. Semi-diagrammatic palatal view of the skull of Typhlonectes natans showing articulations and potential movement (double headed arrows) of the cheek region (indicated by thickened line). 1, 3, 4 and 5 are the points of articulation between the cheek and the rest of the cranium as described in the text. Point 2 is not visible in this ventral view. Point $l$ serves as a pivot about which the cheek is hypothesised to rotate during cranial kinesis.

muscles within the adductor chamber indicates that they would tend to pull the pseudangular, and indirectly the posterior part of the cheek unit, medially, dorsally, and slightly anteriorly. We observe that when such an action is imitated manually, the entire cheek region is displaced about the point of contact between the maxillopalatine and the nasopremaxillae and vomers (Fig. 24), which thus acts as a pivot. Similarly, the lower jaws are correspondingly displaced about the mandibular symphysis. Contractions of the $m$. interhyoideus, $m$. depressor mandibulae, $m$. levator quadrati (when present), and possibly the $m$. intermandibularis also, might contribute to this displacement of the cheek and mandibles or otherwise influence cheek mobility at the end of the bite cycle.

Functionally, the important consequence of this kinesis may be that the maxillary, palatine, and dentary (and in Atretochoana the splenial) tooth rows are displaced slightly medially toward the end of the bite, tending to force prey medially. Softbodied prey such as earthworms and grubs (which probably comprise much of the diets of most terrestrial caecilians) would be compressed by any medial movement of the cheeks and the mandibles. Anteriorly the static vomerine and premaxillary teeth series would prevent the compressive force from being translated into an anterior elongation of the prey out of the mouth. Therefore, the compression would result in an elongation of the prey posteriorly toward the pharynx. Peristaltic actions of the pharynx are probably important in completing ingestion (Bemis et al. 1983). The form of kinesis envisioned would aid in the movement of the prey within the mouth from the primary ingestive apparatus (teeth and jaws) to the secondary apparatus (the pharynx). At the end of the bite cycle, the muscles would relax, and 
the cheek would tend to passively return to its more laterally displaced normal position aiding the disengagement of the conical recurved teeth from the prey.

This model of kinesis is most similar to one recently proposed by Straub (1985) who suggested that: " $\ldots$ only some lateral parts of the skull, namely the pterygoquadrate and the squamosal, if present the ectopterygoid and possibly a small part of the maxillopalatine, move in relation to the rest of the skull. Both the pterygobasal and the quadratostapedial joints are taken to be sliding joints. No strict axis of rotation is proposed, but a slight stretching of the syndesmosis between the maxillopalatine and the squamosal or some degree of bending of the maxillopalatine in the region of the orbit to achieve a slight dorsomedial rotation of the pterygoquadrate-squamosal apparatus." Straub (1985) proposed the term pleurokinetic (moving laterally) for this new form of kinesis.

The main differences in our model are that: (1) the maxillopalatine is fully incorporated into the movable cheek; (2) the articulation of this bone with the nasopremaxilla and vomer forms the pivot for the rotation of the whole cheek unit; (3) movement of the cheek is primarily a medial displacement rather than a dorsolateral rotation; and (4) bending, or relative movement of the squamosal and maxillopalatine, although not discounted, are inessential. Straub's (1985) model was the result of his work on the cranial anatomy of caeciliids, but, as he pointed out, it differs significantly from previous models in that it is quite general and not dependent on the presence of a m. levator quadrati or a stapes. We have found the cheek region to form a movable unit in all genera of caecilians for which glycerine skeletal specimens have been examined, but note some variation in its development and the possibility that in some forms there may be movement of the components of the cheek relative to each other as envisaged by Straub. When this is the case, movement of the posterior cheek will produce a less significant displacement of the anterior palatal cheek teeth, and the major tooth displacement would be of the dentary and splenial series.

In Atretochoana, the basic form of kinetism is retained but the magnitude of cheek movements is greatly increased. The basipterygoid process projects laterally more strongly in Atretochoana than in other caecilians, supporting the laterally displaced pterygoid process of the quadrate, but also overlapping it more extensively and providing a broader surface for articulation. The loss of the postchoanal process of the maxillopalatine and the quadratostapedial articulation eliminates two points of articulation between the cheek and the 'median' skull, and the loss of the postorbital process of the squamosal and the bony covering of the tentacular groove dramatically reduces a third. Together these changes have greatly increased the mobility of the cheek. In addition, the mandibular symphysis is very flexible in Atretochoana.

The reduced postchoanal process of the maxillopalatine of Potomotyphlus does not appear to be related to an increased mobility of the cheek in this form. It is probably a consequence of the posterior expansion of the maxillopalatine that occurred in a lineage ancestral to Potomotyphlus and Atretochoana. The ventrolateral margins of the parasphenoid region of the os basale, with which the postchoanal process articulates, converge anteriorly. Therefore, as the maxillopalatine was phyletically extended posteriorly, a reduced medial extension of its postchoanal process was sufficient to maintain a contact with the os basale. Without a corresponding reduction in the postchoanal process, the degree of overlap between it and the os basale would have increased and led to a firmer bracing of the cheek and a reduction in its mobility.

The more nearly horizontal orientation of the adductor musculature in Atretochoana 
indicates that it would be capable of producing a greater medial displacement of the cheek than in other caecilians and would tend to produce a less significant dorsal displacement. The major modification of the kinetic system is, however, in the role of the stapes and the $m$. pterygoideus. In other caecilians, the $m$. pterygoideus originates mainly from the pterygoid process of the quadrate and inserts on the posteromedial and lateral edges of the retroarticular process. It runs mainly in a longitudinal plane and is unlikely to play a role in the movement of the cheek and presumably serves simply to adduct the jaws. In Atretochoana, this muscle is extremely large and is differentiated into a pars mandibularis with the ancestral origin and insertion, which presumably remains relatively unimportant in kinesis, and a novel pars stapedialis, the fibres of which run between the stapes and the posterior margin of the maxillopalatine.

The stapes makes no contact with the posteriorly displaced quadrate, but it is massively enlarged and extends posteriorly and slightly dorsolaterally from the foramen ovalis. It is mobile mainly in the horizontal plane, with its vertical movement restricted by the shape of the foramen ovalis, but some ventral movement is possible. This novel musculoskeletal configuration almost certainly provides additional power for kinesis. Because of the lateral displacement of the cheek, the 'origin' of the pars stapedialis from the maxillopalatine is lateral to its 'insertion' onto the connective tissue sheath of the stapes. Ignoring any movement of the stapes itself, the most straightforward interpretation of contraction of the pars stapedialis is that it would tend to pull the cheek medially and posteriorly, complementing the action of the internal adductors.

However, the mobility of the stapes itself is a complicating factor that limits any functional interpretation based on static morphology alone. Movement of the stapes could indirectly produce movements of the posterior cheek unit that are antagonistic to our interpretation of the action of the pars stapedialis. Because the stapes and its musculature fill the space between 'neck' region and the posterior cheek (squamosal and quadrate), any lateral displacement of the stapes would be translated into lateral displacement of the cheek. Similarly, because the space between the posterior cheek and neck region narrows ventrally, any ventral displacement of the stapes would also be expected to translate into lateral displacement of the cheek. The potentially antagonistic actions that could result from mobility of both the origin and insertion of the pars stapedialis may modify the degree of medial displacement of the cheek produced by the most straightforward interpretation of the action of the pars stapedialis. It is plausible that movement of the stapes and of the maxillopalatine occur sequentially rather than simultaneously, so that contraction of the pars stapedialis, in conjunction with the actions of other muscles (jaw adductors, $m$. interhyoideus, $m$. intermandibularis, $m$. depressor mandibulae), moves the cheek medially and then laterally.

In caecilians, as in other tetrapods, the stapes is associated with hearing and transmits vibrations to the inner ear via the fenestra ovalis (Wever, 1975). The stapes of Atretochoana retains the ancestral association with the fenestra ovalis, and presumably a role in auditory signal transduction. The elongation of the stapes, its mobility and association with cranial kinesis, and its supporting of a large cranial muscle must impact considerably upon its auditory function. Muscles are also associated with the sound conducting apparatus in some frogs and salamanders, though the functional significance of their opercularis complex is unclear. Consideration of the auditory function of the stapes adds to the uncertainty of our functional interpretations in terms of cranial kinesis. This enigmatic functional complex demands experimental study. 
The form and inferred current action of the elongate stapes and medial head of the $m$. pterygoideus is a radical departure from the typical caecilian cranial morphology that is essentially conserved in all other caecilians, except the scolecomorphids which have lost the stapes (Brand, 1956; Nussbaum, 1985a). We suggest that the original development of muscular attachment to the stapes, or to an adjacent region of the os basale, may have been important in increasing the degree of kinesis. Elongation of the stapes and of the pars stapedialis may have initially accompanied the posterior extension of the quadrate while the quadratostapedial articulation persisted. Elongation of the pars stapedialis would have increased the excursion of this muscle, its contribution to kinesis, and provided a reason for the continued posterior extension of the muscle and the stapes after the loss of the quadratostapedial articulation. McDowell (1986) described modifications in the $m$. pterygoideus of some advanced snakes that are related to kinesis and extend the loose parallel between snakes and Atretochoana.

Increased kinesis may itself have been selected in response to increasing gape size and size of prey items if kinesis plays a role, as we suggest, in manipulating the prey once grasped. The enhanced kinesis in Atretochoana would be more effective in aiding the manipulation of prey other than soft bodied items than would the more limited kinesis of other caecilians from which it evolved. The degree of mobility of the cheek suggests that kinesis could act as a direct translocatory rather than a compressional mechanism and might also generate significant shearing stresses within the prey tissues. The increased flexibility of the articulation of the tooth crowns and pedicels in Atretochoana, and the increased numbers of splenial teeth, are consistent with the transformation of the kinetic system from a compressional to a translocational one.

Corroboration or refutation of our functional interpretation of kineticism in Atretochoana must await the discovery of further specimens and biomechanical analyses, but the simple model of which it is assumed to be a phyletic elaboration could be tested by X-ray cinematographic study of feeding in other caecilian species, especially other typhlonectids. As noted above, muscles such as the $m$. interhyoideus and $m$. depressor mandibulae could also play an important role in the kinetic system. The dramatic mesial inflection of the retroarticular process of the lower jaw in Atretochoana has shifted the insertion of the $m$. interhyoideus so that it is slightly medial to its origin. Contraction of this muscle with the jaws closed would tend to displace the lower jaws and cheeks laterally, in opposition to the inferred action of the adductors. Thus, the cranial mechanics of Atretochoana are expected to be highly complex.

\section{Are the evolutionary changes in respiratory and feeding systems correlated?}

Although the evolution of lunglessness and modification of the jaws to increase the gape may be uncorrelated, the conservation of gape size relative to overall skull proportions in all other caecilians, together with the ubiquitous retention of lungs, suggests that a causal relationship between their modifications in Atretochoana may have existed. The common factor is the mouth. Lunged caecilians require a functional buccopharyngeal force pump for ventilation. Modification of the mouth (such as its enlargement) may thus be constrained by this requirement.

In terrestrial burrowing caecilians, a further, and possibly more significant, constraint on the evolution of an enlarged gape may be the functional requirement of skull consolidation for burrowing. In aquatic caecilians, such as the hypothesized 
ancestor of Atretochoana and Potomotyphlus, which were no longer engaged in active burrowing, this latter constraint would be relaxed. Expansion of the floor of the mouth through the evolution of an enlarged gape would potentially increase the capacity of the buccopharyngeal force pump, and Schmalhausen (1957, cited in Szarski [1962]) noted that increasing the distance between the mandibles is one means of increasing the efficiency of the buccopharyngeal pump. However, in Atretochoana, this widening is accompanied by a posterior migration of the jaw articulation, and the utilization of a pump expanded in this manner would require concomitant shifts in the muscles that power the pump (particularly the $m$. rectus cervicus, and the pars pharyngeobranchialis of the m. obliquus internus) that are not apparent. Indeed, the conserved origin of the $m$. interhyoideus in the face of the posterior migration of its insertion on the retroarticular process suggests that such shifts may not be readily accomplished. Furthermore, enlargement of the pump would also significantly increase the mass of water resisting buccal expansion, as well as increase the intrinsic mass of the pump itself, tending to reduce, rather than enhance, the efficiency of the pump and consequently constrain any selection for increased gape size. If selection had led to the loss of lungs and made the buccopharyngeal force pump redundant, then this further possible constraint on the evolution of the floor of the mouth would be relaxed and gape enlargement could proceed. In an analogous manner, it has been argued that the evolution of lunglessness in plethodontids facilitated the specializations of the feeding apparatus seen within that family (Wake, 1982). Other scenarios are of course possible, but, without intermediates, there is no way to evaluate the above scenario beyond the critical evaluation of its plausibility.

\section{Evolutionary significance of Atretochoana}

The major restructuring of the skull in the evolution of Atretochoana is macroevolutionary in extent. By this we do not mean that the mechanism of cranial evolution has been macroevolutionary as opposed to microevolutionary, but rather that the result of cranial evolution is an extremely divergent morphology with no known intermediate forms, and that such great morphological divergences traditionally characterize the differences between higher taxa and thus may often form the bases for adaptive radiations.

If our interpretation of the evolution of Atretochoana is correct, it provides an example of how modification of one system (in this case the respiratory system) can have a profound influence on the subsequent evolution of another system (in this case the feeding system). This is only to be expected because organisms are highly integrated wholes, and Natural Selection has acted so as to produce successful integration of their parts. Thus the morphological evolution of any system may be constrained by the requirement of successful integration with other systems. This is not a new insight, but merely an aspect of pleiotropy.

Pleiotropic integrative consequences of morphological modification may be extremely complex, but we suggest the following simple dichotomy in their likely consequences. Firstly, modification of one system generates coevolutionary selection pressures on linked systems for compensatory changes to maintain levels of integration. Secondly, modification of one system reduces the linkage between it and previously more tightly-linked systems. In this case, selection for compensatory modification of previously-linked systems will not be generated. Instead, the flexibility 
of a lineage to respond to selection pressures, and thus its evolutionary potential is likely to increase. The dichotomy is obviously a simplification. Any single change may have consequences of both kinds and changes may simply have the fortuitous effect of enhancing integration. In the case of the evolution of Atretochoana, we suggest that abandonment of life in mud burrows and warm lowland waters removed environmental constraints on gas exchange surfaces and the head (those related to its borrowing function), and that the transition to cutaneous respiration led to the loss of additional morphofunctional constraints on the head (those related to its ventilatory function). Removal of these constraints facilitated major modifications of the head related to prey handling.

\section{ACKNOWLEDGEMENTS}

We thank the following individuals and institutions for the loan of or access to specimens used in this study: D. R. Frost, C. W. Myers, American Museum of Natural History (AMNH); E. V. Malnate, Academy of Natural Sciences, Philadelphia (ANSP); E. N. Arnold and B. T. Glarke, British Museum (Natural History) (BMNH); R. C. Drewes, California Academy of Sciences (CAS); the late C. J. McCoy, Carnegie Museum (GM); the curators, Estacíon Biologiá de Rancho Grande; R. F. Laurent, Fundación Miguel Lillo, Tucuman; R. F. Inger, H. Marx, and O. Rieppel, Field Museum of Natural History (FMNH); O. Elter, Museo di Zoologia, University of Torino; W. E. Duellman, University of Kansas, Museum of Natural History $(\mathrm{KU})$; J. Wright, Los Angeles County Museum of Natural History (LACM); J.-M. Exbrayat and M. Delsol, Faculté Catholique des Sciences de Lyon; the curators, Universidad Central, Museo de Biologiá, Caracas (MBUCV); P. Alberch and J. Rosado, Museum of Comparative Zoology, Harvard (MCZ); P. E. Vanzolini, Museu de Zoologia da Universidade de São Paulo (MZUSP); V. Mahnert and J.-L. Perret, Muséum d'Histoire Naturelle de Genève; J. Lescure, Muséum National d'Histoire Naturelle, Paris; G. Lenglet, Institut Royal des Sciences Naturelles de Belgique; L. Capocaccia, Museo Civico di Storia Naturale, Genova; F. Tiedemann and A. Cabella, Naturhistorisches Museum, Wien (NMW); M. S. Hoogmoed, Rijksmuseum van Natuurlijke Historie (RMNH); W. Böhme, Zoologisches Forschungsinstitut und Museum Alexander Koenig; L. J. Borkin, Zoological Institute, Academy of Sciences, Leningrad; R. Günther, Universität Humboldt, Zoologisches Museum, Berlin; H. W. Koepke, H. Wilkens, and R. Dohse, Universität Hamburg, Zoologisches Museum; J. Rasmussen, Zoologisk Museum, Copenhagen; U. Gruber, Zoologisches Staatssammlung, München.

We are especially grateful to W. E. Duellman, D. R. Frost, the late C. J. McCoy, M. S. Hoogmoed, E. N. Arnold, B. T. Glarke, and J. Wright for permission to dissect and clear and stain caecilian specimens. Special thanks are due to Franz Tiedemann for generously allowing us to dissect and describe the holotype and, at that time, single known specimen of Atretochoana. MW thanks Jonah Rihui of the Kenyan Wildlife Service, and Damaris Rotich and Anton Espira of the National Museums of Kenya for facilitating collection of Boulengerula taitanus. Joyce Klevering prepared magnified radiographs for our initial studies of the skull of Atretochoana, Greg Schneider helped with clearing and staining. David Bay, Margaret Van Bolt, Mark Orsen, and Teresa Peterson helped prepare the figures. We thank H. Don 
Cameron for advice on nomenclature. MW thanks Antonia Cabella for her assistance in Vienna. This work was supported in part by grants from the NERC (GST/02/ 832 ) and the NSF (DEB 8817453).

\section{REFERENCES}

Acolat L. 1939. Variations de l'appareil respiratoire et de l'appareil circulatoire central chez quelques Gymnophiones. Compte Rendue de l'Association d'Anatomique du Nancy 3: 3-15.

Azpelicueta M, Williams JD, Gudynas E. 1987. Osteologia y notas miologicas en la cecilia neotropical Chthonerpeton indistinctum (Reinhardt and Lutken, 1861), con una diagnosis de la familia Typhlonectidae. Iheringia 66: 69-81.

Badenhorst A. 1978. The development and the phylogeny of the organ of Jacobson and the tentacular apparatus of Ichthyophis glutinosus (Linné). Annale Universiteit van Stellenbosch, Serie A2 (Zoölogie) 1: 1-26.

Beachy CK, Bruce RC. 1992. Lunglessness in plethodontid salamanders is consistent with the hypothesis of a mountain stream origin: a response to Ruben and Boucot. American Naturalist 139: 839847.

Bemis WE, Schwenk K, Wake MH. 1983. Morphology and function of the feeding apparatus of Dermophis mexicanus (Amphibia: Gymnophiona). Zoological Joumal of the Linnean Society 77: 75-96.

Berthold AA. 1859. Einige neue Reptilien des Akademie Zoologisches Museums zu Göttingen. Nachrichten von der Gesellschaft der Wissenschaften und der Georg-Augustus-Universität zu Göttingen 1859: 197-181.

Billo R, Wake MH. 1987. Tentacle development in Dermophis mexicanus (Amphibia: Gymnophiona), with an hypothesis of tentacle origin. Journal of Morphology 192: 101-111.

Bjerring HL. 1989. Apertures of craniate olfactory organs. Acta Zoologica 70: 71-85.

Boulenger GA. 1882. Catalogue of the Batrachia Gradientia S. Caudata and Batrachia Apoda in the collection of the British Museum. London: Taylor \& Francis.

Brand DJ. 1956. On the cranial morphology of Scolecomorphus ulugunuensis (Barbour \& Loveridge). Annals of the University of Stellenbosch 32: 1-25.

Bridge TW, Haddon AC. 1893. Contributions to the anatomy of fishes II. The air bladder and Weberian ossicles in the siluroid fishes. Philosophical Transactions of the Royal Society, London, Series B 184: $65-333$.

Bruce RC, Beachy CK, Lenzo PG, Pronych SP, Wassersug RJ. 1994. Effects of lung reduction on rheotactic performance in amphibian larvae. Foumal of Experimental Zoology 268: 377-380.

Bruner HL. 1914. Jacobson's organ and the respiratory mechanism of amphibians. Morphologischen Jahrbuch 48: 157-165.

Carrier DR, Wake MH. 1995. Mechanism of lung ventilation in the caecilian Dermophis mexicanus. Joumal of Morphology 226: 289-295.

Cascon P, Lima-Verde JS, Marques RB. 1991. Uma nova espécie de Typhlonectes da Amazônia Brasileira (Amphibia: Gymnophiona, Typhlonectidae). Boletim di Museo Paraense, Emilio Goeldi, séries Zoologia 7: 95-100.

Darnell RM. 1949. The aortic arches and associated arteries of caudate Amphibia. Copeia 1949: 18-41.

Duellman WE, Trueb L. 1986. Biology of Amphibians. NewYork: McGraw-Hill.

Duméril AMC, Bibron G. 1841. Erpétologie Générale ou Histoire Naturelle complète des Reptiles VIII. Paris.

Dunn ER. 1926. The Salamanders of the family Plethodontidae. Northampton: Smith College.

Edgeworth FH. 1935. The Cranial muscles of Vertebrates. Cambridge: Cambridge University Press.

Estes R, Wake MH. 1972. The first fossil record of caecilian amphibians. Nature 239: 228-231.

Foxon GEN. 1964. Blood and respiration. In: Moore JA, ed. Physiology of the Amphibia. New York: Academic Press, 151-209.

Fuhrmann O. 1914. Le Genre Thyphlonectes [sic]. Mémoires de la Société des Sciences Naturalles de Neuchâtel 5: $112-138$.

Gaggero P. 1934. Hallazgo de un batracio apodo del genero Chthonerpeton en la region del Rio Santiago. Notas Preliminarios de la Museo de la Plata 13: 173-182.

Gans C. 1974. Biomechanics: an approach to vertebrate biology. Philadelphia: J. B. Lippencott Company.

Gaymer R. 1971. Comparative studies on the caecilian amphibian Hypogeophis rostratus. PhD. Dissertation. University of Bristol. 
Gonçalves AA. 1977. Dimorfismo sexual de Typhlonectes compressicaudus (Amphibia: Apoda). Boletim Fisiologia Animale, Universidade de Sãu Paulo 1: 141-142.

Gould SJ. 1989. Wonderful Life. The Burgess Shale and the Nature of History. New York: Norton.

Greven H. 1986. On the diversity of tooth crowns in Gymnophiona. Memoires de la Sociéte Zoologique de France 43: 85-86.

Grinkaut CN. 1949. Sôbre o Pulmão traqueal (accessório) de Typhlonectes compressicauda compressicauda (Amphibia-Gymnophiona). Boletim de Faculte Filosophia, Ciências y Letras, Univesidade de São Paulo, Zoologia. 14: 267-275.

Gronowski R. 1980. Funktionelle Kopfanatomie von Afrocaecilia und Chthonerpeton. Diplomarbeit, Universität Zurich.

Gudynas E, Williams JD, Azpelicueta M. 1988. Morphology, ecology and biogeography of the South American caecilian Chthonerpeton indistinctum (Amphibia: Gymnophiona: Typhlonectidae). Zoologische Mededelingen 62: 5-28.

Häupl M, Tiedemann F. 1978. Kataloge der wissenschaftlichen Sammlungen des Naturhistorischen Museums in Wien Band 2 Vertebrata 1 Typenkatalog der Herpetologischen Sammlung. Amphibia. Wien.

Hedges SB, Nussbaum RA, Maxson L. 1993. Caecilian phylogeny and biogeography inferred from mitochondrial DNA sequences of the $12 \mathrm{~S}$ and $16 \mathrm{~S}$ rRNA genes (Amphibia: Gymnophiona). Herpetological Monographs 7: 64-76.

Himstedt W, Simon D. 1995. Sensory basis of foraging behaviour in caecilians (Amphibia: Gymnophiona). Herpetological Journal 5: 266-270.

Ihering R von. 1911. Cobras e amphibios das Ilhotas de "Aguape". Revista do Museu Paulista 3: 454-461.

Lahanas PN, Savage JM. 1992. A new species of Caecilian from the Peninsular de Osa of Costa Rica. Copeia 1992: 703-708.

Laubmann W. 1927. Über die Morphogenesis von Gehirn und Geruchsorgan der Gymnophionen (Beitrag zur Kenntnis der Gymnophionen Nr. 10). Zeitschrift fir Anatomie und Entwicklungsgeschichte 84: $597-637$.

Lawson R. 1965. The anatomy of Hypogeophis rostratus. II The musculature. Proceedings of the University of Newcastle upon Tyne Philosophical Society 1: 52-63.

Lescure J, Renous S, Gasc JP. 1986. Proposition d'une nouvelle classification des amphibiens gymnophiones. Memoires de la Societe Zoologique de France 43: 145-177.

Marcus H. 1923. Über den Übergang von der Wasser- zur Luftatmung mit besonderer Berucksichtigung des Atemmechanismus von Hypogeophis. Zeitschrift fur Anatomie und Entwicklungsgeschichte 69: $328-343$.

Marcus H. 1930. Uber Bildung von Geruchsorgan, Tentakel und Choanen bei Hypogeophis. Zeitschrift fir Anatomie und Entwicklunggsgeschichte 91: 658-691.

Maurer F. 1892. Der Aufbau und der Entwicklung der ventralen Rumpfmuskulatur be den urodelen Amphibien und deren Beziehungen zu den gleichen Muskeln der Selachier und Teleostier. Morphologisches Jahrbucher 18: 76-179.

Maurer F. 1911. Die ventral Rumpfmuskulatur von Menobranchus, Menopoma und Amphiuma, vergleichen mit den gleichen Muskeln anderer Urodelen. Jena Zeitschrift für Naturwissenschafte 47: 1-42.

McDowell SB. 1986. The architecture of the corner of the mouth of Colubroid snakes. Joumal of Herpetology 20: 353-407.

Moodie GEE. 1978. Observations on the life history of the caecilian Typhlonectes compressicaudus (Dumeril and Bibron) in the Amazon Basin. Canadian Jourmal of Zoology 56: 1005-1008.

Naylor BG, Nussbaum RA. 1980. The trunk musculature of caecilians (Amphibia: Gymnophiona). Journal of Morphology 166: 259-273.

Nishi. 1916. Zur vergleichenden Anatomie der eigenlichen Ruckensmuskeln. Morphologisches Jahrbucher 50: $167-318$.

Noble GK. 1925. The integumentary, pulmonary, and cardiac modifications correlated with increased cutaneous respiration in the Amphibia: a solution to the 'hairy frog' problem. Joumal of Morphology and Physiology 40: 341-416.

Norris HW, Hughes SP. 1918. The cranial and anterior spinal nerves of the caecilian amphibians. Journal of Morphology 31: 490-557.

Nussbaum RA. 1977. Rhinatrematidae: A new family of caecilians (Amphibia: Gymnophiona). Occasional Papers of the Museum of Zoology, University of Michigan 682: 1-30.

Nussbaum RA. 1979. The taxonomic status of the caecilian genus Uraeotyphlus Peters. Occasional Papers of the Museum of Zoology,University of Michigan 687: 1-20. 
Nussbaum RA. 1983. The evolution of a unique dual jaw-closing mechanism in caecilians (Amphibia: Gymnophiona) and its bearing on caecilian ancestry. Joumal of Zoology 199: 545-554.

Nussbaum RA. 1985a. Systematics of the caecilians (Amphibia: Gymnophiona) of the family Scolecomorphidae. Occasional Papers of the Museum of Zoology, University of Michigan 713: 1-49.

Nussbaum RA. 1985b. The evolution of parental care in salamanders. Miscellaneous Publications of the Museum Zoology, University of Michigan 169: 1-50.

Nussbaum RA. 1986. Chthonerpeton onorei, a new caecilian (Amphibia: Gymnophiona: Typhlonectidae) from Ecuador. Revue Suisse de Zoologie 93: 911-918.

Nussbaum RA. 1988. On the status of Copeotyphlinus syntremus, Gymnopis oligozona, and Minascaecilia sartoria (Gymnophiona: Caeciliidae): a comedy of errors. Copeia 1988: 921-928.

Nussbaum RA, Hinkel H. 1994. Revision of East African caecilians of the genera Afrocaecilia Taylor and Boulengerula Tornier (Amphibia: Gymnophiona: Caeciliidae). Copeia 1994: 750-760.

Nussbaum RA, Naylor BG. 1982. Variation in the trunk musculature of caecilians (Amphibia: Gymnophiona). Joumal of Zoology 198: 383-398.

Nussbaum RA, Wilkinson M. 1987. Two new Chthonerpeton (Amphibia: Gymnophiona: Typhlonectidae) from Brazil. Occasional Papers of the Museum of Zoology, University of Michigan 716: 1-15.

Nussbaum RA, Wilkinson M. 1989. On the classification and phylogeny of caecilians (Amphibia: Gymnophiona), a critical review. Herpetological Monographs 3: 1-42.

Nussbaum RA, Wilkinson M. 1995. A new genus of lungless tetrapod: a radically divergent caecilian (Amphibia: Gymnophiona). Proceedings of the Royal Society, London, Series B 261: 331-335.

Parker HW. 1941. The caecilians of the Seychelles. Annals and Magazine of Natural History, Series 2 7: 1-17.

Parker HW, Wettstein O. 1929. A new Caecilian from Brazil Annals and Magazine of Natural History 10: $594-596$.

Peter K. 1894. Die Wirbelsaule der Gymnophionen. Berichte der naturforschung Gesselschaft zu Freiburg 9: 35-58.

Peters W. 1875. Uber die entwickelung der Caecilien. Monatsberichte der Akademie der Wissenschaften zu Berlin 1875: 483-493.

Peters W. 1879. Uber dei eintheilung der Caecilien und insbesondere uber die gattungen Rhinatrema und Gymnopis. Monatsberichte der Akademie der Wissenschaften zu Berlin 1879: 924-943.

Ramaswami LS. 1941. Some aspects of the cranial morphology of Uraeotyphlus narayani Seshachar (Apoda). Records of the Indian Museum 43: 143-207.

Reagan NL, Verrell PA. 1991. The evolution of plethodontid salamanders: did terrestrial mating facilitate lunglessness? American Naturalist 138: 1307-1313.

Reinhardt JT, Lütken CF. 1861. Bidrag til Kundskab om Brasiliens Padder og Krybdyr Videnskabelige Meddelelser fra den naturhistoriske Forening i Kjobenhawn. Copenhagen.

Roze J, Solano H. 1963. Una nueva especie de cecilidos (Amphibia: Gymnophiona) de Venezuela, con notas sobre los géneros Chthonerpeton y Typhlonectes. Acta Biológica Venezuelica 3: 279-282.

Ruben JA, Boucot AJ. 1989. The origin of the lungless salamanders (Amphibia: Plethodontidae). American Naturalist 134: 161-169.

Ruben JA, Reagan NL, Verrell PA, Boucot AJ. 1993. Plethodontid salamander origins: a response to Beachy and Bruce. American Naturalist 142: 1038-1049.

Sawaya P. 1947. Metabolismo respiratoria de anfibio Gymnophiona, Typhlonectes compressicauda (Dum. et Bibr.). Boletim di Faculte de Filosophia, Ciencias y Letres. Universidae de Sau Paulo, Zoology 12: 51-56.

Sawaya P. 1948. O sistema cárdio-vascular do Anfibio- Ápodo Typhlonectes compressicauda compressicauda (Dum. e Bibr., 1841) Boletim di Museo Paraense E. Goeldi 10: 279-289.

Schmalhausen II. 1957. Biologitshskiie osnovi vozniknovieniia nazemnikh pozvonotshnikh. Izvestiya Akademii Nauk SSSR. Biologicheskii 1957: 3-30.

Skuk D. 1985. El tentaculo del anfibio apodo Chthonerpeton indistinctum (Amphibia: Gymnophiona) I: Estructura osea. Actas Joumadas Zoologica de Unuguay 1985: 40-41.

StraubJO. 1985. Contributions to the cranial anatomy of the genus Grandisonia Taylor 1968 (Amphibia: Gymnophiona). Inaugural dissertation, Universität Basel.

Szarski H. 1962. The origin of the Amphibia. Quarterly Review of Biology 37: 189-291.

Taylor EH. 1968. The caecilians of the world. Lawrence: University of Kansas Press.

Taylor EH. 1969. Skulls of the Gymnophiona and their significance in the taxonomy group. University of Kansas Science Bulletin 48: 585-689.

Taylor EH. 1977a. The comparative anatomy of caecilian mandibles and their teeth. University of Kansas Science Bulletin 51: 261-282. 
Taylor EH. 1977b. Comparative anatomy of caecilian anterior vertebrae. University of Kansas Science Bulletin 51: 261-282.

Toews D, Macintyre D. 1978. Respiration and circulation in an apodan amphibian. Canadian foumal of Zoology 56: 998-1004.

Vavra, 1907. Zárodek cervore brasilského. Vesmir 36: 11.

Versluys J. 1912. Das streptostylie-problem und die bewegangen in schadel bei sauropsiden. Zoologishes Jahrbucher Supplement b. 15: 545-707.

Wake DB. 1982. Functional and developmental constraints and opportunities in the evolution of feeding systems in urodeles. In: Mossakowski D, Roth G, eds. Environmental Adaptation and Evolution. New York: Gustav Fischer, 51-66.

Wake MH. 1974. The comparative morphology of the caecilian lung. Anatomical Record 178: 483.

Wake MH. 1978. Comments on the ontogeny of Typhlonectes obesus, particularly its dentition and feeding. Papeis Avulsos de Zoologia 32: 1-13.

Wake MH. 1980. Morphometrics of the skeleton of Dermophis mexicanus (Amphibia: Gymnophiona). Part one. The vertebrae, with comparisons to other species. Journal of Morphology 165: 117-130.

Wake MH. 1992. Reproduction in caecilians. In: Hamlett WC, ed. Reproductive Biology of South American Vertebrates. Springer-Verlag, 112-120.

Wake MH, Exbrayat J-M, Delsol M. 1985. The development of the chondrocranium of Typhlonectes compressicaudus (Gymnophiona), with comparison to other species. Joumal of Herpetology 19: 68-77.

Wake MH, Hanken J. 1982. The development of the skull of Dermophis mexicanus (Amphibia: Gymnophiona), with comments on skull kinesis and amphibian relationships. Joumal of Morphology 173: 203-223.

Wake MH, Schwenk K. 1986. A preliminary report on the morphology and distribution of taste buds in gymnophiones, with comparison to other amphibians. Joumal of Herpetology 20: 254-256.

Weidersheim R. 1879. Die Anatomie der Gymnophionen. Jena.

Wever EG. 1975. The caecilian ear. Joumal of Experimental Biology 191: 63-72.

Whitford WG, Hutchison VH. 1966. Cutaneous and pulmonary gas exchange in ambystomatid salamanders. Copeia 1966: 573-577.

Wilder IL, Dunn ER. 1920. The correlation of lunglessness in salamanders with a mountain brook habitat. Copeia 1920: 63-68.

Wilkinson M. 1980. Notes on a caecilian, Nectocaecilia sp. Herptile 5: 22-24.

Wilkinson M. 1988. On the status of Nectocaecilia cooperi Taylor, with comments on the genus Nectocaecilia Taylor (Amphibia: Gymnophiona: Typhlonectidae). Joumal of Herpetology 22: 119-121.

Wilkinson M. 1989. On the status of Nectocaecilia fasciata Taylor, with a discussion of the phylogeny of the Typhlonectidae (Amphibia: Gymnophiona). Herpetologica 45: 23-36.

Wilkinson M. 1991. Adult tooth crown morphology in the Typhlonectidae (Amphibia: Gymnophiona): a reinterpretation of variation and its significance. Zeitschrift fur zoologische Systematische und Evolutionsforschung 29: 304-311.

Wilkinson M. 1992. Novel modification of the tetrapod cardiovascular system in the West African Caecilian Herpele squalostoma (Amphibia: Gymnophiona: Caecilidae). Foumal of Zoology 228: 277-286.

Wilkinson M. 1996a. Resolution of the taxonomic status of Nectocaecilia haydee (Roze) (Amphibia: Gymnophiona: Typhlonectidae). Joumal of Herpetology 30: 413-415.

Wilkinson M. 1996b. The taxonomic status of Typhlonectes venezuelense Fuhrmann (Amphibia: Gymnophiona: Typhlonectidae). Herpetological Journal 6: 30-31.

Wilkinson M. 1996c. The heart and aortic arches of rhinatrematid caecilians (Amphibia: Gymnophiona). Zoological Joumal of the Linnean Society 118: 135-150.

Wilkinson M, Nussbaum. RA. 1992. The status of Mimosiphonops and Pseudosiphonops (Amphibia: Gymnophiona), with the description of a new species. Journal of Natural History 26: 675-688.

Wilkinson M, Nussbaum RA. 1996. On the phylogenetic position of the Uraeotyphlidae (Amphibia: Gymnophiona). Copeia 1996: 550-562. 


\title{
APPENDIX
}

\author{
Specimens examined
}

Observations of external and buccal morphology include the specimens listed by Wilkinson (1989), and here we list only those specimens used for other morphological examinations. Institutional acronyms used are those given in the acknowledgements; UMMZ = University of Michigan Museum of Zoology. Anatomical preparations are indicated in parentheses: $A=$ dissection; $C=$ cleared and stained skeletal preparation; $\mathrm{D}=$ dry skeletal preparation, $\mathrm{L}=$ latex injected arterial system, $\mathrm{S}=$ serial sections.

Atretochoana eiselti: NMW 9144 (holotype - A).

Boulengerula taitanus: UMMZ 171947-8, 175119-20 (C); UMMZ 184336, 190443 (D).

Brasilotyphlus sp.: MVSP 57080 (A, C).

Caecilia sp.: UMMZ 190443 (A, C).

Caudacaecilia weberi: UMMZ 181759, 181760 (A, C).

Chthonerpeton indistinctum: CM 65037, RMNH 23194 (A, C).

Crotaphatrema lamottei UMMZ 174497 (A, C).

Dermophis mexicanus UMMZ 214094 (A, C); UMMZ 150623 (C); UMMZ 190128 (D).

Epicrionops marmoratus. UMMZ 185826, 185856, 185861, 185871, 188835 (A, C); UMMZ 189485 (D).

Epicrionops petersi: UMMZ 174041 (A, C).

Gegeneophis ramaswamii: UMMZ 182014 (C).

Geotrypetes seraphini: UMMZ 177010 (C); BMNH 1936.3.4.5 (A); BMNH 1936.3.4.15 (S).

Grandisonia alternans: UMMZ 167914, 182012, 198674 (C), UMMZ 180002 (A, C); UMMZ 183243 (S).

Grandisonia brevis: UMMZ 190229 (A, C).

Grandisonia larvata: UMMZ 145176 (A, C); UMMZ 189211 (C).

Grandisonia sechellensis: UMMZ 175439 (A, C); UMMZ 189208, 189209 (C).

Herpele squalostoma: BMNH 1914.5.27.36 (A).

Hypogeophis rostratus: UMMZ 146013 (A, C); UMMZ 146742, 172187, 172188, 174031; uncatalogued specimen loaned by O. Rieppel (S).

Ichthyophis bannanicus: UMMZ 188026 (A, C, L); UMMZ 189477 (D); UMMZ 190246, 190248, 190252 (A, C).

Ichthyophis glutinosus: UMMZ 135191 (A, C).

Ichthyophis kohtaoensis: UMMZ 154071 (D).

Idiocranium russeli: BMNH 1936.3.4.48 (C).

Indotyphlus battersbyi: UMMZ 183696 (C); CM 67519 (A).

Microcaecilia albiceps: KU 125300 (A, C).

Nectocaecilia petersii: UMMZ 190446 (A, C).

Panvicaecilia nicefori: AMNH 25388 (A, C).

Potomotyphlus kaupit: UMMZ 211206 (A, C).

Praslinia cooperi: UMMZ 175392, 179957 (A, C).

Schistometopum gregori: UMMZ 177011 (C)

Schistometopum thomense: UMMZ 188027 (A, C, L); UMMZ 189488 (D); UMMZ 201278 (C).

Scolecomorphus vittatus: UMMZ 183695 (A, C).

Scolecomorphus uluguruensis: MCZ 12218 (D).

Siphonops annulatus: UMMZ 150624 (D), 190437 (A, C).

Typhlonectes compressicauda: BMNH 1982.104, UMMZ 190441 (A, C); UMMZ 129897, 150625 (D).

Typhlonectes natans: LACM 67435, 67453, 67454, 67502, UMMZ 182228, 185923 (A,C); UMMZ

183617, 183656, 183900-02, 188060-62, 188064, 189490 (D); UMMZ 185923 (C); UMMZ 188025

$(\mathrm{A}, \mathrm{C}, \mathrm{L})$.

Uraeotyphlus narayani: UMMZ 139811 (A, C). 